\title{
Should you switch off or stay engaged?
}

\author{
Citation for published version (APA):
}

Firoozabadi, A. (2019). Should you switch off or stay engaged? the consequences of thinking about work outside work for well-being and job performance (9789463239691 ed.). [Doctoral Thesis, Maastricht University]. Gildeprint Drukkerijen. https://doi.org/10.26481/dis.20191211af

\section{Document status and date:}

Published: 01/01/2019

DOI:

10.26481/dis.20191211af

Document Version:

Publisher's PDF, also known as Version of record

\section{Please check the document version of this publication:}

- A submitted manuscript is the version of the article upon submission and before peer-review. There can be important differences between the submitted version and the official published version of record.

People interested in the research are advised to contact the author for the final version of the publication, or visit the DOI to the publisher's website.

- The final author version and the galley proof are versions of the publication after peer review.

- The final published version features the final layout of the paper including the volume, issue and page numbers.

Link to publication

\footnotetext{
General rights rights.

- You may freely distribute the URL identifying the publication in the public portal. please follow below link for the End User Agreement:

www.umlib.nl/taverne-license

Take down policy

If you believe that this document breaches copyright please contact us at:

repository@maastrichtuniversity.nl

providing details and we will investigate your claim.
}

Copyright and moral rights for the publications made accessible in the public portal are retained by the authors and/or other copyright owners and it is a condition of accessing publications that users recognise and abide by the legal requirements associated with these

- Users may download and print one copy of any publication from the public portal for the purpose of private study or research.

- You may not further distribute the material or use it for any profit-making activity or commercial gain

If the publication is distributed under the terms of Article $25 \mathrm{fa}$ of the Dutch Copyright Act, indicated by the "Taverne" license above, 


\section{SHOULD YOU SWITCH OFF OR STAY ENGAGED?}

The consequences of thinking about work outside work for well-being and job performance

Abbas Firoozabadi 
(C) Abbas Firoozabadi, Maastricht 2019

Cover design by: Mojtaba Firoozabadi | ISTA design office

Printed by: Gildeprint | www. gildeprint.nl | The Netherlands

ISBN 9789463239691

NUR 771

All rights are reserved. No part of this publication may be reproduced, distributed, stored in a retrieval system, or transmitted in any from or by any means, electronic, mechanical, photocopying, recording or otherwise, without prior written permission of the author. For the articles published or accepted the copyright has been transferred to the respective publisher. 


\section{SHOULD YOU SWITCH OFF OR STAY ENGAGED?}

The consequences of thinking about work outside work for well-being and job performance

\section{DISSERTATION}

To obtain the degree of Doctor at Maastrich University, On the authority of the Rector Magnificus, Prof. dr. Rianne M. Letschert, In accordance with the decision of the Board of Deans,

To be defended in public

On Wednesday 11 December 2019, at 10:00 hours

By

Abbas Firoozabadi 
Promotor:

Prof. dr. F. R. H. Zijlstra

Co-promotor:

Dr. Sjir Uitdewilligen

\section{Assessment Committee:}

Prof. dr. Ute Hülsheger-Brülls (chair)

Prof. dr. Evangelia Demerouti (Eindhoven University of Technology)

Prof. dr. Mark Cropley (University of Surrey, UK)

Prof. dr. IJmert Kant

Prof. dr. Peter Muris 


\section{Table of Contents}

Chapter1: General introduction........................................ 7

Chapter 2: Should you switch off or stay engaged? The consequences of thinking about work on the trajectory of psychological well-being over time.

Chapter 3: Solving problems or seeing troubles? A day-level study on the consequences of thinking about work on recovery and well-being, and the moderating role of self-regulatio

Chapter 4: Week-level dynamics and person-level differences of the relation between work-related perseverative thinking and job performance-related outcomes, the mediating role of emotion regulation

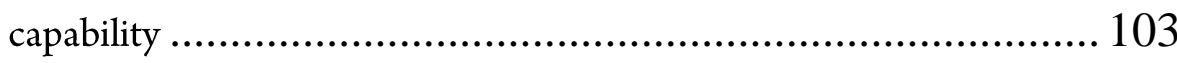

Chapter 5: $\quad$ General discussion ......................................... 137

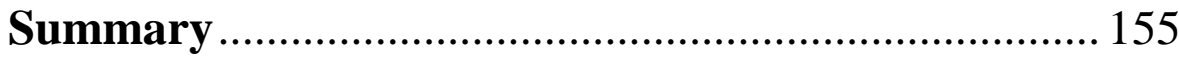

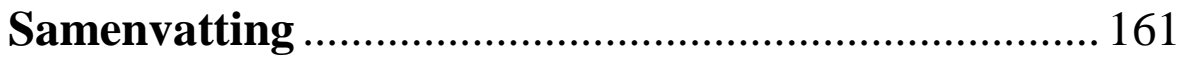

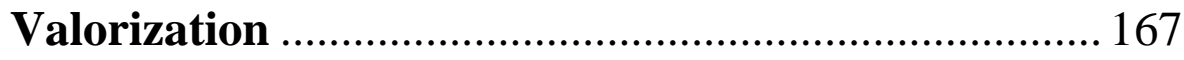

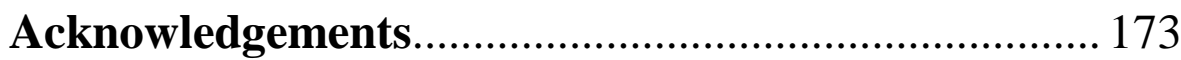

Curriculum vitae …....................................................... 180

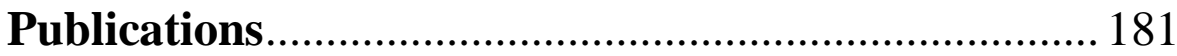




\section{CHAPTER 1}

General introduction 



\section{Introduction}

Work-related stress and burnout are since quite some time known as major concerns that have a negative influence on employees' well-being and organizations' effectiveness (Maslach, Schaufeli, \& Leiter, 2001; Nixon, Mazzola, Bauer, Krueger, \& Spector, 2011; Demerouti, Mostert, \& Bakker, 2010). Burnout has been recognized as a cause of general health impairment, increased absenteeism and job turnover, decreased commitment to work, and decreased organizational productivity (Carod-Artal \& Vázquez-Cabrera, 2013). Several studies (e.g. Rotenstein et al., 2018; Vercambre, Brosselin, Gilbert, Nerrière, \& Kovess-Masféty, 2009; Embriaco, Papazian, Kentish-Barnes, Pochard, \& Azoulay, 2007 ) have shown a high prevalence (30\% to $70 \%)$ of burnout for employees in western and industrialized countries. Compared to western countries, people in developing countries, where $75 \%$ of the world's labor force work, have been even more at risk of burnout and impaired health. This higher risk can be attributed to factors such as globalization of the economy, increasing changes in the nature of work, less job security, less knowledge about occupational health and job stress prevention strategies, and a lack of occupational health services (Houtman, Jettinghoff, \& Cedillo, 2007).

Research on the causes of burnout has primarily focused on job characteristics (e.g. work demands, time pressure, and work control), in order to study how they may contribute to burnout and impaired well-being. However, the way that people experience their non-work time (i.e. recovery in the evening or the weekend) has been also recognized to be crucial for employees' well-being (Sonnentag \& Zijlstra, 2006). In a study with a sample of industrial employees, Kivimäki et al. (2006) found that insufficient recovery constituted a high risk factor for cardiovascular disease mortality in the following 25 years.

Research has shown that psychological detachment is an essential recovery experience that is highly beneficial for well-being and job performance (Sonnentag \& Fritz, 2015; Sonnentag, 2012). Psychological detachment is defined as the sense of switching off mentally from work-related issues during offjob time (Etzion, Eden, \& Lapidot, 1998). People may experience lack of psychological detachment during their off-job time because they engage in perseverative thinking about their work-related issues (Brosschot, Gerin, \& Thayer, 2006; Brosschot, Pieper \& Thayer, 2005). Perseverative thinking concerns the experience of repeated, pervasive, and prolonged activation due to 
being mentally occupied with work-related issues. Perseverative thinking has been conceptualized as a mechanism by which work-related stress is translated into impaired well-being (Brosschot et al., 2005; Berset, Elfering, Lüthy, Lüthi \& Semmer, 2011).

Cropley and Zijlstra (2011) proposed two fundamentally different types of work-related perseverative thinking, which they labeled 'affective rumination' and 'problem-solving pondering'. Affective rumination is described as perseverative cognitive processes in which thoughts are mainly directed to dysfunctional emotions associated with work-related issues. Problem-solving pondering refers to perseverative cognitive processes in which thoughts are directed to finding solutions to work-related problems or to reflect on workrelated processes in order to improve performance. It has been proposed that these two types of work-related perseverative thinking may have different effects on the recovery process and consequently on well-being and job performance.

Up to now, there have been a few studies (e.g. Querstret \& Cropley 2012; Hamesch, Cropley, \& Lang, 2014; Syrek, Weigelt, Peifer, \& Antoni, 2017; Bennett, Gabriel, Calderwood, Dahling, \& Trougakos, 2016; Kinnunen et al., 2017) that focused directly on the relationships between these two types of workrelated perseverative thinking and well-being. These studies have shown that affective rumination is detrimental to well-being, whereas the effects of problemsolving pondering on well-being have not been consistent, indicating positive or non-significant effects. Nevertheless, the related knowledge needs to be extended by considering the remaining questions. The main goal of this dissertation is to investigate the effect of recovery from work on well-being and job performance with a central focus on these two types of work-related perseverative thinking.

This dissertation aims to extend the literature in five directions. First, research needs to consider the accumulative effects of affective rumination and problem-solving pondering on well-being in the long run. Therefore, I investigate how these two types of perseverative thinking impact changes in well-being outcomes over a period of one year. Second, to date, the relationships between the two types of perseverative thinking and job performance-related outcomes have not been tested. Therefore, I aim to investigate how different types of perseverative thinking contribute to job performance-related outcomes. Third, the previous studies on perseverative thinking have mainly focused on betweenperson effects. However, perseverative thinking may differ not only between persons but may also fluctuate within persons over time; an individual's level of 
affective rumination and problem-solving pondering may differ across working days or across weekends. Therefore, conducting diary studies, I aim to provide insight into the short-term dynamics of the relationships between the different types of perseverative thinking and outcomes such as recovery, well-being, and job performance on a time-to-time basis. Fourth, although the previous studies have shown that the two experiences of being mentally engaged with work-related issues lead to different consequences, the dynamic mechanisms by which these two experiences may operate differently on the organism have not been studied. Addressing this gap in the literature, this dissertation investigates the underlying dynamic psychological mechanisms through which affective rumination and problem-solving pondering may have diverging effects on well-being and job performance. Finally, research is needed to shed light on the previous inconsistent findings concerning the relationship between problem-solving pondering and well-being (Kinnunen et al., 2017; Bennett et al., 2016; Syrek et al., 2017; Hamesch et al., 2014; Querstret \& Cropley, 2012). In order to shed light on these inconsistent findings, I propose that problem-solving pondering may not be beneficial for everyone. I suggest trait self-regulation (Zijlstra, Cropley, \& Rydstedt, 2014; Carver \& Scheier, 1998) as an individual factor that influences people's ability to generate solutions to work-related problems and may thereby determine the effect of problem-solving pondering on recovery from work.

Before drawing the outlines of this thesis, I will first put the concept of recovery in a theoretical perspective by presenting three theories that can explain how the quality of recovery during non-work time is an important determinant for employees' well-being and job performance. In order to place this project in perspective, I will then present a general history of research on the topic of recovery by clarifying the methods and strategies that researchers have used to study the effect of recovery on well-being and job performance. After that, I will focus on the conceptualization of affective rumination and problem-solving pondering as two different types of work-related perseverative thinking that employees may experience during their recovery time. I will also present a history of empirical research on the topic of work-related perseverative thinking by reviewing a number of key studies. This then helps us to show what we still need to know and how this research can contribute to the existing knowledge of the link between recovery, well-being, and job performance. Finally, I will end this chapter by a presentation of my research questions and an outlook of the following chapters. 


\section{Recovery: a theoretical perspective}

This dissertation aims to investigate the effects of affective rumination and problem-solving pondering on well-being and job performance by considering how these two experiences during non-work time impede or facilitate the recovery process. Therefore, in order to explain how experiencing these two types of perseverative thinking during non-work time influence the recovery process, the concept of recovery from work should firstly be conceptualized. To do so, I conceptualize the concept of recovery from work by drawing on three key theoretical perspectives. These theories provide a dynamic conceptualization that can then explain the effects of affective rumination and problem-solving pondering on employees' well-being and job performance.

Effort-recovery theory (Meijman \& Mulder, 1998): According to this theory, people actively decide to mobilize their resources to meet work-related demands and to accomplish work-related tasks (i.e. work procedure). Due to this expenditure of effort during working time, short-term psycho-physiological load reactions occur. According to Meijman and Mulder (1998), these load reactions are reversible adaptive responses that may lead to work-related products. Therefore, these short-term load reactions will not cause impaired well-being if employees can sufficiently recover after working time (see Figure 1.1). Accordingly, recovery occurs during non-work time when a range of physical, cognitive, or emotional job demands and work stressors no longer draw upon individuals' resources. By disengagement from job demands and work-related stressors, psycho-physiological load reactions can be reversed and individuals revert to the pre-demand state of functioning. Recovery correspondingly refers to the process by which employees are no longer confronted with work-related demands and their psycho-physiological system is rebalanced. In contrast, inadequate physical or mental release of job demands or work-related stressors (i.e. lack of recovery) continuously drains an individual's energetic resources and prolongs psycho-physiological load reactions. Lack of recovery inhibits daily functioning and thereby requires additional effort expenditure (Hockey, 1993) in order to accomplish work-related tasks and maintain a satisfactory level of performance. This higher expenditure of effort in turn prolongs and even intensifies psycho-physiological load reactions and a greater need for recovery (Sluiter, van der Beek, \& Frings-Dresen, 1999). The accumulative process of prolonged load reactions may then have negative consequences on well-being and job performance over time. Figure 1.1 presents the effort-recovery model. 
Building on the effort-recovery theory, I argue that by ruminating affectively about work-related issues during non-work time, job stressors remain mentally present. Therefore, affective rumination is likely to cause prolonged psycho-physiological activation which inhibits the recovery process and has straining effects on the organism. In contrast, problem-solving pondering may not be detrimental for the recovery process because it is likely to cause only short lasting psycho-physiological activations while individuals engage in cognitive processes aimed at discovering solutions for work-related problems or at finding ways to improve their work-related performance (Cropley \& Zijlstra, 2011).

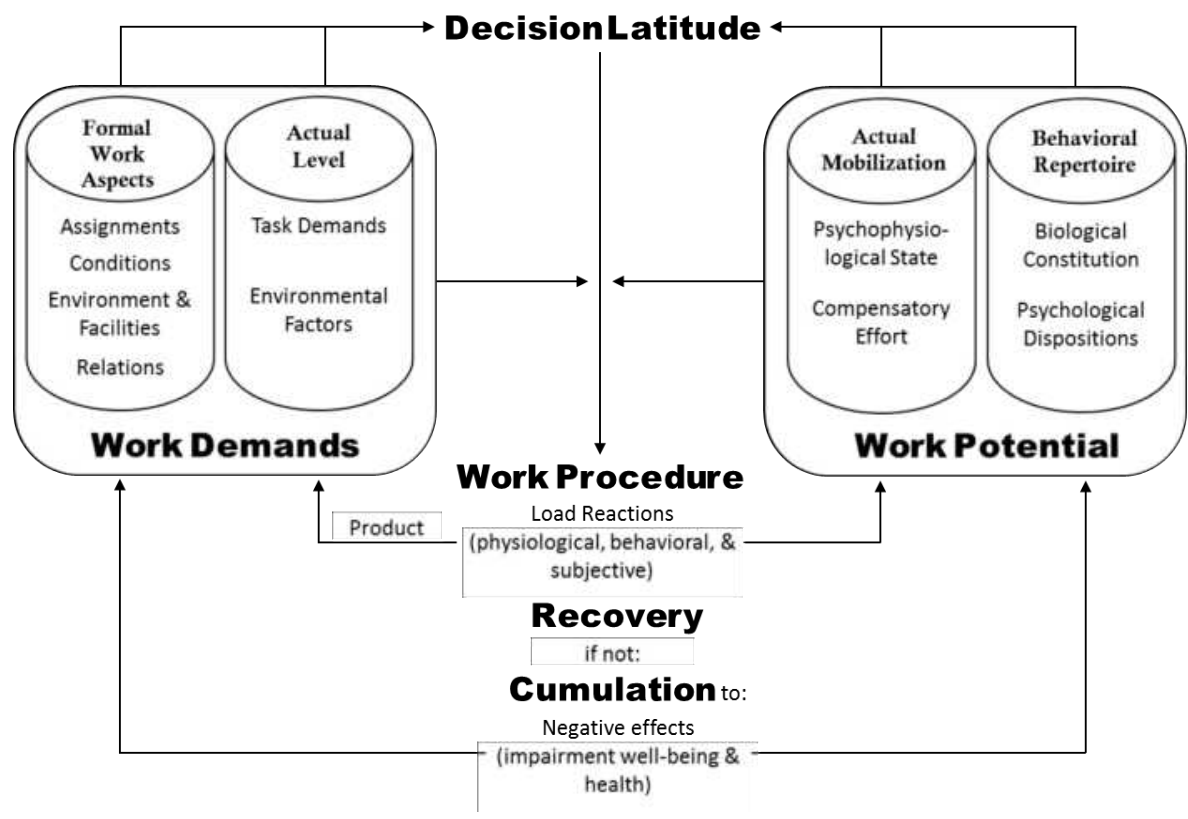

Figure 1.1: The effort-recovery model (Meijman \& Mulder, 1998)

Conservation of resources theory (Hobfoll, 1989): This theory assumes that individuals strive to obtain, maintain, and protect their resources. Resources are defined as "objects, personal characteristics, conditions, or energies that are valued by the individual or that serve as a means for attainment of these objects, personal characteristics, conditions, or energies" (Hobfoll, 1989, p. 516). Under circumstances in which individuals' resources are threatened or lost, strain develops and individuals' need for recovery increases. According to this theory, recovery occurs when individuals experience their non-work time as an opportunity to conserve their remaining energetic resources or to replenish their depleted ones. By adopting successful recovery strategies (i.e. successful 
adaptation), individuals' resource pools are again replenished which, in turn, prevents acute and chronic depletion and increases the likelihood of success in later actions. In contrast, due to a continuous incomplete recovery (i.e. unsuccessful adaptation), a prolonged failure to replenish depleted resource exacerbates the chronic or acute loss circumstances that leads to resource loss cycles and resource depletion (Hobfoll, 2001; 2002). Resource depletion then causes long-term negative consequences on well-being (e.g. Burnout) and job performance (e.g. less productivity) (Hobfoll \& Shirom, 2001; Wright \& Cropanzano, 1998; Westman \& Eden, 1997; Lee \& Ashforth, 1996). Figure 1.2 presents the conservation of resources theory.

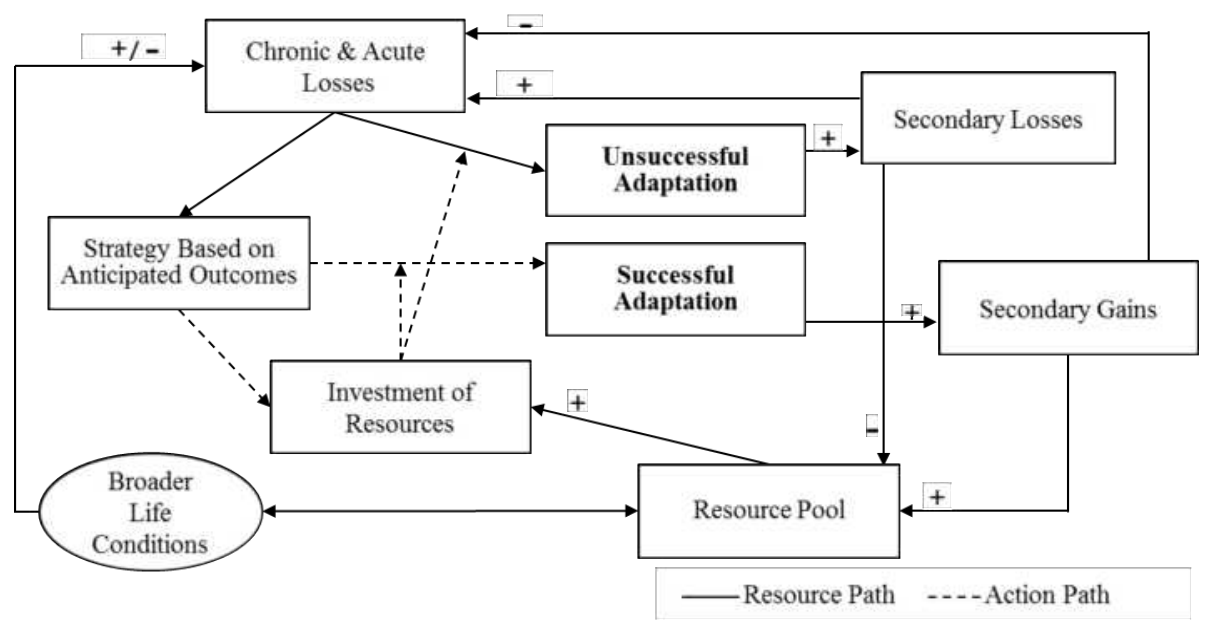

Figure 1.2: The conservation of resources theory (Hobfoll, 2001)

Based on the conservation of resources theory, I argue that affective rumination hinders recovery from work as it sustains the effortful process of engaging with dysfunctional emotions and thereby continuously draws on both cognitive and emotional resources. In contrast, engaging with dysfunctional emotions does not play a prominent role in problem-solving pondering. Therefore, it is less likely (vs. affective rumination) to drain emotional resources and cause straining effects on the organism. Moreover, problem-solving pondering is likely to act as a resource-providing experience by producing positive affect. It is likely to promote positive affect by engaging in thinking processes through which people experience a sense of achievement, competence, and proficiency. 
Control theory (Carver \& Scheier, 1981, 1998): Control theory is based on cybernetics which concern the science of negative feedback loops involved in the control and regulation of values within a human system (Carver \& Scheier, 1998; Vancouver \& Day, 2005; Carver \& Scheier, 2011). This function of feedback loops is called negative because it serves the purpose of negating a discrepancy between a sensed value and a reference value. The theory considers individuals not as passive receptors of information; instead, they are considered to play an active role in continuously monitoring, evaluating and acting on discrepancies between the perceived and the desired states of an organism.

Drawing on control theory, the recovery process is considered as a downregulation process by which the level of psycho-physiological activation (i.e. arousal), which has been increased during working time, is adjusted to the optimal psycho-physiological activation of resting time (Zijlstra et al., 2014). After working time, people are no longer confronted with job demands and therefore their need for effort expenditure is reduced. Hence, they need to decrease their level of activation in order to not only maintain their current level of resources but also to rebuild depleted resources. A discrepancy occurs between the sensed level of psycho-physiological activation as the input function and the optimal psychophysiological activation of resting time as the reference value. As long as the discrepancy exists, a downward self-regulation process (i.e. recovery) continues to reduce the discrepancy until a desired state of activation is achieved. Therefore, people may engage in a variety of either passive or active experiences labeled as psycho-physiological unwinding strategies or output functions in a cyberneticssystem perspective. These experiences (e.g. psychological detachment) contribute to recovery by causing a reduction in psycho-physiological activation.

According to this model, insufficient recovery occurs if people fail to reduce appropriately their enhanced level of psycho-physiological activation after working time (Zijlstra et al., 2014). The model conceptualizes the second feedback path as a gradual process of change in the reference value that may occur if the output functions (i.e. recovery experiences) consistently fail to reduce the discrepancy. By the gradual change in the reference value over time, discrepancy decreases and people experience a level of activation during their non-working time as high as their activation during their working time. The prolonged psychophysiological activation during non-work time may then cause impaired wellbeing by draining energetic resources over time. 
Based on control theory, I argue that affective rumination counteracts psycho-physiological unwinding strategies during non-work time. Thereby it inhibits the down-regulation process of recovery, which is aimed at achieving the optimal psycho-physiological activation during resting time. Moreover, it may even increase the level of psycho-physiological activation during non-work time while individuals engage with thinking about their dysfunctional emotions. Unlike affective rumination, problem-solving pondering is conceptualized as a goaldirected cognitive process by which individuals aim to manage their work-related problems and reduce their uncertainty about their work performance. Therefore, although pondering about work-related issues may cause short-lasting psychophysiological activation, it is likely to facilitate the down-regulation process of recovery when individuals experience positive affect in reaction to discovering and generating solutions to work-related problems.

Taking all these theories into account, recovery refers to the process by which employees are no longer confronted with work-related demands and thus provides the possibility to replenish their depleted resources and to rebalance the suboptimal systems.

\section{Recovery: a research perspective}

In order to place this research in the recovery perspective, below I present a general history of research on the topic of recovery by clarifying the methods and strategies that researchers have used to study the effect of recovery on well-being and job performance. This historical background shows the previous and current state of research on the topic of recovery in the work and organizational field. It also shows how the current research can contribute to the existing knowledge of the link between recovery, well-being and job performance.

Initial research on recovery considered how different types of off-job activities during non-work time may facilitate or inhibit the recovery process (e.g. Sonnentag, 2001; Sonnentag \& Natter, 2004; Fritz \& Sonnentag, 2005; Sonnentag \& Bayer, 2005; Rook \& Zijlstra, 2006; Sonnentag \& Zijlstra, 2006; Fritz \& Sonnentag, 2006). During non-work time, individuals are involved in two main categories of off-job activities namely resource-providing activities and resource-consuming activities (Demerouti, Bakker, Geurts, \& Taris, 2009).

Resource-providing activities refer to activities that have the potential to enhance recovery and include activities such as low effort activities, physical 
activities, and social activities. These activities were assumed to facilitate the recovery process through: (a) rebuilding energetic resources that have been diminished during working time (Demerouti et al., 2009), (b) enhancing human resources such as vigor, self-efficacy, and positive mood (ten Brummelhuis \& Bakker, 2012; Fritz \& Sonnentag, 2005), (c) terminating the psycho-physiological stress response (Guerts \& Sonnentag, 2006), (d) detaching mentally from workrelated stressors (Brosschot et al, 2005), (e) placing demands other than those related to work-related issues on a person, and (f) drawing on different resources than those needed for accomplishing work-related tasks (Rook \& Ziljstra, 2006; Winwood, Bakker, \& Winefield, 2007).

Resource-consuming activities refer to activities that inhibit the recovery process and include activities such as work-related activities (e.g., working overtime, administrative tasks) and daily non-work hassles (e.g. more than usual housework, household chores, interpersonal conflicts, or sudden problems). These activities were assumed to inhibit the recovery process through (a) causing and prolonging high levels of the psycho-physiological stress response and thereby further depleting individuals' resources (Demerouti et al., 2009; Zijlstra \& Cropley, 2006), (b) triggering a greater likelihood of affective rumination about work-related issues, and (c) restricting the time of recovery.

Although empirical research focused on off-job activities provided evidence to support the importance of recovery periods for the recovery process and well-being, it has not provided consistent evidence to support this distinction for off-job activities. For instance, some studies (e.g. Sonnentag \& Zijlstra, 2006; Sonnentag, 2001) showed that engaging with social activities during non-work time is positively associated with well-being. In contrast, some studies found a non-significant association (Rook \& Zijlstra, 2006; Sonnentag \& Bayer, 2005; de Bloom et al, 2011) or even a negative association (e.g. Sonnentag \& Natter, 2004) for the link between social activities and well-being.

There are two reasons to explain these inconsistent findings. First specific types of off-job activities might not be equally beneficial for people with different types of job demands. For example, people with a mentally demanding job may be more likely to benefit from physical off-job activities, whereas people with a physically demanding job may be more likely to benefit from mentally challenging off-job activities. Therefore, depending on the nature of job demands people might have different preferences for how to spend their non-work time. The degree to which that an off-job activity matches the individual's preference seems 
important to determine the benefits of such activity on his/her recovery process and well-being.

Second, it is not the type of off-job activity per se which is important for the recovery process and well-being; it is rather the subjective experience associated with each off-job activity. In a study by Van Hooff, Geurts, Beckers, and Kompier (2011), it was found that the extent to which an employee experiences off-job activities as pleasant during an evening is related to the higher level of vigor and lower level of fatigue at the subsequent bedtime. Therefore, the degree to which people benefit from off-job activities is likely to depend on the degree to which they experience pleasure and control during their engagement with those activates. For instance, the greater social control and pleasure that individuals experience with their social activities, the higher levels of well-being they experience afterwards.

In order to achieve a more comprehensive insight on the effect of off-job activities on well-being, research then considered the psychological mechanisms by which different types of off-job activities may have differential contributions to the recovery process and well-being (Sonnentag \& Fritz, 2007; Thoits, 2011). In a between-person study Ragsdale, Beehr, Grebner, and Han (2011) found that recovery experiences such as psychological detachment, relaxation, and control mediate the relationship between off-job activities and recovery outcomes. In a within-person study, ten Brummelhuis and Bakker (2012) showed that resourceproviding off-job activities (i.e. social, low-effort, and physical activities) are related to higher levels of recovery through increased psychological detachment and relaxation. In contrast, resource-consuming off-job activities (i.e. workrelated, household, and childcare activities) are related to lower levels of recovery through diminished psychological detachment and relaxation. According to Sonnentag and Fritz (2007), subjective recovery experiences are underlying mechanisms that contribute to the recovery process during non-work time. They conceptualized four recovery experiences namely relaxation, control, mastery, and psychological detachment experiences.

Relaxation refers to a subjective experience associated with low physical and mental activation and high positive affective states. Relaxation acts as a mechanism that is likely to facilitate the recovery process and prevent impaired well-being by terminating the prolonged activation caused by job stressors. Control experience has potentially facilitating effects on the recovery process through increasing a feeling of self-efficacy and competence and causing positive 
affective states. Mastery experiences are associated with activities directed by individuals' interests and values. These experiences are likely to enhance recovery by causing positive feeling of achievement, competence, and proficiency. Psychological detachment refers to individuals' sense of unwinding from workrelated demands. The experience of detachment leads to recovery because individuals' resources are no longer drained by mentally experience of workrelated demands during non-work time. A large body of research using with- and between-person designs provided empirical evidence for the positive effect of these off-job experiences on the recovery process and on well-being (e.g. Sonnentag \& Fritz, 2007; Fritz, Sonnentag, Spector, \& McInroe, 2010; Fritz, Yankelevich, Zarubin, \& Barger, 2010; Rogsdale et al., 2011; Sonnentag, Binnewies, \& Mojza, 2008; Sonnentag, Mojza, Binnewies, \& Scholl, 2008; Sonnentag, Kuttler, \& Fritz, 2010; Sonnentag and Bayer, 2005).

Research has shown that in particular psychological detachment is an essential recovery experience that is highly beneficial for well-being and job performance (Sonnentag \& Fritz, 2015; Sonnentag, 2012). People may experience lack of psychological detachment during their off-job time when they engage in perseverative thinking by experiencing repeated, pervasive, and prolonged activation due to being mentally occupied with their work-related issues (Demerouti, Bakker, Sonnentag, \& Fullagar, 2012; Brosschot et al, 2006; Brosschot et al, 2005). According to Cropley and Zijlstra's (2011) conceptualization, people can experience two fundamentally different types of work-related perseverative thinking during their non-work time: affective rumination and problem-solving pondering. Accordingly, mentally engaging with work-related issues during non-work time does not necessary inhibit the recovery process as this depends on the type of work-related perseverative thinking. It has been proposed that these two types of work-related perseverative thinking may have different effects on the recovery process and consequently on well-being and job performance. Therefore, to gain a comprehensive understanding of the recovery process, research needs to consider how these two types of perseverative thinking influence the recovery process.

\section{Two types of perseverative thinking: affective rumination versus problem-solving pondering}

Perseverative thinking refers to a class of recurrent, pervasive, and prolonged thoughts representing work-related issues in the absence of immediate environmental demands (Brosschot et al., 2006). It includes cognitions that are 
focused not only on the past but also on the anticipation of negative events in the future. Scholars (e.g. Flaxman, Ménard, Bond, \& Kinman, 2012; Brosschot et al., 2005; Brosschot et al., 2006; Brosschot, van Dijk, \& Thayer, 2002) conceptualized perseverative thinking as the core cognitive-emotional process involved in worry and rumination about stressors that negatively influence psychological and physical health by triggering stress reactions.

According to Brosschot et al. (2005), perseverative thinking acts as a mechanism that enhances sustained activation through which psychological stressors are translated into health impairments and job performance inefficiencies in the long run. Thinking about work-related issues during their non-work time may lead to prolonged mental representation of job stressors that, in turn, drains further energetic resources. As a consequence of prolonged physiological activation (Brosschot,Verkuil, \& Thayer, 2010), employees' health is negatively influenced in the long run. Moreover, this leads to less available energetic resources to invest in the job, leading to a further decrease in job performance. To explain how perseverative thinking causes prolonged stress reactions, Brosschot et al. (2006) suggest a vicious circle in which the experience of uncontrollability of stressors triggers perseverative thinking. Perseverative thinking then prolongs and exacerbates the experience of uncontrollability, which in turn increases perseverative thinking. However, perseverative thinking that is not associated with prolonged worrying (i.e. less uncontrollability) is less likely to prolong stress reactions and impair well-being (Brosschot et al., 2010).

Cropley and Zijlstra (2011) distinguished between two fundamentally different types of work-related perseverative thinking that people experience in the work context, namely affective rumination and problem-solving pondering. They state that these two types of perseverative thinking have different effects on the recovery process and well-being because of their differential impact on psycho-physiological activation. According to Cropley and Zijlstra (2011), affective rumination prolongs psycho-physiological activation and straining effects on the organism because it leads to prolonged exposure to dysfunctional emotions associated with work-related issues. In contrast, problem-solving pondering is less likely to cause prolonged psycho-physiological activation and it may only lead to a short lasting activation. Moreover, it is likely to act as a resource-providing experience by producing positive affect when employees experience progress in thinking (e.g., discovering a solution) or feel a sense of mastery and control. 
According to the Cognitive Activation Theory of Stress (CATS: Ursin \& Eriksen, 2004; Ursin \& Eriksen, 2010), the degree to which stressors cause psycho-physiological activation depends on the type of associated response outcome expectancies. Response outcome expectancies refer to individuals' estimates about the outcomes of their given responses. Response outcome expectancies are described as negative or positive depending on whether the produced response is expected to lead to negative or positive results, respectively. Negative outcome expectancies are likely to cause sustained activation especially when individuals do not experience progress in thinking about the problem. The sustained activation will then become intense when individuals continue to endorse the negative outcome expectancy by engaging in rumination (Eriksen, Murison, Pensgaard, \& Ursin, 2005). Hopelessness (i.e. when individuals meet negative results) and helplessness (i.e. when individuals respond inefficiently) are known as two negative response outcome expectancies that cause health impairment through sustained activation and their straining effects on the organism (Ursin \& Eriksen, 2004; Meurs \& Perrewe, 2011).

Building on this theoretical framework, affective rumination causes prolonged activation because it is more likely to be associated with negative outcome expectancies for solving problems. This means that individuals expect that their available responses lead to negative results and they are not able to solve the problem and cope successfully with the situation. Affective rumination will then exacerbate these negative expectancies over time and increase the perceived experience of uncontrollability. On the contrary, problem-solving pondering is more likely to be associated with positive outcome expectancies in which individuals believe that they are able to handle the situation with positive results. Although individuals still experience a short-lasting activation, this level of activation will be reduced once individuals perceive progress in thinking. Finding a solution and feeling a sense of control are both known as adequate ways of reducing psycho-physiological activation (Ursin \& Eriksen, 2004).

\section{Research on affective rumination and problem-solving pondering}

Previous research on perseverative thinking has mainly been conducted in the field of clinical psychology and focused predominantly on the emotional aspect of rumination (i.e. affective rumination). Up to now, few studies investigated how work-related affective rumination and problem-solving pondering influence recovery and well-being. 
There are a set of studies that have only focused on perseverative thinking without an explicit distinction between affective rumination and problem-solving pondering. In a longitudinal study, Rydstedt, Cropley, Devereux, and Michalianou (2009) examined to what extent workers' trait rumination can predict their psycho-physiological activation and need for recovery measured after four years. They use the average saliva cortisol secretion measured over seven consecutive days including five evenings of a working week and two evenings of the following weekend as the indicator of psycho-endocrinological response. The results showed that trait rumination is positively related to higher levels of evening saliva cortisol secretion and need for recovery after four years. Cropley, Rydstedt, Devereux, and Middleton (2015) found that teachers scoring high on workrelated rumination during a mid-week evening showed higher levels of cortisol secretion at bedtime, compared with teachers scoring low on rumination. In a study with a sample of professional coaches, Donahue et al. (2012) found that high levels of work-related rumination are associated with high levels of exhaustion. By using a longitudinal design in study with a sample of nurses, Donahue et al. (2012) found consistent findings indicating a positive relationship between work-related rumination and exhaustion after three months.

A limited number of studies has examined the effect of affective rumination and problem-solving on recovery and well-being. In a cross-sectional study, Querstret and Cropley (2012) found that high levels of affective rumination were associated with high levels of acute and chronic fatigue. In contrast, they found that high levels of problem-solving pondering were associated with lower levels of acute and chronic fatigue. However, they did not draw a definitive conclusion about these results due to the identified suppression effect (Pandey \& Elliott, 2010) of problem-solving pondering in their analysis. In another study, Hamesch et al. (2014) using a sample of dental students, found that higher levels of work-related affective rumination were positively associated with higher levels of depressive symptoms measured after six months. However, the relation between problem-solving pondering and depression was not found significant. A two-year longitudinal study by Kinnunen et al. (2017) showed that people with higher levels of affective rumination are more likely to experience impaired well-being (i.e. higher exhaustion, greater sleep problems, and lower work engagement) across time. They also found that the pattern of engaging in one of two types of perseverative thinking remained stable across two years.

Recently researchers suggested it is not about the individual experiences, but it is the specific combination of these experiences (i.e. profiles) that impact 
well-being. Bennett et al. (2016) in their research considered the effect of different profiles of recovery experiences (i.e., psychological detachment, relaxation, mastery, control, and problem-solving pondering) on well-being instead of distinct recovery experiences. They found that the lack of psychological detachment is less crucial for well-being (i.e., higher work engagement, lower emotional exhaustion and somatic complaints) if employees experience higher levels of problem-solving pondering. They also concluded that since problemsolving pondering causes higher levels of engagement, it is more likely to cause emotional exhaustion and somatic complaints if it is not conjointly performed with other recovery experiences.

The previous studies on the two types of perseverative thinking have mainly focused on between-person differences. However, the study of withinperson fluctuations is important because it provides insight into the short-term dynamics of the relationships between different types of perseverative thinking and outcomes such as recovery, well-being, and job performance on a time-totime basis. Syrek et al. (2017) conducted a study to examine differential indirect links between unfinished tasks as work-related stressors and sleep impairment through affective rumination versus problem-solving pondering. Using weekly surveys across twelve weeks, the results at within-person level showed a positive relationship between affective rumination and sleep impairment and a marginally negative relationship between problem-solving pondering and sleep impairment during the weekend. They also found that affective rumination positively mediates the relationship between unfinished tasks and sleep impairment. However, the mediation effect of problem-solving pondering was not significant.

\section{Summary and central research questions}

Research has shown insufficient recovery as a high risk factor for impaired wellbeing and inadequate job-performance. Moreover, psychological detachment can be seen as an essential recovery experience that is highly beneficial for well-being and job performance. People may experience low psychological detachment during their non-work time when engaging in perseverative thinking. Perseverative thinking is defined as repeated, pervasive, and prolonged activation of mentally occupation with their work-related issues. Although perseverative thinking has been conceptualized as a mechanism by which work-related stressors are translated into impaired well-being, this might not always be true as it depends on the type of perseverative thinking. 
Cropley and Zijlstra (2011) proposed two fundamentally different types of work-related perseverative thinking namely affective rumination and problemsolving pondering. Affective rumination is described as perseverative cognitive processes in which thoughts are mainly directed to dysfunctional emotions associated with work-related issues. Problem-solving pondering refers to perseverative cognitive processes in which thoughts are directed to possible solutions to work-related problems in order to progress toward choice of a solution or reevaluate work-related performance in order to consider how it can be improved. It has been proposed that compared to affective rumination that impedes the recovery process by prolonging psycho-physiological activation and draining emotional resources, problem-solving pondering is less likely to cause prolonged psycho-physiological activation and may even act as a resourceproviding experience by facilitating progression towards solving problems.

As the review of the literature showed there have been a few studies that examined the relationship between these two types of work-related perseverative thinking and well-being. Nevertheless, the related literature can be extended in several ways.

First, although using a cross-lag design, a study by Hamesch et al. (2014) and a recent study by Kinnunen et al. (2017) considered the time-lagged effects of the two types of perseverative thinking on well-being, little is known about their accumulative effects on well-being in the long run. Therefore, research needs to consider the accumulative effects of affective rumination and problem and problem-solving pondering on well-being. Particularly in the long run, affective rumination may result in cumulative effects on well-being by chronically depleting resources over time (Frese \& Zapf, 1988; Sluiter, Frings-Dresen, van der Beek, \& Meijman, 2001), whereas problem-solving pondering may reduce cumulative effects on well-being by producing psychological resources over time (Fredrickson \& Joiner, 2002).

Second, research (e.g. Fritz \& Sonnentag, 2005, 2006) has shown that the quality of recovery during non-work time is crucial factor for employees' job performance. Higher quality of recovery is characterized with higher levels of energetic resources that employees need to meet situational demands of work and successfully accomplish work-related tasks (Wickens \& Hollands, 2000; Beal, Weiss, Barros, \& MacDermid, 2005). Moreover, due to diverging pattern of drawing on emotion regulatory resources, affective rumination and problemsolving pondering may have different influences on the recovery process. Up to 
now, there has been no study examining the consequences of affective rumination and problem-solving pondering on job performance-related outcomes. Therefore, there is a need to investigate how different types of perseverative thinking contribute to job performance-related outcomes.

Third, the previous studies on perseverative thinking have mainly focused on between-person effects. However, perseverative thinking may differ not only between persons but may also fluctuate within persons over time. According to Xanthopoulou, Bakker, and Ilies (2012), a significant amount of variance in core indicators of employees' well-being and job performance may be attributed to within-person fluctuations. Considering these within-person fluctuations then provides insights into the dynamic patterns of relationships between the study variables. Therefore, research is needed to investigate the short-term dynamic patterns of the relationships between the two types of perseverative thinking and outcome variables such as recovery, well-being, and job performance on a time-to-time basis.

Fourth, the previous research on this topic has shown that the two experiences of being mentally engaged with work-related issues lead to different health consequences. However, knowledge on the dynamic mechanisms underlying these effects is still missing. Therefore, the literature can be extended by investigating the underlying dynamic mechanisms through which affective rumination and problem-solving pondering may have diverging effects on wellbeing and job performance. Increased insight in these mechanisms can improve the theoretical conceptualization of affective rumination and problem-solving pondering and develop interventions to prevent the detrimental effects of workrelated perseverative thinking.

Fifth, previous research showed inconsistent findings concerning the relationship between problem-solving pondering and well-being (Kinnunen et al., 2017; Bennett et al., 2016; Syrek et al., 2017; Hamesch et al., 2014; Querstret \& Cropley, 2012). This signifies that there may be potential moderators at play. I propose that problem-solving pondering may not be beneficial for everyone as it may depend on the extent to which employees experience progress in thinking or experience positive affect by discovering a solution. I suggest trait self-regulation as an individual factor that may influence people's ability to generate solutions to work-related problems and thereby the effect of problem-solving pondering on recovery from work. 
To summarize, this dissertation contributes to three central research questions considering the effects of the two types of work-related perseverative thinking on recovery, well-being, and job performance.

Research question 1: What are the consequences of work-related affective rumination and problem-solving pondering on wellbeing and job-performance?

Research question 2: Through what underlying dynamic processes do workrelated affective rumination and problem-solving pondering have differential consequences on well-being and job-performance?

Research question 3: How is the consequence of work-related problem-solving pondering on recovery from work influenced by individual differences in trait self-regulation?

\section{Dissertation outline}

The main goal of this dissertation is examining the effect of recovery on well-being and job performance by a central focus on the two types of work-related perseverative thinking namely affective rumination and problem-solving pondering. In order to answer the research questions, I carried out three longitudinal field studies with different time intervals using diary data.

In Chapter 2, I present the findings of a longitudinal three-wave study with a time lag of six months between each wave. This study examined how the experience of affective rumination and problem-solving pondering during evenings cause changes in two psychological impaired well-being outcomes over one year period. I conducted a diary survey over five consecutive working days to measure the levels of affective rumination and problem-solving pondering that employees experience during evenings of working week. Moreover, to fully capture both work-related and general factors of well-being, I distinguished between exhaustion and general mental health complaints as two impaired wellbeing outcomes in the long run. Using a latent growth curve modeling analysis provided the possibility to investigate within-person changes in impaired wellbeing outcomes over time as well as between-subject differences in such changes. This chapter provides empirical evidence for Research question 1. 
In Chapter 3, I present the findings of a diary study over five consecutive working days. This study examined, using a within-person design, how fluctuations in work-related affective rumination and problem-solving pondering during the evening are related to recovery and well-being. Using a moderated multilevel mediation approach provided the possibility to examine the moderating role of trait self-regulation on the relationship between problem-solving during the evening and the state of being recovered at bedtime. This statistical approach also gave the possibility to test the indirect link between daily variations in affective rumination and problem-solving pondering and well-being in the subsequent morning through the state of being recovered in the evening, while accounting for the moderating role of trait-self regulation on the ponderingrecovery relationship. This chapter is aimed to provide empirical findings concerning Research questions 1, 2, and 3.

Chapter 4 focuses on the indirect relationships between the experience of affective rumination and problem-solving pondering during the weekend and job performance-related outcomes that employees experience during the subsequent working week through emotion-regulation strength. Drawing on the dynamic models of energetic resources, I hypothesized that the two types of workrelated perseverative thinking have different consequences on two job performance-related outcomes (i.e. effort expenditure and task performance) via their differential draining effects on individuals' emotion regulatory resources. I conducted a week-level study over a period of six consecutive weeks in which participants responded to weekly web-based surveys at the beginning and at the end of working week. Using a multilevel approach, my study provided a complete understanding of the dynamic nature of all proposed paths at a within-person level as well as the individual differences of those paths at the between-person level. This chapter thus provides empirical findings examining Research questions 1 and 2 .

Finally, Chapter 5 provides an overview of the main findings of my research and a general discussion shedding light on the research questions. I discuss then theoretical, methodological, and practical implications and provide suggestions for future research. 


\section{References}

Beal, D. J., Weiss, H. M., Barros, E., \& MacDermid, S. M. (2005). An episodic process model of affective influences on performance. Journal of Applied Psychology, 90, 1054-1068. http://doi.org/10.1037/0021-9010.90.6.1054

Bennett, A. A., Gabriel, A. S., Calderwood, C., Dahling, J. J., \& Trougakos, J. P. (2016). Better together? Examining profiles of employee recovery experiences. Journal of Applied Psychology, 101, 1635-1654.http://doi.org/10.1037/apl0000157

Berset, M., Elfering, A., Luthy, S., Luthi, S., \& Semmer, N. K. (2010). Work stressors and impaired sleep: Rumination as a mediator. Stress and Health, 27, e71-e82. http://doi.org/10. $\underline{1002 / \text { smi. } 1337}$

Brosschot, J. F., Gerin, W., \& Thayer, J. F. (2006). The perseverative cognition hypothesis: A review of worry, prolonged stress-related physiological activation, and health. Journal of Psychosomatic Research, 60, 113-124.http://doi.org/10.1016/j.jpsychores.2005.06.074

Brosschot, J. F., Pieper, S., \& Thayer, J. F. (2005). Expanding stress theory: Prolonged activation and perseverative cognition. Psychoneuroendocrinology, 30, 1043-1049. http://doi.org/ 10.1016/j.psyneuen.2005.04.008

Brosschot, J. F., van Dijk, E., \& Thayer, J. F. (2002). Prolonged autonomic activation, perseverative negative cognition, and daily stressors. International Congress Series, 1241, 329-336. http://doi.org/10.1016/S0531-5131(02)00615-5

Brosschot, J. F., Verkuil, B., \& Thayer, J. F. (2010). Conscious and unconscious perseverative cognition: Is a large part of prolonged physiological activity due to unconscious stress? Journal of Psychosomatic Research, 69, 407-416. http://dx.doi.org/10.1016/j.j psychores.2010.02.002

Carod-Artal, F. J, \& Vázquez-Cabrera, C. (2013). Burnout syndrome in an international setting. In S. Bährer-Kohler (Eds.), Burnout and experts: prevention in the context of living and working. New York: Springer.

Carver, C. S., \& Scheier, M. F. (1981). Attention and self-regulation: A control theory approach to human behavior. New York: Springer-Verlag.

Carver, C.S., \& Scheier, M.F. (1998). On the self-regulation of behavior. Cambridge: Cambridge University Press.

Carver, C.S., \& Scheier, M.F. (2011). Self-regulation of action and affect. In K. D. Vohs \& R. F. Baumeister (Eds.), Handbook of self-regulation: Research, theory, and applications (pp. 3-21). New York, NY: Guilford Press.

Cropley, M., Rydstedt, L. W., Devereux, J. J., \& Middleton, B. (2015). The relationship between work-related rumination and evening and morning salivary cortisol secretion. Stress and Health, 31,150-157. http://doi.org/10.1002/smi.2538

Cropley, M., \& Zijlstra, F. R. H. (2011). Work and rumination. In J. Langan-Fox \& C. L. Cooper (Eds.), Handbook of stress in the occupations. Cheltenham: Edward Elgar.

Carod-Artal, F. J, \& Vázquez-Cabrera, C. (2013). Burnout syndrome in an international setting. In S. Bährer-Kohler (Eds.), Burnout and experts: prevention in the context of living and working. New York: Springer.

de Bloom, J., Geurtsa, S. A. E., Sonnentag, S., Tarisac, T., de Weerth, C., \& Kompier, M. A. J. (2011). How does a vacation from work affect employee health and well-being? Psychology and Health, 26, 1606-1622. https://doi.org/10.1080/08870446.2010. $\underline{546860}$ 
Demerouti, E., Bakker, A.B., Geurts, S.A.E., \& Taris, T.W. (2009). Daily recovery from workrelated effort during non-work time. In S. Sonnentag, P. Perrewe, \& D. Ganster (Eds.), Research in occupational stress and well-being: Current perspectives on job-stress recovery (Vol. 7, pp. 85-123). Bingley, UK: JAI Press.

Demerouti, E., Bakker, A.B., Sonnentag, S., \& Fullagar, C. J. (2012). Work-related flow and energy at work and at home: A study on the role of daily recovery. Journal of Organizational Behavior, 33, 276-295. https://doi.org/10.1002/job.760

Demerouti, E., Mostert, K., \& Bakker, A. B. (2010). Burnout and work engagement: A thorough investigation of the independency of both constructs. Journal of Occupational Health Psychology, 15, 209-222. http://doi.org/10.1037/a0019408

Donahue, E. G., Forest, J., Vallerand, R. J., Lemyre, P. N., Crevier-Braud, L., \& Bergeron, É. (2012). Passion for work and emotional exhaustion: The mediating role of rumination and recovery. Applied Psychology: Health and Well-Being, 4, 341-368. http://doi.org/10. $\underline{1111 / \mathrm{j} .1758-0854.2012 .01078 . \mathrm{x}}$

Embriaco, N., Papazian, L., Kentish-Barnes, N., Pochard, F., \& Azoulay, E. (2007). Burnout syndrome among critical care healthcare workers. Current Opinion in Critical Care, 13, 482-488. http://doi.org/10.1097/MCC.0b013e3282efd28a

Eriksen, H. R., Murison, R., Pensgaard, A. M., \& Ursin, H. (2005). Cognitive activation theory of stress (CATS): From fish brains to the olympics. Psychoneuroendocrinology, 30, $933-$ 938. http://doi.org/10.1016/j.psyneuen.2005.04.013

Etzion, D., Eden, D., \& Lapidot, Y. (1998). Relief from job stressors and burnout: Reserve service as a respite. The Journal of Applied Psychology, 83, 577-585. http://doi.org/10.1037/ $\underline{0021-9010.83 .4 .577}$

Flaxman, P. E., Ménard, J., Bond, F. W., \& Kinman, G. (2012). Academics' experiences of a respite from work: Effects of self-critical perfectionism and perseverative cognition on postrespite well-being. Journal of Applied Psychology, 97, 854-865. http://dx.doi.org/ $10.1037 / \mathrm{a} 0028055$

Fredrickson, B. L., \& Joiner, T. (2002). Positive emotions trigger upward spirals toward emotional well-being. Psychological Science, 13, 172-175. http://doi.org/10.1111/14679280 .00431

Frese, M., \& Zapf, D. (1988). Methodological issues in the study of work stress: Objective vs subjective measurement of work stress and the question of longitudinal studies. In C. L. Cooper \& R. Payne (Eds.), Causes, coping, and consequences of stress at work (pp. 375411). Wiley, Chichester

Fritz, C., \& Sonnentag, S. (2005). Recovery, health, and job performance: Effects of weekend experiences. Journal of Occupational Health Psychology, 10, 187-199. http://doi.org/ $\underline{10.1037 / 1076-8998.10 .3 .187}$

Fritz, C., \& Sonnentag, S. (2006). Recovery, well-being, and performance-related outcomes: The role of workload and vacation experiences. The Journal of Applied Psychology, 91, $936-$ 945. http://doi.org/10.1037/0021-9010.91.4.936

Fritz, C., Sonnentag, S., Spector, P., \& McInroe, J. (2010). The weekend matters: Relationships between stress recovery and affective experiences. Journal of Organizational Behavior, 31, 1137-1162. https://doi.org/10.1002/job.672

Fritz, C., Yankelevich, M., Zarubin, A., \& Barger, P. (2010). Happy, healthy, and productive: The role of detachment from work during nonwork time. Journal of Applied Psychology, 95, 977-983. https://doi.org/10.1037/a0019462 
Geurts, S.A.E., \& Sonnentag, S. (2006). Recovery as an explanatory mechanism in the relation between acute stress reactions and chronic health impairment. Scandinavian Journal of Work, Environment \& Health, 32, 482-492.https://doi.org/10.5271/sjweh.1053

Hamesch, U., Cropley, M., \& Lang, J. (2014). Emotional versus cognitive rumination: Are they differentially affecting long-term psychological health? The impact of stressors and personality in dental students. Stress and Health, 30, 222-231. http://doi.org $\angle 10.1002 / \mathrm{smi} .2602$

Hobfoll, S. E. (1989). Conservation of resources. A new attempt at conceptualizing stress. The American Psychologist, 44, 513-524.http://doi.org/10.1037/0003-066X.44.3.513

Hobfoll, S. E. (2001). The influence of culture, community, and the nested-self in the stress process: Advancing conservation of resources theory. Applied Psychology: An International Review, 50, 337-421. http://dx.doi.org/10.1111/1464-0597.00062

Hobfoll, S.E., \& Shirom, A. (2001). Conservation of resources theory: Applications to stress and management in the workplace. In R.T. Golembiewski (Ed.), Handbook of organizational behavior (2nd ed., pp. 57-80). New York: Marcel Dekker, Inc.

Hockey, G. R. J. (1993). Cognitive-energetical control mechanisms in the management of work demands and psychological health. In A. D. Baddeley \& L. Weiskrantz (Eds.), Attention, selection, awareness and control: A tribute to Donald Broadbent (pp. 328-345). Oxford, UK: Clarendon Press.

Houtman, I., Jettinghoff, K., \& Cedillo, L. (2007). Raising awareness of stress at work in developing countries: A modern hazard in a traditional working environment: Advice to employers and worker representatives (Protecting Workers' Health Series No. 6). Geneva: World Health Organization. http://www.who.int/occupational_health/publications/raisinga warenessofstress. pdf. Accessed 5 Nov 2011.

Kinnunen, U., Feldt, T., Sianoja, M., de Bloom, J., Korpela, K., \& Geurts, S. (2017). Identifying long-term patterns of work-related rumination: associations with job demands and wellbeing outcomes. European Journal of Work and Organizational Psychology, 26, 514-526. https://doi.org/10.1080/1359432X.2017.1314265

Kivimäki, M., Leino-Arjas, P., Kaila-Kangas, L., Luukkonen, R., Vahtera, J., Elovainio, M., Härmä, M., \& Kirjonen, J. (2006). Is incomplete recovery from work a risk marker of cardiovascular death? Prospective evidence from industrial employees. Psychosomatic Medicine, 68, 402-407.https://doi.org/10.1097/01.psy.0000221285.50314.d3

Lee, R. T., \& Ashforth, B. E. (1996). A meta-analytic examination of the correlates of the three dimensions of job burnout. Journal of Applied Psychology, 81, 123-133. http:// dx.doi.org/10.1037/0021-9010.81.2.123

Maslach, C., Schaufeli, W. B., \& Leiter, M. P. (2001). Job burnout. Annual Review of Psychology, 52, 397-422. http://doi.org/10.1146/annurev.psych.52.1.397

Meijman, T. F., \& Mulder, G. (1998). Psychological aspects of workload. In P. J. D. Drenth \& H. Thierry (Eds.), Handbook of work and organizational psychology: Vol. 2. Work psychology (pp. 5-33). Hove, England: Psychology Press.

Meurs, J. A., \& Perrewe, P. L. (2011). Cognitive activation theory of stress: An integrative theoretical approach to work stress. Journal of Management, 37, 1043-1068. http:// doi.org/10.1177/0149206310387303

Nixon, A.E., Mazzola, J.L., Bauer, J., Krueger, J.R., \& Spector, P.E. (2011). Can work make you sick? A meta-analysis of the relationships between job stressors and physical symptoms. Work \& Stress, 25, 1-22. https://doi.org/10.1080/02678373.2011.569175 
Pandey, S., \& Elliott, W. (2010). Suppressor variables in social work research: Ways to identify in multiple regression models. Journal of the Society for Social Work and Research, 1, 2840. http://doi.org/10.5243/jsswr.2010.2

Querstret, D., \& Cropley, M. (2012). Exploring the relationship between work-related rumination, sleep quality, and work-related fatigue. Journal of Occupational Health Psychology, 17, 341-53. http://doi.org/10.1037/a0028552

Ragsdale, J. M., Beehr, T. A., Grebner, S., \& Han, K. (2011). An integrated model of weekly stress and weekend recovery of students. International Journal of Stress Management, 18, 153180. http://doi.org/10.1037/a0023190

Rotenstein, L. S., Torre,M., Ramos, M. A., Rosales, R. C., Guille, C., Sen, S., \& Mata, D. A. (2018). Prevalence of burnout among physicians: A systematic review. JAMA, 320, 1131-1150. http://doi.org/doi:10.1001/jama.2018.12777

Rook, J. W., \& Zijlstra, F. R. H. (2006). The contribution of various types of activities to recovery. European Journal of Work and Organizational Psychology, 15, 218-240. http://dx. doi.org/10.1080/13594320500513962

Rydstedt, L. W., Cropley, M., Devereux, J. J., \& Michalianou, G. (2009). The effects of gender, long-term need for recovery and trait inhibition-rumination on morning and evening saliva cortisol secretion. Anxiety, Stress, and Coping, 22, 465-474. http://doi.org/ $\underline{10.1080 / 10615800802596378}$

Sluiter, J. K., Frings-Dresen, M. H. W., Van Der Beek, A. J., \& Meijman, T. F. (2001). The relation between work-induced neuroendocrine reactivity and recovery, subjective need for recovery, and health status. Journal of Psychosomatic Research, 50, 29-37. http:// doi.org/10.1016/S0022-3999(00)00213-0

Sluiter, J. K., van der Beek, A. J., \& Frings-Dresen, M. H. W. (1999). The influence of work characteristics on the need for recovery and experienced health: A study on coach drivers. Ergonomics, 42, 573-583. http://doi.org/10.1080/001401399185487

Sonnentag, S. (2001). Work, recovery activities, and individual well-being: A diary study. Journal of Occupational Health Psychology, 6, 196-210. http://doi.org/10.1037/1076$\underline{8998.6 .3 .196}$

Sonnentag, S. (2012). Psychological detachment from work during leisure time: The benefits of mentally disengaging from work. Current Directions in Psychological Science, 21, 114118. http://doi.org/10.1177/0963721411434979

Sonnentag, S., \& Bayer, U. V. (2005). Switching off mentally: Predictors and consequences of psychological detachment from work during off-job time. Journal of Occupational Health Psychology, 10, 393-414. http://doi.org/10.1037/1076-8998.10.4.393

Sonnentag, S., Binnewies, C., \& Mojza, E. J. (2008). “Did you have a nice evening?” A day-level study on recovery experiences, sleep, and affect. Journal of Applied Psychology, 93, 674684. http://doi.org/10.1037/0021-9010.93.3.674

Sonnentag, S., \& Fritz, C. (2007). The recovery experience questionnaire: Development and validation of a measure for assessing recuperation and unwinding from work. Journal of Occupational Health Psychology, 12, 204-221. http://dx.doi.org/10.1037/1076$\underline{8998.12 .3 .204}$

Sonnentag, S., \& Fritz, C. (2015). Recovery from job stress: The stressor-detachment model as an integrative framework. Journal of Organizational Behavior, 36, S72-S103. http://dx. doi.org/10.1002/job.1924

Sonnentag, S., Kuttler, I., \& Fritz, C. (2010). Job stressors, emotional exhaustion, and need for recovery: A multi-source study on the benefits of psychological detachment. Journal of Vocational Behavior, 76, 355-365. http://doi.org/10.1016/j.jvb.2009.06.005 
Sonnentag, S., Mojza, E. J., Binnewies, C., \& Scholl, A. (2008). Being engaged at work and detached at home: A week-level study on work engagement, psychological detachment, and affect. Work \& Stress, 22, 257-276. http://doi.org/10.1080/02678370802379440

Sonnentag, S., \& Natter, E. (2004). Flight attendants' daily recovery from work: Is there no place like home? International Journal of Stress Management, 11, 366-391. http://dx.doi.org/ $\underline{10.1037 / 1072-5245.11 .4 .366}$

Sonnentag, S., \& Zijlstra, F. R. H. (2006). Job characteristics and off-job activities as predictors of need for recovery, well-being, and fatigue. The Journal of Applied Psychology, 91, 330350. http://doi.org/10.1037/0021-9010.91.2.330

Syrek, C. J., Weigelt, O., Peifer, C. \& Antoni, C. H. (2016). Zeigarnik's sleepless nights: How unfinished tasks at the end of the week impair employee sleep on the weekend through rumination. Journal of Occupational Health Psychology, 22, 225-238. http://dx.doi.org/ $10.1037 /$ ocp0000031

ten Brummelhuis, L. L., \& Bakker, A. B. (2012). Staying engaged during the week:The effect of offjob activities on next day work engagement. Journal of Occupational Health Psychology, 17, 445-455. http://dx.doi.org/10.1037/a0029213

Thoits, P. A. (2011). Mechanisms linking social ties and support to physical and mental health. Journal of Health and Social Behavior, 52, 145-161. https://doi.org/10.1177/ $\underline{0022146510395592}$

Ursin H., \& Eriksen, H. R. (2004). The cognitive activation theory of stress. Psychoneuroendocrinology, 29, 567-592. http://doi.org/10.1016/S0306-4530(03) 00091-X

Ursin, H., \& Eriksen, H. R. (2010). Cognitive activation theory of stress (CATS). Neuroscience and Biobehavioral Reviews, 34, 877-881. http://doi.org/10.1016/j.neubiorev. 2009.03.001

van Hooff, M.L.M., Geurts, S.A.E., Beckers, D.G.J., \& Kompier, M.A.J. (2011). Daily recovery from work: The role of activities, effort and pleasure. Journal of Work \& Stress, 25, 55-74. https://doi.org/10.1080/02678373.2011.570941

Vancouver, J. B., \& Day, D. V. (2005). Industrial and organisation research on self-regulation: From constructs to applications. Applied Psychology, 54, 155-185. https://doi.org/10. $1111 /$ i.1464-0597.2005.00202.x

Vercambre, M. N., Brosselin, P., Gilbert, F., Nerrière, E., \& Kovess-Masféty, V. (2009). Individual and contextual covariates of burnout: A cross-sectional nationwide study of French teachers. BioMed Central Public Health, 10, 333-344. https://doi.org/10.1186/14712458-9-333

Westman, M., \& Eden, D. (1997). Effects of a respite from work on burnout: Vacation relief and fadeout. Journal of Applied Psychology, 82, 516-527. https://doi.org/10.1037//00219010.82.4.516

Wickens, C. W., \& Hollands, J. G. (Eds.). (2000). Engineering psychology and human performance (3 edn). Upper Saddle River, NJ, USA: Prentice Hall.

Winwood, P. C., Bakker, A. B., \& Winefield, A. H. (2007). An investigation of the role of non-work time behavior in buffering the effects of work strain. Journal of Occupational and Environmental Medicine, 49, 862-871. https://doi.org/10.1097/JOM.0b013e31 $\underline{8124 \mathrm{a} 8 \mathrm{dc}}$

Wright, T. A., \& Cropanzano, R. (1998). Emotional exhaustion as a predictor of job performance and voluntary turnover. Journal of Applied Psychology, 83, 486-493. http://dx.doi.org $\angle 10.1037 / 0021-9010.83 .3 .486$ 
Xanthopoulou, D., Bakker, A. B., \& Ilies, R. (2012). Everyday working life: Explaining withinperson fluctuations in employee well-being. Human Relations, 65, 1051-1069. http://doi.org/10.1177/0018726712451283

Zijlstra, F. R. H., \& Cropley, M. (2006). Recovery after work. In F. Jones, R. J. Burke, \& M. Westman (Eds.), Work-life balance: A psychological perspective (pp. 219-234). New York, NY: Psychology Press.

Zijlstra, F. R. H., Cropley, M., \& Rydstedt, L. W. (2014). From recovery to regulation: An attempt to reconceptualize recovery from work. Stress and Health 30, 244-252. https://doi.org/10.1002/smi.2604 


\section{CHAPTER 2}

\section{Should you switch off or stay engaged? The consequences of thinking about work on the trajectory of psychological well-being over time}

This chapter is based on: Firoozabadi, A., Uitdewilligen, S., \& Zijlstra, F. R. H. (2018). Should you switch off or stay engaged? The consequences of thinking about work on the trajectory of psychological well-being over time. Journal of Occupational Health Psychology, 23, 278-288. http://dx.doi.org/10.1037/ ocp0000068 



\begin{abstract}
This study examined how two different ways of being mentally engaged with work-related issues during evenings (affective rumination and problem-solving pondering) cause changes in psychological well-being over one year period. We conducted a three-wave longitudinal study with a time lag of six months between each wave. At the first measurement moment, participants filled out a survey over five consecutive working days assessing work-related affective rumination and problem-solving pondering during evenings. Exhaustion and health complaints were assessed at the first measurement moment as well as after six and after 12 months. The three waves of data obtained from a total of 123 participants with full-time and primarily mentally demanding jobs were analyzed using latent growth curve modeling (LGM). The results showed that affective rumination is a significant predictor of increase in exhaustion over time. Problem-solving pondering was not found to be a significant predictor of change in psychological well-being over time. These findings demonstrate that work-related rumination during evenings may lead to health problems over time depending on the type of rumination. It suggests that unlike affective rumination, problem-solving pondering during evenings has no influence on psychological well-being over time.
\end{abstract}

Keywords: psychological well-being, exhaustion, recovery, work-related rumination, problem-solving 


\section{Introduction}

Previous research consistently shows that repeated insufficient recovery from work results in resource depletion and impairs employees' well-being especially over extended periods of time (Rook \& Zijlstra, 2006; Sonnentag \& Zijlstra, 2006; Hobfoll \& Shirom, 2001).

Psychological detachment as an essential recovery experience has been reported to be beneficial for well-being both in the short and long run (e.g. Sonnentag, Kuttler, \& Fritz, 2010; Sonnentag, Binnewies, \& Mojza, 2010; Sonnentag \& Bayer, 2005). Psychological detachment has been defined as the sense of being away from work situations and the ability to switch off mentally from work (Etzion, Eden, \& Lapidot, 1998; Sonnentag \& Bayer, 2005). The lack of psychological detachment during off-job time implies to be mentally occupied with work stressors by thinking about work-related issues. The repeated or chronic activation of the cognitive representation of stressors is defined as perseverative cognition (Brosschot, Pieper \& Thayer, 2005). According to Brosschot, Gerin, and Thayer (2006), perseverative cognition acts as the core feature of rumination that links stress exposure to impaired health.

Cropley and Zijlstra (2011) proposed two different types of work-related rumination labeled affective rumination and problem-solving pondering. Affective rumination is described as the experience of intrusive, pervasive and recurrent thoughts, in which attention is mainly directed to feelings related to work problems. Problem-solving pondering is described as prolonged thinking about possible solutions to a problem in order to progress toward choice of a solution (Pravettoni, Cropley, Leotta, \& Bagnara, 2007). Cropley and Zijlstra (2011) proposed that these two qualities of work-related rumination may have different effects on the recovery process due to their diverging effects on psychophysiological arousal.

There are only a few studies that examined the relationship between these two types of work-related rumination and well-being (e.g. Querstret \& Cropley 2012; Hamesch, Cropley, \& Lang, 2014; Syrek, Weigelt, Peifer, \& Antoni, 2016). Although, these studies indeed suggest differential relationships between affective rumination and problem solving on well-being, little is still known about their long-term health consequences. Particularly in the long run, affective rumination may result in cumulative effects on well-being by chronically depleting resources over time (Frese \& Zapf, 1988; Sluiter, Frings-Dresen, Van 
Der Beek, \& Meijman, 2001), whereas problem-solving pondering may reduce cumulative effects on well-being by producing psychological resources over time (Fredrickson \& Joiner, 2002). Therefore, in this study, we investigate how the two different ways of being mentally engaged with work-related issues during evenings influence the trajectory of well-being over a one year period.

Our study makes several contributions to the recovery literature. First, it extends the recovery literature by examining the long-term accumulative effects of recovery during evenings of the working week on well-being. Second, in contrast to previous research, the present study examines the idea that the lack of detachment is not necessarily a threatening factor for well-being, depending on the type of work-related rumination. Finally, to fully capture both work-related and general factors of well-being, we include two long-term well-being outcomes: exhaustion and general mental health complaints. According to Warr (1987), when investigating employees' well-being in the long run, a distinction should be drawn between 'context-specific' and 'context-free' mental health. Contextspecific mental health refers explicitly to job-related mental health such as exhaustion. In contrast, context-free mental health is a more global construct that is not tied to a specific context and reflects the general status of well-being. Therefore, our study contributes to occupational health literature by differentiating between these two well-being outcomes.

\section{Work-related affective rumination vs. problem-solving pondering}

Rumination is conceptualized as "a class of conscious thoughts that revolve around a common instrumental theme and that recur in the absence of immediate environmental demands requiring the thoughts" (Martin, \& Tesser, 1996, p. 7). Cropley and Zijlstra (2011) argued that people may engage in qualitatively different types of work-related rumination, namely affective rumination and problem-solving pondering. They state that affective rumination and problemsolving pondering have different effects on the recovery process because of their differential impact on psycho-physiological arousal. Whereas, affective rumination causes prolonged psycho-physiological activation that has straining effects on the organism, problem-solving pondering may only lead to a short lasting psychophysiological activation (Cropley \& Zijlstra, 2011). To develop a conceptualization of different effects of affective rumination and problem-solving pondering on prolonged activation and well-being, we draw on the Cognitive Activation Theory of Stress (CATS: Ursin \& Eriksen, 2004). 
CATS (Ursin \& Eriksen, 2004) is a comprehensive theory of stress that proposes that dealing with stressors leads to varying degrees of psychophysiological arousal depending on the response outcome expectancies. Response outcome expectancies are defined as individuals' estimates about the outcomes of their given responses. CATS distinguishes between negative and positive outcome expectancies depending on whether the produced response is expected to handle the situation with negative or positive results, respectively. Accordingly, negative outcome expectancies lead to sustained arousal especially when individuals do not see a solution to the problem. This heightened arousal will be sustained until the reason for the arousal has been eliminated. Moreover, sustained arousal occurs when one continues to endorse the negative outcome expectancy by rumination (Eriksen, Murison, Pensgaard, \& Ursin, 2005). According to CATS, hopelessness and helplessness are two negative response outcome expectancies that occur when there is no successful coping. Hopelessness occurs when individuals learn that their responses have led to negative results. Helplessness occurs when individuals perceive that their responses have not been effective in avoiding the aversive stimulus. It is assumed that both states threaten health through sustained arousal that has straining effects on the organism (Ursin \& Eriksen, 2004; Meurs \& Perrewe, 2011). Based on CATS, affective rumination leads to prolonged activation because there are negative outcome expectancies for solving problems and coping with the situation. Rumination exacerbates these negative expectancies over time and increases the perceived lack of control. When individuals establish the expectancy that they are not able to cope with the situation for instance by finding a solution or avoiding aversive thoughts, hopelessness and helplessness may occur. Cognitive models of clinical psychology conceptualized helplessness and hopelessness as the mechanisms by which anxiety and depression occur (Waikar \& Craske, 1997; Henkel, Bussfeld, Möller, \& Hegerl, 2002; Pryce et al., 2011; Vollmayr \& Gass, 2013).

CATS defines coping as positive response outcome expectancies in which individuals believe that they are able to handle the situation with positive results (Ursin \& Eriksen, 2010). Although individuals still experience a shortlasting activation or phasic arousal when handling a difficult or unfinished task, this level of arousal will be reduced as soon as a solution is found or a positive result achieved. Based on CATS, in terms of dealing with stressors, problemsolving pondering can function as a form of coping in which individuals think about work-related issues with positive outcome expectancies. Therefore, they have a feeling of being able to control the situation by finding a solution to the 
problem. Finding a solution and feeling a sense of control are both known as adequate ways of reducing arousal (Ursin \& Eriksen, 2004).

\section{Work-related affective rumination and psychological well-being}

Work-related affective rumination during evenings is likely to lead to a decrease in well-being in the long run for several reasons. When people ruminate affectively about work, they generally think repetitively about negative aspects such as failure or negative events (Binnewies, Sonnentag, \& Mojza, 2009). Because in this way job stressors remain mentally present, it leads to prolonged activation (Brosschot et al., 2005). As a result, prolonged activation causes impaired well-being as it draws on individuals' resources during recovery time (Brosschot, van Dijk, \& Thayer, 2002). In addition, ruminating about the negative aspects of work is associated with increased negative affect (Thomsen et al., 2004, Thomsen, Mehlsen, Christensen, \& Zachariae, 2003) which influences well-being negatively in the long run (Finch, Baranik, Liu, \& West, 2012, Mayne, 1999). Furthermore, according to Brosschot et al. (2006), affective rumination has a negative effect on health not only by prolonging the effects of a stressor but also by increasing its degree of uncontrollability. In fact, effortful thinking without finding a cognitive gain or solution results in prolonged experience of uncontrollability. Prolonged experience of uncontrollability is likely to lead to a decrease in well-being via causing impaired cognitive functioning such as the lack of attentional control (von Hecker \& Sedek, 1999; Bukowski, Asanowicz, Marzecová, \& Lupiáñez, 2015). It can also lead to health impairment by causing learned helplessness (Seligman, 1975) when there is no reduction of the initial uncertainty despite the individual's continuous cognitive effort (Sedek \& Kofta, 1990; Kofta, 1993). Finally, affective rumination may affect health over a long time via its negative effects on healthrelated behavior. Previous studies showed that people engaging in much rumination have poorer health behaviors such as smoking, drinking, physical inactivity and sleep disturbance (Thomsen et al, 2004; Cropley, Dijk, \& Stanley, 2006). Especially in the long run, these negative behaviors may lead to impaired well-being.

Previous research on rumination has mainly been conducted in the field of clinical psychology and focused predominantly on the emotional aspect of rumination. These studies showed that rumination is associated with a variety of psychological states such as anxiety (Mellings \& Alden, 2000), depression and negative affect (Lyubomirsky, Caldwall, \& Nolen-Hoeksema, 1998; Thomsen et al., 2003), anger (Hogan \& Linden, 2004), physiological and somatic symptoms 
(Brosschot et al., 2006), and poor sleep quality (Thomsen et al., 2003). Up to now, few studies investigated how work-related rumination influences well-being. In a cross-sectional study, Querstret and Cropley (2012) found that high levels of affective rumination were associated with high levels of acute and chronic fatigue. Another study by Donahue et al. (2012) found a positive relationship between work-related rumination and exhaustion reported by professional coaches. By using a longitudinal design of study on nurses, Donahue et al. (2012) reported the same results, indicating a positive relationship between work-related rumination and exhaustion after three months. In another study, Hamesch et al. (2014) found that in a sample of dental students, work-related affective rumination was positively related to depression measured after six months. In the present study we go beyond looking at the delayed effects of rumination by investigating whether the extent to which people experience affective rumination during evenings is related to the slope of psychological well-being over a one year period. We hypothesize that:

Hypothesis 1: The experience of work-related affective rumination during evenings is positively related to the rate of change in exhaustion (a) and health complaints (b) over time.

\section{Work-related problem-solving pondering and psychological well- being}

In contrast to affective rumination, problem-solving pondering during evenings may have long term positive effects on well-being for several reasons. Although problem-solving pondering during recovery time draws on individual's cognitive resources, it is likely to act as a resource-providing experience by producing positive affect. People may experience positive affect when they ponder about interesting work-related issues or positive aspects of work. Moreover, problemsolving pondering may result in the discovery of solutions that causes positive affect. Therefore, problem-solving pondering may improve well-being by producing positive affect (Seo, Barrett, \& Bartunek, 2004). Especially in the long run, according to the broaden-and-build theory of positive emotions (Fredrickson, 1998), momentary experiences of positive emotions can trigger upward spirals towards well-being over time by building psychological resources (Fredrickson \& Joiner, 2002). Furthermore, according to the self-regulation model of ruminative thought (Martin \& Tesser, 1996), finding a solution as a goal attainment mechanism stops ruminative thinking processes. Then individuals have more time to engage in recovery experiences. Taking together, the 
experience of problem-solving pondering during off-job time may benefit individuals' well-being because it reduces the effect of work-related stressors and enhances their resources to deal with future stressors.

A few studies have addressed the effects of problem-solving pondering on well-being. In a cross-sectional study by Querstret and Cropley (2012), problemsolving pondering was associated with lower levels of acute and chronic fatigue. However, a longitudinal study using a student sample (Hamesch et al., 2014) did not find any significant effect of problem-solving pondering on depression. In the current study, we examine how the experience of problem-solving pondering during evenings influences the slope of psychological well-being over a one year period. We hypothesize that:

Hypothesis 2: The experience of work-related problem-solving pondering during evenings is negatively related to the rate of change in exhaustion (a) and health complaints (b) over time.

The research model is presented in Figure 2.1.

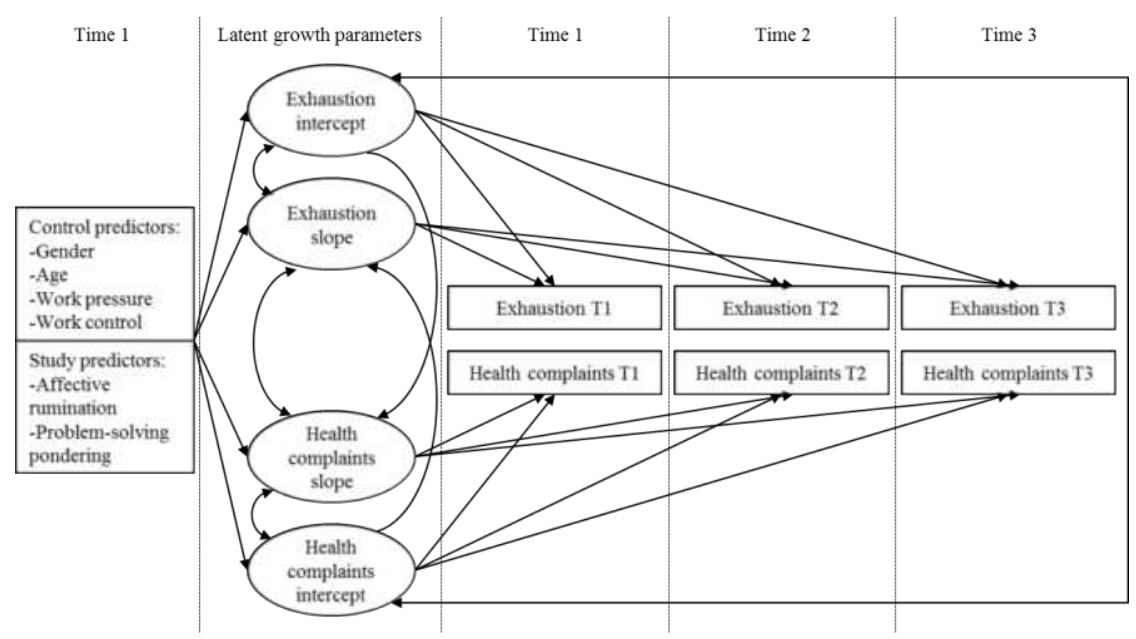

Figure 2.1. The conditional bivariate latent growth model of psychological wellbeing over time. 


\section{Method}

\section{Procedure and sample}

To test the hypotheses, we conducted a three-wave study with a time lag of six months between each wave. However, due to local circumstances the time window in which surveys could be filled in varied from one week earlier to one week later than the exact six months. At Time 1, participants were asked to fill in a general survey and five separate daily surveys administered over the working week. The general survey was used to collect demographic information and access control variables and outcome variables. The daily survey assessed evening-level measures of work-related affective rumination and problem-solving pondering. Schlotz, Hellhammer, Schulz, and Stone (2004) demonstrated that individuals show higher levels of cortisol awakening response during working days compared with weekend days. This difference in cortisol awakening response is attributed to person-levels of work-related rumination. Therefore, the present study focuses only on rumination that people specifically experience during evenings of the working week. To capture this rumination, we conducted a diary study for a whole 5-day week. Moreover, we used the daily measurement because in this way participants would not have to remember over longer time periods to what extent they engaged in affective rumination or problem-solving pondering during evenings. We asked participants to complete the daily survey over a period of five consecutive working days before going to bed. To make sure that participants would not forget to complete the diary in the evening, brief reminder messages were sent on their cell phones. We used the average of five the Time 1 evening measures of work-related affective rumination and problem-solving pondering. At Time 2 and 3 participants were asked again to complete the general survey questionnaire measuring outcome variables.

Participants were recruited from a range of Iranian organizations, including two centers of health and social welfare services, a counseling center of a large university, the educational office and a faculty of a university, two high schools, and a couple of local branches of a bank. We sent a letter to the head of the organizations who informed their employees about the goal of the study as well as the daily and longitudinal nature of the surveys. In the letter we emphasized the anonymity and confidentiality of the data-collection and analysis process. The sample criteria were that each participant must work in a full-time and primarily mentally demanding job. Participants were offered to receive feedback about their results after completion of the data collection as an incentive 
for participation. Of the 240 distributed paper-and-pencil survey packages at Time 1 , a total of 186 persons responded to the general and daily questionnaires. The group of participants, who had completed the Time 1 survey, received the second and third surveys, 6 months (Time 2) and then 12 months (Time 3 ) after the first measurement. At Time 2 and 3 participants were asked to fill out only the questionnaires measuring health complaints and exhaustion. 156 and 138 questionnaires were filled out and returned at Time 2 and Time 3, respectively. Seven participants were omitted owing to reported substantially negative events (e.g. death of a close relative or friend, starting a new job) over the one year study period. We also omitted the data from eight participants who responded to daily surveys over less than three working days. Hence, the data from a final sample of 123 participants were analyzed. Attrition analyses revealed that employees with higher levels of health complaints $(t(184)=-2.22, p<.05)$ at Time 1 were more likely to drop out from the study. However, there was no significant difference between dropouts and non-dropouts with respect to exhaustion $(t(184)=-1.68$, $p=.09)$, affective rumination $(t(184)=-.91, p=.36)$, and problem-solving pondering $(t(184)=-1.27, p=.21)$, making it unlikely that attrition would have confounded the results (Goodman \& Blum, 1996).

The final panel group $(\mathrm{N}=123)$ consisted of 61 female and 62 male employees working in different types of job (26\% in health services, $45 \%$ in educational services and $29 \%$ in social services). The majority of the participants (84\%) were married. At Time 1 age ranged from 21 to 54 years $(M=32.85 ; \mathrm{SD}=$ 5.82). They were educated in a range of degrees from Basic Diploma to $\mathrm{PhD}(10 \%$ basic diploma, $9 \%$ associate, $50 \%$ bachelor, $25 \%$ master, and $6 \% \mathrm{PhD}$ ).

\section{Measures}

Data were collected by conducting general and daily surveys. All items were in Persian. Items developed in English were translated into Persian by the first author and translated back to English by two interpreters to ensure conceptual consistency. Cronbach's alphas for all scales are displayed in Table 2.1.

Exhaustion. We assessed exhaustion with the related subscale of Oldenburg Burnout Inventory (OLBI; Demerouti, Mostert, \& Bakker, 2010; Demerouti, Bakker, Nachreiner, \& Schaufeli, 2001). The subscale of exhaustion consists of 8 items (e.g., "During my work, I often felt emotionally drained") scored on a 4-point scale ranging from 1 (strongly disagree) to 4 (strongly agree). 
Scores were coded in such a way that higher scores indicate more exhaustion during the past few weeks.

Health complaints. To measure health complaints, we used the 12 -item General Health Questionnaire (GHQ-12; Goldberg \& Williams, 1988). GHQ-12 consists of 12 items that each one assesses the severity of a mental problem over the past few weeks (e.g., "I felt constantly under strain") on a 4-point scale from 0 (not at all) to 3 (much more than usual). Scores were coded such that higher scores indicate worse mental health.

Work-related rumination. We measured two different type of workrelated rumination including affective rumination and problem-solving pondering each by five adapted items of The Work-Related Rumination Questionnaire (WRRQ; Cropley, Michalianou, Pravettoni, \& Millward, 2012). Affective rumination and problem-solving pondering subscales included items such as, "During evening, I was irritated by work issues" and "During evening, I found solutions to my work-related problems", respectively. Items were responded by using a five-point Likert scale ranging from 1 (very seldom/never) to 5 (very often/always).

To test whether these two ruminative experiences represented distinct constructs, we ran a set of confirmatory factor analyses. Compared to the onefactor model $\left(\chi^{2}(30)=162.983, p<0.001\right.$; CFI $=.80$; TLI $=.71$; RMSEA = .19; SRMR =.16), the two-factor model $\left(\chi^{2}(29)=41.701, p=.06\right.$; CFI $=.98 ;$ TLI $=$ .97 ; RMSEA $=.06 ;$ SRMR $=.05)$ was found to fit the observed data at Day 1 significantly better $\left(\Delta \chi^{2}(1)=121.282, p<.001\right)$. The two-factor model was also the best fit to the data at Day $2,3,4$, and 5 .

To achieve the person-level of affective rumination and problem-solving pondering, we aggregated and averaged the five daily evening measures of them. In order to justify the aggregations and average across the five daily measurements, we estimated the two forms of the intraclass correlation coefficient: the ICC1 and ICC2 (Bliese, 2000, 2013). ICC1s' results revealed that $68 \%$ and $64 \%$ of variance, respectively, in affective rumination and problemsolving pondering lying between persons. Moreover, the ICC2s' values of .91 and .89 were found for affective rumination and problem-solving pondering, respectively. These estimates indicate that individuals can significantly (Bliese, 2013) be reliably differentiated in terms of the averages of affective rumination and problem-solving pondering. 
Job situation control variables. Work pressure was assessed using 13-item work pressure subscale of Tilburg Work Pressure Questionnaire (T-WPQ; Roe \& Zijlstra, 2000). Participants were asked to indicate the extent to which they agreed with each item (e.g., "During my work I feel urged or hurried") on a 5-point Likert scale ranging from 1 (strongly disagree) to 5 (strongly agree). Participants with higher scores experienced greater work pressure. Work control was measured using the Job Control Questionnaire developed by Greenberger, Strasser, Cummings, and Dunham (1989). The job control questionnaire consists of 16 items about task control, organization control, and resource control (e.g., "How much influence do you have over the amount of work you do?"). The items were rated on a 5-point Likert scale ranging from 1 (very little) to 5 (very much), with higher scores reflecting greater job control.

\section{Analytical model}

The research hypotheses were examined using latent growth curve modeling (LGM; Duncan, Duncan, Strycker, Li, \& Alpert, 1999; Kaplan, 2000). As a structural equation modeling approach to the analysis of longitudinal data, LGM is used to investigate within-person changes in outcome variables over time as well as between-subject differences in such changes (Muthén \& Khoo, 1998). To do so, LGM estimates two latent growth curve parameters of outcome variables; the initial level (i.e., intercept) and the rate of change over time (i.e., slope). LGM then provides the possibility to examine the interactions between these two latent growth parameters, as well as their between-person differences across a set of predictors (Willett \& Sayer, 1994).

The analyses were conducted using Mplus statistical software version 7 (Muthén \& Muthén, 2012) and model fit was evaluated using five indicators: the Chi-square goodness of fit test; the comparative fit index (CFI; Bentler, 1990); the Tucker-Lewis index (TLI; also known as the non-normed fit index; Tucker \& Lewis, 1973); the root mean square error of approximation (RMSEA; Steiger, 1990); and the standardized root mean square residual (SRMR; Hu \& Bentler, 1999).

To analysis the data, we started with an unconditional univariate growth model of each outcome variable, by which we examined how exhaustion and general mental health changed over the one year period of study. Then, we tested the unconditional bivariate growth model (McArdle, 1988), suggested for the multivariate situation in which more than one growth model are simultaneously 
estimated at the level of the random slopes (Willett \& Sayer, 1994). This allowed us to examine how changes in the two study outcome variables are associated with each other over time. Finally, we tested the conditional bivariate growth model. This model included gender, age, work pressure, and work control as the control variables. We also entered affective rumination and problem-solving pondering about work-related issues during evenings as the core predictors of four latent growth factors, as displayed in Figure 2.1.

\section{Results}

Table 2.1 presents the means, standard deviations, Cronbach's alphas, and correlations for all predictors and Time 1, Time2, and Time 3 measures of exhaustion and general health complaints. The mean levels of both exhaustion and health complaints show an increasing trajectory over time. In addition exhaustion and health complaints are positively correlated both within and across waves of measurements. 
Table 2.1

Mean, standard deviation, and correlations for the study variables

\begin{tabular}{|c|c|c|c|c|c|c|c|c|c|c|c|c|c|c|}
\hline Variable & $M$ & $S D$ & $a$ & 1 & 2 & 3 & 4 & 5 & 6 & 7 & 8 & 9 & 10 & $\overline{11}$ \\
\hline 1. Gender & 0.48 & 0.50 & & - & & & & & & & & & & \\
\hline 2. Age & 32.85 & 5.80 & & -.12 & - & & & & & & & & & \\
\hline 3.Time 1 exhaustion & 2.26 & 0.48 & .80 & $.22^{*}$ & -.12 & - & & & & & & & & \\
\hline 4. Time 2 exhaustion & 2.34 & 0.52 & .87 & $.25^{* *}$ & -.09 & $.61^{* *}$ & - & & & & & & & \\
\hline 5. Time 3 exhaustion & 2.41 & 0.45 & .75 & $.33^{* *}$ & -.03 & $.32^{* *}$ & $.36^{* *}$ & - & & & & & & \\
\hline 6. Time 1 health complaints & 0.81 & 0.37 & .79 & .16 & -.16 & $.57^{* *}$ & $.43^{* *}$ & $.31^{*}$ & - & & & & & \\
\hline 7. Time 2 health complaints & 0.91 & 0.49 & .86 & $.25^{* *}$ & -.13 & $.37^{* *}$ & $.69^{* *}$ & $.37^{* *}$ & $.52^{* *}$ & - & & & & \\
\hline 8. Time 3 health complaints & 0.97 & 0.46 & .85 & $.27^{* *}$ & .08 & .17 & $.23^{* *}$ & $.65^{* *}$ & $.22^{*}$ & $.33^{* *}$ & - & & & \\
\hline 9. Work pressure & 2.74 & 0.67 & .79 & .12 & -.07 & $.49^{* *}$ & $.44^{* *}$ & $.29^{* *}$ & $.33^{* *}$ & $.33^{* *}$ & $.21^{*}$ & - & & \\
\hline 10. Work control & 3.10 & 0.62 & .87 & -.12 & $.20^{*}$ & $-.19^{*}$ & -12 & $-.23^{*}$ & $-.25^{* *}$ & -.05 & -.02 & .02 & - & \\
\hline 11. Affective rumination & 1.92 & 0.66 & .87 & .09 & .09 & .15 & $.25^{* *}$ & $.31^{* *}$ & $.28^{* *}$ & $.27^{* *}$ & $.30^{* *}$ & $.35^{* *}$ & -.05 & - \\
\hline 12. Problem-solving pondering & 2.33 & 0.69 & .90 & -.04 & .005 & -.09 & -.08 & .03 & -.03 & -.02 & .08 & $.20^{*}$ & .11 & $.35^{* *}$ \\
\hline
\end{tabular}

${ }^{*}$ Note. Cronbach's alphas for variables measured daily are mean internal consistencies averaged over all measurement days. All correlations are at the person-level $(N=123)$. Gender (male $=0$, female $=1) .{ }^{*} p<.05$ (two-tailed). ${ }^{* *} p<.01$ (two-tailed 


\section{Testing the unconditional univariate growth model of psychological well-being over time}

Before conducting the latent growth models, the factorial invariance (Chan, 1998) was tested with a longitudinal covariance structure model. To do so, we compared a model with the factor loading freely estimated to a model with the factor loading constrained for each outcome construct separately. No significant chi-square difference statistic was found between the two models for either exhaustion $\left(\Delta \chi^{2}(2)=1.424, p=.491\right)$ or health complaints $\left(\Delta \chi^{2}(2)=4.711, p<\right.$ $.095)$. These findings indicate that the both constructs are factorially invariant across time.

The first step in the latent growth model analysis was to examine how exhaustion and health complaints changed over the three waves of measurements. The linear latent growth model of exhaustion was found to fit the observed data quite well $\left.\chi^{2}(1)=.016, p=.89\right)$ with the acceptable fit indices of CFI $=1.0$., TLI $=1.0$. RMSEA $=.00[.00 ; .108]$, and SRMR $=.003$. Statistically, a value of .95 or greater on the CFI and TLI, .06 or lower on the RMSEA, and .08 or lower on the SRMR, indicate an acceptable model fit ( $\mathrm{Hu} \&$ Bentler, 1999). Moreover, the linear model of exhaustion resulted in significant mean intercept $(M i=2.26, p<$ $.001)$ and slope $(M s=.078, p<.01)$. These estimates indicate that the average score of exhaustion at time 1 was 2.26 (the intercept), and there was a significant and steady increase in exhaustion, on average, by .078 (the slope) over the subsequent twelve months. The variances for the intercept and slope were $\mathrm{Vi}=$ $.241, p<.001$ and $V s=.05, p<.01$, respectively, indicating significant variation across individuals in terms of initial status of exhaustion and its rate of change over time. In addition there was a significant negative correlation $(r=-.78, p<.001)$ between the intercept and slope of exhaustion, indicating that lower initial values were associated with higher rates of change in exhaustion over time.

The linear latent growth model of health complaints was then tested. The model produced an acceptable Chi-square test statistic, $\chi^{2}(1)=.245, p=.62$, and fit indices, CFI $=1.0 ., \mathrm{TLI}=1.0 ., \mathrm{RMSEA}=.00[.00 ; .189]$, and SRMR $=.012$, indicating a very good fit to the data. This linear growth model showed significant means of intercept $(M i=.81, p<.001)$ and slope $(M s=.084, p<.001)$, indicating that on average over all participants health complaints showed a systematic increase over time. Further, there was significant variance in both intercept ( $\mathrm{Vi}=$ $.147, p<.01)$ and slope $(V s=.044, p<.01)$, indicating there was substantial 
individual variability about the initial level of health complaints and its rate of change over time. Finally, the correlation between the intercept and slope was found significant $(r=-.67, p<.001)$, indicating that lower initial levels of health complaints were associated with steeper increases over time.

Additional test revealed no significant quadratic trend in the slope for both exhaustion and health complaints.

\section{Testing the unconditional bivariate growth model of psychological well-being over time}

The second step of analysis was evaluating the interrelations between exhaustion and health complaints growth models. A bivariate latent growth model was estimated to examine how the initial statuses and increasing trajectories of exhaustion and health complaints were associated. The bivariate growth model yielded a Chi-square statistic of $\chi^{2}(7)=4.569, p=.60$ and fit indices, CFI $=1.0$., $\mathrm{TLI}=1.0 ., \mathrm{RMSEA}=.00[.00 ; .10]$, and SRMR $=.043$, indicating a significant acceptable model. The results of the bivariate model showed that the initial levels of the two outcomes were significantly positively correlated $(r=.60, p<.001)$. This means that high initial levels of exhaustion were associated with high initial levels of health complaints. The rate of change in the two health outcomes was also significantly and positively correlated $(r=.68, p<.001)$. This indicates that an individual's growth trajectory on exhaustion was very similar to that same individual's growth trajectory on health complaints. In other words, changes in exhaustion were significantly correlated with changes in health complaints. Furthermore, there were significant correlations between the intercept of exhaustion and the slope of health complaints $(r=-.29, p<.05)$, and also between the intercept of health complaints and the slope of exhaustion $(r=-.31, p<.01)$. These findings indicate that higher initial levels of one health outcome were negatively associated with lower rates of change in another health outcome over time.

\section{Testing the conditional bivariate growth model of psychological well- being over time}

In the final step of the analysis, covariates were simultaneously included in the bivariate model to evaluate their effects on the four latent growth factors of exhaustion and health complaints. The findings are presented in Table 2.2. The 
model produced a good fit to the data $\left(\chi^{2}(18)=14.829, p=.67\right.$ and fit indices, $\mathrm{CFI}=1.0 ., \mathrm{TLI}=1.0 ., \mathrm{RMSEA}=.00[.00 ; .065]$, and $\mathrm{SRMR}=.032)$.

As Table 2.2 shows, gender was only significantly related to the slope of health complaints $(\beta=.23, p<.05)$ suggesting that compared to males, females experienced a steeper increase in health problems over time. Age was significantly related to neither intercepts nor slopes of both health outcomes. Work pressure was significantly related to both intercept $(\beta=.54, p<.001)$ and slope $(\beta=-.35, p$ $<.01)$ of exhaustion. These findings indicate that although subjects with higher levels of work pressure reported higher initial levels of exhaustion, they experienced flatter trajectories of exhaustion over time. Work pressure was also significantly related to the intercept of health complaints $(\beta=.28, p<.01)$, indicating that individuals with higher levels of work pressure reported higher initial levels of health complaints. Work control was found to be significantly related to the intercept of health complaints $(\beta=-.21, p<.05)$, suggesting that employees who reported higher levels of work control experienced lower initial levels of health complaints.

Table 2.2 also shows the results related to the two experiences of workrelated rumination. The relationship between affective rumination and the initial level of exhaustion was not found significant. However, there was a significant relationship between the experience of work-related affective rumination during evenings and the initial level of health complaints $(\beta=.22, p<.05)$. This indicates that individuals who experienced higher levels of affective rumination during evenings reported higher initial levels of health complaints. The results also showed that affective rumination was significantly associated to the rate of increasing change in exhaustion $(\beta=.23, p<.05)$ over time. This finding indicates that people who experienced higher levels of work-related affective rumination during the time of recovery in evenings showed a steeper trajectory of growth in exhaustion over time (Figure 2.2). Hypothesis 1a was then supported. Nevertheless, the results showed that affective rumination during evenings was not a significant predictor of the slope of health complaints over time. Therefore, Hypothesis $1 \mathrm{~b}$ was not supported. 
Table 2.2

Conditional bivariate growth model of psychological well-being with covariates

\begin{tabular}{lcccc}
\hline Variable & \multicolumn{2}{c}{ exhaustion } & \multicolumn{2}{c}{ Health complaints } \\
\cline { 2 - 5 } & Intercept & Slope & Intercept & Slope \\
Gender & $0.12(1.43)$ & $0.13(1.27)$ & $0.06(0.68)$ & $0.23^{*}(2.24)$ \\
Age & $-0.03(-0.35)$ & $0.06(0.63)$ & $-0.12(-1.45)$ & $0.18(1.61)$ \\
Work pressure & $0.54^{* * *}(5.71)$ & $-0.35^{* *}(-2.95)$ & $0.28^{* *}(2.75)$ & $-0.11(-0.84)$ \\
Work control & $-0.17(-1.73)$ & $0.005(0.04)$ & $-0.21^{*}(-2.84)$ & $0.19(1.77)$ \\
Affective rumination & $0.01(0.12)$ & $0.23^{*}(2.15)$ & $0.22^{*}(2.16)$ & $0.07(0.61)$ \\
Problem-solving & $-0.19^{*}(-2.50)$ & $0.13(1.19)$ & $-0.14(-1.54)$ & $0.09(0.92)$ \\
pondering & & & & \\
\hline
\end{tabular}

${ }^{*}$ Note. All effects are presented using standardized parameter estimates. ${ }^{*} p<.05$ (twotailed). ${ }^{* *} p<.01$ (two-tailed). ${ }^{* * *} p<.001$ (two-tailed). Number in parenthesis is the ratio of the parameter estimate to standard error. Gender $($ male $=0$, female $=1) . N=123$.

The results related to the work-related problem solving pondering during evenings showed a negative and significant relation with the intercept of exhaustion $(\beta=-.19, p<.05)$, and a negative but non-significant relation with the intercept of health complaints $(\beta=-.14, p=.12)$. This finding indicates that individuals who experienced higher levels of problem-solving pondering during evenings reported lower initial levels of exhaustion. Furthermore, problem solving pondering was not found as the significant predictor of either slope of health outcomes. Therefore Hypothesis 2 was not supported. 


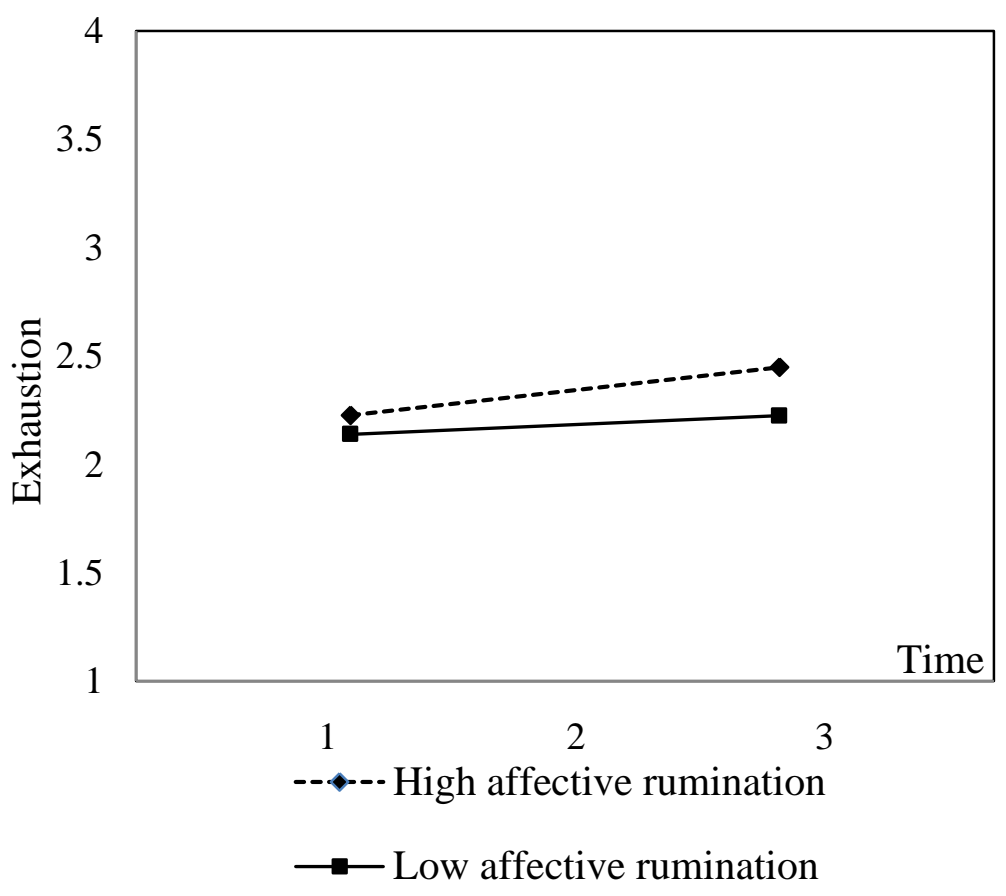

Figure 2.2. Growth trajectories of exhaustion over time at different levels of workrelated affective rumination during evenings

\section{Discussion}

In this 3-wave longitudinal study, we investigated how the experience of work-related affective rumination and problem-solving pondering during evenings influence employees' well-being over time. Latent growth curve modeling (LGM) was used to examine the hypotheses. We hypothesized that the experience of work-related affective rumination during evenings is positively related to the growth rate of change in exhaustion and health complaints over time (Hypothesis 1). In contrast, we expected that the experience of work-related problem-solving pondering during evenings is negatively related to the growth rate of change in exhaustion and health complaints over time (Hypothesis 2). Hypothesis 1 was partially supported and Hypothesis 2 was not supported.

The conditional bivariate growth model of psychological well-being showed that work-related affective rumination was positively associated with the initial level of health complaints. This finding indicates that employees who 
experienced lower levels of mental health reported simultaneously higher levels of affective rumination. From the clinical point of view, the current finding replicates findings from previous cross-sectional studies (e.g. Hughes, Alloy, \& Cogswell, 2008; for a review, see Thomsen, 2006), demonstrating that intrusive and negative rumination is associated with depression and anxiety symptoms. However, the positive relation between affective rumination and the initial level of exhaustion was not significant. This results stands in contrast to findings of previous cross-sectional studies (e.g. Querstret \& Cropley, 2012; Donahue et al., 2012). One potential explanation for this result is that people generally have resources to deal with affective rumination for a limited period of time; however, affective rumination leads to exhaustion by drawing on resources over a period of time (Sonnentag, Binnewies at al., 2010). Moreover, work-related problemsolving pondering showed a negative relation with the intercept of exhaustion. This finding is consistent with findings of a cross-sectional study (Querstret \& Cropley, 2012) that showed participants reporting higher levels of problemsolving pondering reported simultaneously lower levels of work-related fatigue. A possible explanation for this effect is that because engaging in problem solving pondering requires mental energy, individuals with low energy levels are less likely to engage in problem solving pondering. Demerouti and her colleagues (2010) found that exhaustion is negatively related to vigor. Vigor is characterized by high levels of energy and willingness to invest effort (Schaufeli \& Bakker, 2004). Accordingly, employees with lower levels of exhaustion are more likely to engage in problem-solving pondering.

Our results showed that work-related affective rumination during evenings was a significant predictor of increase in exhaustion across a period of 12 months. This finding is in line with a past research that found a positive relationship between affective rumination and exhaustion after three months (Donahue et al., 2012). This finding extends the recovery literature by showing how the insufficient recovery during evenings influences well-being over time. According to Cropley and Zijlstra (2011), affective rumination leads to prolonged activation because it draws not only on cognitive resources but also on emotional resources. Therefore, as the consequence of prolonged activation and draining of emotional resources, exhaustion occurs (Sonnentag, Binnewies at al., 2010). However, our study showed that affective rumination was not a significant predictor of change in general mental health over time. This result was in contrast to a prior study (Hamesch et al., 2014) that found that affective rumination was positively associated with depressive mood that individuals reported after six months. These findings suggest that work-related affective rumination only 
impairs work-specific mental health over time. A possible explanation is that whereas exhaustion is mainly affected by work-related factors, impairment of general mental health may also be caused and modified by other life conditions, such as illness, economic circumstances and the family situation. Therefore, these findings also contribute to the psychological health literature by demonstrating that "work-specific" and "context-free" mental health are two distinct constructs (Warr, 1987), as their patterns of associations with work-related affective rumination were different.

Our results did not show a significant relationship between problemsolving pondering during evenings and changes in either indicator of psychological well-being over time. This finding is also in line with past research (Hamesch et al., 2014) suggesting that problem-solving pondering is less detrimental to well-being than affective rumination. According to NolenHoeksema (1996), the key feature in determining the effectiveness of problemsolving is whether progression in thoughts occurs over a reasonable period of time. Therefore, although it is assumed that problem-solving facilitates the recovery process by causing positive affect and increasing the likelihood that solutions are found; it may conversely impede the recovery process when employees continuously think about their work problems without any progression in finding solutions. Future research is needed to investigate circumstances under which problem-solving pondering facilitates or conversely impedes the recovery process during non-work time.

These findings are consistent with the assumption that the two types of work-related rumination may operate differently on recovery process and in turn have different effects on well-being (Cropley \& Zijlstra, 2011). This suggests that in contrast to affective rumination, problem-solving pondering during evenings is not a risk factor for impaired well-being in the long-run. According to Brosschot et al. (2005), rumination leads to prolonged activation as a risk factor of health problems by maintaining an active cognitive representation of individuals' job stressors. However, this study showed that it is not necessarily being mentally engaged with job-stressors per se that causes prolonged activation during off-job time. Drawing on CATS theory (Ursin \& Eriksen, 2004; Ursin \& Eriksen, 2010), dealing with job-stressors causes prolonged activation only when individuals experience negative outcome expectancies. Affective rumination is likely to be associated with negative outcome expectancies in which individuals believe that their responses are not expected to handle the situation and they may even lead to negative results. In contrast, problem-solving pondering does not lead to 
prolonged activation because it is likely to be associated with positive outcome expectancies in which individuals believe that their responses are expected to handle the situation with positive results.

As an additional finding, our results showed a significant increase in impaired well-being over time. According to Schaufeli, Leiter, and Maslach (2009), people in developing countries are more likely to become exhausted because of rapid changes in modern working life such as increasing demands of learning new skills, the need to adopt new types of work, pressure of higher quality of work, and time pressure. Moreover, the results of bivariate growth model showed a positive correlation between the rate of change in exhaustion and health complaints over time. This finding contributes to the previous literature investigating the link between mental health and exhaustion (e.g. Demerouti et al., 2010; Maslach, Schaufeli, \& Leiter, 2001) by indicating that changes in exhaustion and mental health are associated with each other over time. Our results show that an individual's growth trajectory on health complaints is similar to his or her corresponding growth trajectory on exhaustion across the same period of time. It is possible that there is a causal relationship between the changes in exhaustion and general mental health over time. This would mean that changes in "workspecific" and "context-free" mental health (Warr, 1987) affect each other across time. According to the compensatory control model (Hockey 1993, 1997), in the case of feeling exhaustion, individuals may be exposed to subsequent work demands in a suboptimal state. Therefore, they need to invest compensatory effort to deal with those demands and perform adequately at work. As a consequence, the prolonged compensatory effort results in physiological and psychological costs on health. Conversely, mental health impairment may cause exhaustion. For instance, employees with higher levels of mental health cope with job stressors more effectively and consequently are less likely to experience exhaustion (Maslach et al., 2001; Jenkins \& Maslach 1994).

\section{Strengths and limitations}

Our study has several strengths. First, conducting latent growth curve modeling permitted us to study how the different types of work-related rumination predict trajectories of health outcomes over time. Second, employing a diary design allowed us to assess the level of work-related rumination that people experience particularly during evenings of the working week. Third, including two outcomes of exhaustion and mental health complaints as 'work-specific' and 'context-free' mental health respectively, provided a comprehensive model of employees' well- 
being. Fourth, by controlling for work pressure and work control, we examined how far the reported work-related rumination during evenings explained changes in health outcomes over time.

As with any study, there are several limitations that should be addressed and considered prior to the interpretation of the findings. First, this research involved only employees who work in a primarily mentally demanding environment; therefore, the generalizability of the findings to industrial workers who has been assumed to experience a different quality of rumination (Pravettoni et al., 2007) is restricted. Second, we used paper-and-pencil surveys to collect data that did not provide us an indication of the day and time that participants filled in the diaries. In this study, we decided to use paper-and-pencil surveys in order not to restrict the sample to only those who had Internet access especially in the hours before going to bed. Third, all data were gathered by self-report measures; therefore common method bias may have accounted for the findings. However, the longitudinal design of our research reduced the effects of common method bias (Podsakoff, MacKenzie, Lee, \& Podsakoff, 2003). Fourth, in the present study we had a final sample size of 123 participants. Although, a sample size greater than 100 has been suggested as sufficient to reliably estimate linear growth models (Curran, Obeidat, \& Losardo, 2010; Fan \& Fan, 2005), the power of the latent growth modeling will be enhanced by increasing the sample size (Zhang \& Wang, 2009). Furthermore, we had the minimum number of measurement points. Although, growth models typically require at least three repeated measures per individual, it has been documented that the number of measurements plays an important role in the estimation and statistical power of the model (Curran et al., 2010; Zhang \& Wang, 2009). In fact, the power of the latent growth modeling increases with a larger numbers of measurement occasions. However, as an exception, Fan and Fan (2005) showed that the number of repeated measures in detecting linear growth had no effect on the statistical power of the latent growth modeling.

\section{Practical implications and directions for future research}

For many people, work nowadays is primarily mentally demanding rather than physically demanding. Moreover, due to advances in communication technologies, the experience of unwinding from work during the time of recovery has become more difficult. Based on the results of this study, organizations are recommended to provide adequate conditions facilitating the recovery process. To do so, it is important not only to facilitate employees in overcoming obstacles 
to establish detachment but also to enhance their problem-solving skills. According to Nolen-Hoeksema (1996), a successful problem-solving generally occurs in three steps, namely, assessing the problem, evaluating possible solutions to the problem, and finally deciding about which solution to choose. It seems that training skills related to each of these steps may help employees to act as more successful problem solvers during non-work time.

We recommend future research to study the mechanisms by which affective rumination and problem-solving pondering lead to different levels of psycho-physiological arousal. For instance, from the cognitive point of view discussed by CATS theory, being mentally engaged with job stressors causes prolonged activation only when individuals experience negative outcome expectancies. Therefore, a study may investigate the different response outcome expectancies that people experience in affective rumination compared to problemsolving pondering. It is also recommended to examine the cumulative effects of work-related rumination on well-being over time. In addition, because this study showed that only affective rumination leads to impaired well-being, one may be interested in developing and testing interventions to help employees who ruminate affectively about work-related issues. 


\section{References}

Bentler, P. M. (1990). Comparative fit indexes in structural models. Psychological Bulletin, 107, 238-246. http://doi.org/10.1037/0033-2909.107.2.238

Bliese, P. D. (2000).Within-group agreement, non-independence, and reliability: Implications for data aggregation and analysis. In K. J. Klein\&S.W.Kozlowski (Eds.), Multilevel theory, research, and methods in organizations (pp. 349-381). San Francisco: Jossey-Bass.

Bliese, P. D. (2013). Multilevel modeling in R (2.5): A brief introduction to R, the multilevel package and the nlme package. Washington, DC: Walter Reed Army Institute of Research.

Binnewies, C., Sonnentag, S., \& Mojza, E. J. (2009). Feeling recovered and thinking about the good sides of one's work. Journal of Occupational Health Psychology, 14, 243-256. http:// doi.org/10.1037/a0014933

Brosschot, J. F., Gerin, W., \& Thayer, J. F. (2006). The perseverative cognition hypothesis: A review of worry, prolonged stress-related physiological activation, and health. Journal of Psychosomatic Research, 60, 113-124. http://doi.org/10.1016/j.jpsychores.2005.06.074

Brosschot, J. F., Pieper, S., \& Thayer, J. F. (2005). Expanding stress theory: Prolonged activation and perseverative cognition. Psychoneuroendocrinology, 30, 1043-1049. http://doi.org $\angle 10.1016 /$ j.psyneuen.2005.04.008

Brosschot, J. F., van Dijk, E., \& Thayer, J. F. (2002). Prolonged autonomic activation, perseverative negative cognition, and daily stressors. International Congress Series, 1241, 329-336. http://doi.org/10.1016/S0531-5131(02)00615-5

Bukowski, M., Asanowicz, D., Marzecová, A., \& Lupiáñez, J. (2015). Limits of control: The effects of uncontrollability experiences on the efficiency of attentional control. Acta Psychologica, 154, 43-53. http://doi.org/10.1016/j.actpsy.2014.11.005

Chan, D. (1988). The conceptualization and analysis of change over time: An integrative approach incorporating longitudinal mean and covariance structures analysis (LMACS) and multiple indicator latent growth modeling (MLGM). Organizational Research Methods, 1, 421-483.http://doi.org/10.1177/109442819814004

Cropley, M., Dijk, D. J., \& Stanley, N. (2006). Job strain, work rumination, and sleep in school teachers. European Journal of Work and Organizational Psychology, 15, 181-196. http://doi.org/10.1080/13594320500513913

Cropley, M., Michalianou, G., Pravettoni, G., \& Millward, L. J. (2012). The relation of post-work ruminative thinking with eating behaviour. Stress and Health, 28, 23-30. http://doi.org $\not 10.1002 /$ smi. 1397

Cropley, M., \& Zijlstra, F. R. H. (2011). Work and rumination. In J. Langan-Fox \& C. L. Cooper (Eds.), Handbook of stress in the occupations (pp. 487-503). Cheltenham, PA: Edward Elgar Publishing Ltd.

Curran, P. J., Obeidat, K., \& Losardo, D. (2010). Twelve frequently asked questions about growth curve modeling. Journal of Cognition and Development, 11, 121-136. http://doi.org/ $\underline{10.1080 / 15248371003699969}$

Demerouti, E., Bakker, A. B., Nachreiner, F., \& Schaufeli, W. B. (2001). The job demandsressources model of burnout. Journal of Applied Psychology, 86, 499-512. http://doi. org/10.1037/0021-9010.86.3.499

Demerouti, E., Mostert, K., \& Bakker, A. B. (2010). Burnout and work engagement: A thorough investigation of the independency of both constructs. Journal of Occupational Health Psychology, 15, 209-222. http://doi.org/10.1037/a0019408 
Donahue, E. G., Forest, J., Vallerand, R. J., Lemyre, P. N., Crevier-Braud, L., \& Bergeron, É. (2012). Passion for work and emotional exhaustion: The mediating role of rumination and recovery. Applied Psychology: Health and Well-Being, 4, 341-368. http://doi.org/ 10.1111/j.1758-0854.2012.01078.x

Duncan, T. E., Duncan, S. C., Strycker, L. A., Li, F., \& Alpert, A. (1999). An introduction to latent variable growth curve modeling. Concepts, issues, and applications. Mahwah, NJ: Lawrence Erlbaum.

Eriksen, H. R., Murison, R., Pensgaard, A. M., \& Ursin, H. (2005). Cognitive activation theory of stress (CATS): From fish brains to the olympics. Psychoneuroendocrinology, 30, 933938. http://doi.org/10.1016/j.psyneuen.2005.04.013

Etzion, D., Eden, D., \& Lapidot, Y. (1998). Relief from job stressors and burnout: Reserve service as a respite. The Journal of Applied Psychology, 83, 577-585. http://doi.org/10.1037/ 0021-9010.83.4.577

Fan, X., \& Fan, X. (2005). Power of latent growth modeling for detecting linear growth: Number of measurements and comparison with other analytic approaches. The Journal of Experimental Education, 73, 121-139. http://doi.org/10.3200/JEXE.73.2.121-139

Finch, J. F., Baranik, L. E., Liu, Y., \& West, S. G. (2012). Physical health, positive and negative affect, and personality: A longitudinal analysis. Journal of Research in Personality, 46, 537-545. http://doi.org/10.1016/i.jp. 2012.05.013

Fredrickson, B. L. (1998). What good are positive emotions? Review of General Psychology, 2, 300-319. http://doi.org/10.1037/1089-2680.2.3.300

Fredrickson, B. L., \& Joiner, T. (2002). Positive emotions trigger upward spirals toward emotional well-being. Psychological Science, 13, 172-175. http://doi.org/10.1111/1467928 $\underline{0.00431}$

Frese, M., \& Zapf, D. (1988). Methodological issues in the study of work stress: Objective vs subjective measurement of work stress and the question of longitudinal studies. In C. L. Cooper \& R. Payne (Eds.), Causes, coping, and consequences of stress at work (pp. 375411). Wiley, Chichester

Goldberg, D. P., \& Williams, P. (1988). GHQ: A user's guide to the General Health Questionnaire. Windsor: NFER-Nelson.

Goodman, J. S., \& Blum, T. C. (1996). Assessing the non-random sampling effects of subject attrition in longitudinal research. Journal of Management, 22, 627-652. http://doi.org/ $10.1177 / 014920639602200405$.

Greenberger, D. B., Strasser, S., Cummings, L. L., \& Dunham, R. B. (1989). The impact of personal control on performance and satisfaction. Organizational Behavior and Human Decision Processes, 43, 29-51. http://doi.org/10.1016/0749-5978(89)90056-3

Hamesch, U., Cropley, M., \& Lang, J. (2014). Emotional versus cognitive rumination: Are they differentially affecting long-term psychological health? The impact of stressors and personality in dental students. Stress and Health, 30, 222-231. http://doi.org/ $\underline{10.1002 / \text { smi.2602 }}$

Henkel, V., Bussfeld, P., Möller, H. J., \& Hegerl, U. (2002). Cognitive-behavioural theories of helplessness/hopelessness: Valid models of depression? European Archives of Psychiatry and Clinical Neuroscience, 252, 240-249. http://doi.org/10.1007/s00406-002-0389-y

Hobfoll, S. E., \& Shirom, A. (2001). Conservation of resources theory: Applications to stress and management in the workplace. In R. T. Golembiewski (Ed.), Handbook of organizational behavior (pp. 57-81). New York: Dekker. 
Hockey, G. R. J. (1993). Cognitive-energetical control mechanisms in the management of work demands and psychological health. In A. D. Baddeley \& L. Weiskrantz (Eds.), Attention, selection, awareness and control: A tribute to Donald Broadbent (pp. 328-345). Oxford: Clarendon Press.

Hockey, G. R. J. (1997). Compensatory control in the regulation of human performance under stress and high workload: A cognitive-energetical framework. Biological Psychology, 45, 73-93. http://doi.org/10.1016/S0301-0511(96)05223-4

Hogan, B. E., \& Linden, W. (2004). Anger response styles and blood pressure: At least don't ruminate about it! Annals of Behavioral Medicine: A Publication of the Society of Behavioral Medicine, 27, 38-49. http://doi.org/10.1207/s15324796abm2701_6

Hu, L., \& Bentler, P. M. (1999). Cutoff criteria for fit indexes in covariance structure analysis: Conventional criteria versus new alternatives. Structural Equation Modeling: A Multidisciplinary Journal, 6, 1-55. http://doi.org/10.1080/10705519909540118

Hughes, M. E., Alloy, L. B., \& Cogswell, A. (2008). Repetitive thought in psychopathology: The relation of rumination and worry to depression and anxiety symptoms. Journal of Cognitive Psychotherapy, 22, 271-288. http://doi.org/10.1891/0889-8391.22.3.271

Jenkins, S. R., \& Maslach, C. (1994). Psychological health and involvement in interpersonally demanding occupations: A longitudinal perspective. Journal of Organizational Behavior, 15, 101-127.http://doi.org/10.1002/job.4030150202

Kaplan, D. (2000). Structural equation modeling : Foundations and extensions. Thousand Oaks, CA: Sage.

Kofta, M. (1993). Uncertainty, mental models, and learned helplessness: An anatomy of control loss. In G. Weary, F. Gleicher, \& K. Marsh (Eds.), Control motivation and social cognition (pp. 122-153). New York: Springer.

Lyubomirsky, S., Caldwell, N. D., \& Nolen-Hoeksema, S. (1998). Effects of ruminative and distracting responses to depressed mood on retrieval of autobiographical memories. Journal of Personality and Social Psychology, 75, 166-177. http://doi.org/10.1037/ $\underline{0022-3514.75 .1 .166}$

Martin, L. L., \& Tesser, A. (1996). Some ruminative thoughts. In R. S. Wyer, (Ed.), Advances in social cognition (Vol., IX, pp. 1-47). Hillsdale, NJ: Erlbaum.

Maslach, C., Schaufeli, W. B., \& Leiter, M. P. (2001). Job burnout. Annual Reviews Psychology, 52, 397-422. http://doi.org/10.1146/annurev.psych.52.1.397

Mayne, T. J. (1999). Negative affect and health: The importance of being earnest. Cognition \& Emotion, 13, 601-635. http://doi.org/10.1080/026999399379203

McArdle, J. J. (1988). Dynamic but structural equation modeling of repeated measures data. In R. B. Cattell \& J. Nesselroade (Eds.), Handbook of multivariate experimental psychology (2nd ed., pp. 561-614). New York: Plenum Press.

Mellings, T. M. B., \& Alden, L. E. (2000). Cognitive processes in social anxiety: The effects of selffocus, rumination and anticipatory processing. Behaviour Research and Therapy, 38, 243-257. http://doi.org/10.1016/S0005-7967(99)00040-6

Meurs, J. A., \& Perrewe, P. L. (2011). Cognitive activation theory of stress: An integrative theoretical approach to work stress. Journal of Management, 37, 1043-1068. http://doi.org/10.1177/0149206310387303

Muthen, B. O., \& Khoo, S. T. (1998). Longitudinal studies of achievement growth using latent variable modeling. Learning and Individual Differences, 10, 73-101. http://doi.org/ $\underline{10.1016 / \text { S1041-6080(99)80135-6 }}$ 
Muthén, L. K. \& Muthén, B. O. (2012). Mplus User's Guide. Seventh Edition. Los Angeles, CA: Muthén \& Muthén.

Nolen-Hoeksema, S. (1996). Chewing the cud and other ruminations. In R. S. Wyer, (Ed.), Advances in social cognition (Vol., IX, pp. 135-144). Hillsdale, NJ: Erlbaum.

Podsakoff, P. M., MacKenzie, S. B., Lee, J. Y., \& Podsakoff, N. P. (2003). Common method biases in behavioral research: A critical review of the literature and recommended remedies. The Journal of Applied Psychology, 88, 879-903. http://doi.org/10.1037/00219010.88.5.879

Pravettoni, G., Cropley, M., Leotta, S. N., \& Bagnara, S. (2007). The differential role of mental rumination among industrial and knowledge workers. Ergonomics, 50, 1931-1940. http://doi.org/10.1080/00140130701676088

Pryce, C. R., Azzinnari, D., Spinelli, S., Seifritz, E., Tegethoff, M., \& Meinlschmidt, G. (2011). Helplessness: A systematic translational review of theory and evidence for its relevance to understanding and treating depression. Pharmacology and Therapeutics, 132, 242-267. http://doi.org/10.1016/j.pharmthera.2011.06.006

Querstret, D., \& Cropley, M. (2012). Exploring the relationship between work-related rumination, sleep quality, and work-related fatigue. Journal of Occupational Health Psychology, 17, 341-53. http://doi.org/10.1037/a0028552

Roe, R. A., \& Zijlstra, F. R. H. (2000). Work pressure. Results of conceptual and empirical analysis. In M. Vartiainen, F. Avallone, \& N. Anderson (Eds.), Innovative theories, tools, and practices in work and organizational psychology (Vol. viii, pp. 29-45). Ashland, OH: Hogrefe \& Huber.

Rook, J. W., \& Zijlstra, F. R. H. (2006). The contribution of various types of activities to recovery. European Journal of Work and Organizational Psychology, 15, 218-240. http://doi.org/ $10.1080 / 13594320500513962$

Schaufeli, W. B., \& Bakker, A. B. (2004). Job demands, job resources, and their relationship with burnout and engagement: A multi-sample study. Journal of Organizational Behavior, 25, 293-315. http://doi.org/10.1002/job.248

Schaufeli, W. B., Leiter, M. P., Maslach, C. (2009). Burnout: 35 years of research and practice. Career Development International, 14, 204-220. http://dx.doi.org/10.1108/13620 $\underline{430910966406}$

Schlotz, W., Hellhammer, J., Schulz, P., \& Stone, A. A. (2004). Perceived work overload and chronic worrying predict weekend-weekday differences in the cortisol awakening response. Psychosomatic Medicine, 66, 207-214. http://doi.org/10.1097/01.psy.000011 $\underline{6715.78238 .56}$

Sedek, G., \& Kofta, M. (1990). When cognitive exertion does not yield cognitive gain: toward an informational explanation of learned helplessness. Journal of Personality and Social Psychology, 58, 729-743. http://doi.org/10.1037/0022-3514.58.4.729

Seligman, M. E. P. (1975). Helplessness: On depression, development, and death. San Francisco, CA: Freeman.

Seo, M. G., Barrett, L. F., \& Bartunek, J. M. (2004). The role of affective experience in work motivation. Academy of Management Review, 29, 423-439. http://doi.org/10.5465/ AMR.2004.13670972

Sluiter, J. K., Frings-Dresen, M. H. W., Van Der Beek, A. J., \& Meijman, T. F. (2001). The relation between work-induced neuroendocrine reactivity and recovery, subjective need for recovery, and health status. Journal of Psychosomatic Research, 50, 29-37. http://doi.org/10.1016/S0022-3999(00)00213-0 
Sonnentag, S., \& Bayer, U. V. (2005). Switching off mentally: Predictors and consequences of psychological detachment from work during off-job time. Journal of Occupational Health Psychology, 10, 393-414. http://doi.org/10.1037/1076-8998.10.4.393

Sonnentag, S., Binnewies, C., \& Mojza, E. J. (2010). Staying well and engaged when demands are high: The role of psychological detachment. Journal of Applied Psychology, 95, 965-976. http://doi.org/10.1037/a0020032

Sonnentag, S., Kuttler, I., \& Fritz, C. (2010). Job stressors, emotional exhaustion, and need for recovery: A multi-source study on the benefits of psychological detachment. Journal of Vocational Behavior, 76, 355-365. http://doi.org/10.1016/i.jvb.2009.06.005

Sonnentag, S., \& Zijlstra, F. R. H. (2006). Job characteristics and off-job activities as predictors of need for recovery, well-being, and fatigue. The Journal of Applied Psychology, 91, 330 350. http://doi.org/10.1037/0021-9010.91.2.330

Steiger, J. H. (1990). Structural model evaluation and modification: An interval estimation approach. Multivariate Behavioral Research, 25, 173-180. https://doi.org/10.1207/ s15327906mbr2502_4

Syrek, C. J., Weigelt, O., Peifer, C. \& Antoni, C. H. (2016). Zeigarnik's sleepless nights: How unfinished tasks at the end of the week impair employee sleep on the weekend through rumination. Journal of Occupational Health Psychology. 22, 225-238. http://dx.doi.org $\angle 10.1037 /$ ocp 0000031

Thomsen, D. K. (2006). The association between rumination and negative affect: A review. Cognition \& Emotion, 20, 1216-1235. http://doi.org/10.1080/02699930500473533

Thomsen, D. K., Mehlsen, M. Y., Olesen, F., Hokland, M., Viidik, A., Avlund, K., \& Zachariae, R. (2004). Is there an association between rumination and self-reported physical health? Journal of Behavioral Medicine, 27, 215-231. http://doi.org/10.1023/B:JOBM.00000 28496.41492 .34

Thomsen, D. K., Mehlsen, M. Y., Christensen, S., \& Zachariae, R. (2003). Ruminationrelationship with negative mood and sleep quality. Personality and Individual Differences, 34, 1293-1301. http://doi.org/10.1016/S0191-8869(02)00120-4

Tucker, L. R., \& Lewis, C. (1973). A reliability coefficient for maximum likelihood factor analysis. Psychometrika, 38, 1-10. http://doi.org/10.1007/BF02291170

Ursin H., \& Eriksen, H. R. (2004). The cognitive activation theory of stress. Psychoneuroendocrinology, 29, 567-592. http://doi.org/10.1016/S0306-4530(03) $\underline{00091-X}$

Ursin, H., \& Eriksen, H. R. (2010). Cognitive activation theory of stress (CATS). Neuroscience and Biobehavioral Reviews, 34, 877-881. http://doi.org/10.1016/j.neubiorev. $\underline{2009.03 .001}$

Vollmayr, B., \& Gass, P. (2013). Learned helplessness: unique features and translational value of a cognitive depression model. Cell and Tissue Research, 354, 171-178. http://doi.org/ $10.1007 / \mathrm{s} 00441-013-1654-2$

von Hecker, U., \& Sedek, G. (1999). Uncontrollability, depression, and the construction of mental models. Journal of Personality and Social Psychology, 77, 833-850. http://doi.org/ 10.1037/0022-3514.77.4.833

Waikar, S. V., \& Craske, M. G. (1997). Cognitive correlates of anxious and depressive symptomatology: An examination of the helplessness/hopelessness model. Journal of Anxiety Disorders, 11, 1-16. http://doi.org/10.1016/S0887-6185(96)00031-X

Warr, P. (1987). Work, unemployment and mental health. New York: Oxford University Press. 
Willett, J. B., \& Sayer, A. G. (1994). Using covariance structure analysis to detect correlates and predictors of individual change over time. Psychological Bulletin, 116, 363-381. http://doi.org/10.1037/0033-2909.116.2.363

Zhang, Z., \& Wang, L. (2009). Statistical power analysis for growth curve models using SAS. Behavior Research Methods, 41, 1083-1094. http://doi.org/10.3758/BRM.41.4.1083 


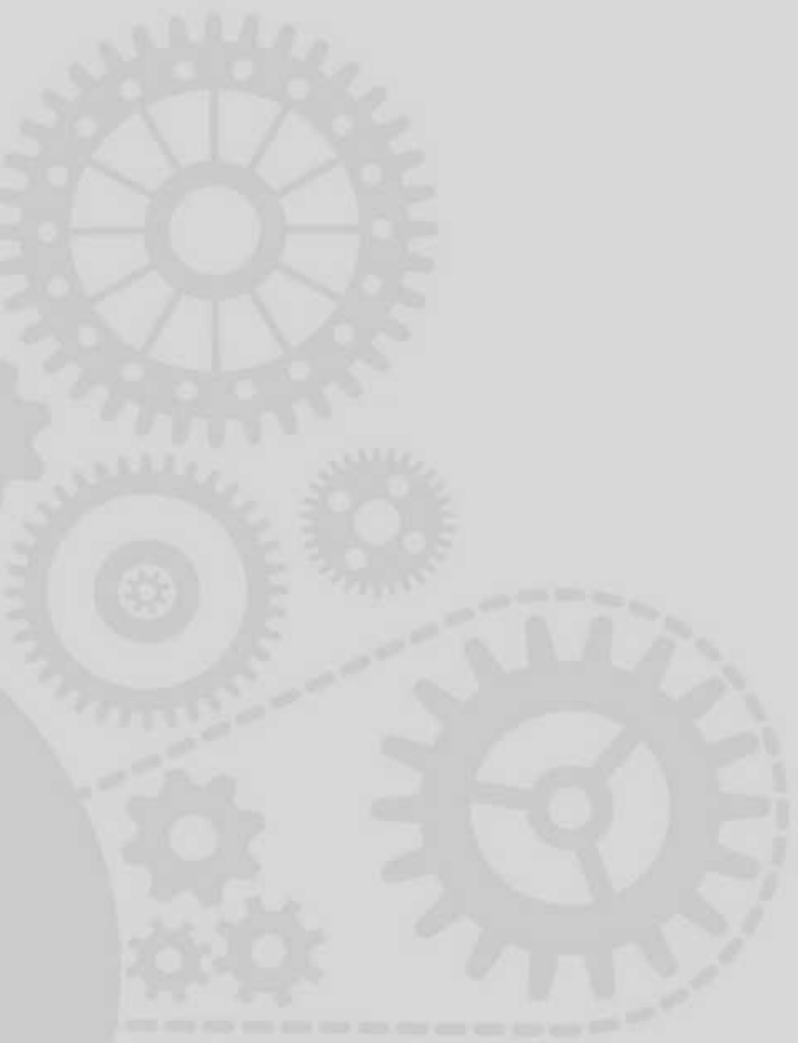




\section{CHAPTER 3}

Solving problems or seeing troubles? A day-level study on the consequences of thinking about work on recovery and well-being, and the moderating role of self-regulation

This chapter is based on: Firoozabadi, A., Uitdewilligen, S., \& Zijlstra, F. R. H. (2018). Solving problems or seeing troubles? A day-level study on the consequences of thinking about work on recovery and well-being, and the moderating role of self-regulation. European Journal of Work and Organizational Psychology, 27, 629-641. https://doi.org/10.1080/1359432X.2018.1505720 



\begin{abstract}
This study examined, using a within-person design, how fluctuations in workrelated affective rumination and problem-solving pondering are related to recovery and well-being $(\mathrm{N}=171 ; 677$ day-level data points over five consecutive work days). We hypothesized that trait self-regulation moderates the relationship between problem-solving during the evening and the state of being recovered at bedtime. We analyzed our data using a moderated multilevel mediation approach. The results showed that affective rumination during the evening was indirectly related to impaired well-being in the subsequent morning through its negative relationship with the state of being recovered at bedtime. Problem-solving was indirectly related to well-being in the subsequent morning through its relationship with the state of being recovered at bedtime. However, this indirect effect was moderated by trait self-regulation in a way that problem-solving pondering was positively related to the state of being recovered and consequently to improved well-being for employees higher in self-regulation, while it was negatively related to the state of being recovered and consequently to impaired well-being for those lower in self-regulation. These findings suggest that problem-solving pondering may be beneficial or unfavorable for recovery and well-being depending on the degree to which employees can regulate their cognitions and feelings.
\end{abstract}

Keywords: work-related rumination, problem-solving, recovery, psychological well-being, self-regulation 


\section{Introduction}

For many people, work nowadays is primarily mentally demanding. Moreover, advances in communication technologies have created a more diffuse boundary between work and non-work time (Perlow, 2012). Therefore, employees are more likely to be mentally exposed to work-related issues and stressors during their nonwork time (Park, Fritz, \& Jex, 2011). This prevents psychological detachment, which is a crucial aspect of the recovery process (Sonnentag \& Bayer, 2005). Psychological detachment is defined as the sense of being away from the work situation and the ability to switch off mentally from work-related issues during non-work time (Etzion, Eden, \& Lapidot, 1998). A substantial body of empirical research has shown that lack of detachment from work during non-work time impedes the recovery process and causes impaired well-being (see Sonnetag \& Fritz, 2015, for a review). However, Cropley and Zijlstra (2011) posed that this may not always be true; they argue that whether or not being mentally engaged with work-related issues during non-work time inhibits or facilitates the recovery process, depends on the type of perseverative thinking.

Cropley and Zijlstra (2011) conceptualized two fundamentally different experiences of work-related perseverative thinking: affective rumination and problem-solving pondering. Affective rumination is defined as an intrusive, pervasive and recurrent cognitive experience in which thoughts are mainly directed to dysfunctional emotions associated with work-related issues. Problemsolving pondering is defined as a prolonged cognitive experience in which thoughts are directed to discover solutions to work-related problems or reevaluate work-related performance in order to consider how it can be improved. Cropley and Zijlstra (2011) argue that these two types of work-related perseverative thinking may have different effects on recovery from work and psychological wellbeing due to their differing impacts on psycho-physiological activation (Brosschot, Pieper, \& Thayer, 2005). Affective rumination impedes the recovery process because it activates prolonged psycho-physiological reactions and draws on individuals' emotional resources. In contrast, problem-solving pondering is less likely to cause prolonged psycho-physiological activation and may even act as a resource-providing experience (Fritz \& Sonnentag, 2006) by facilitating progression towards solving problems. In accordance with this proposition, a number of between-person studies have shown that affective rumination is detrimental to individuals' well-being, whereas the effects of problem-solving pondering on well-being have not been consistent, indicating positive or non- 
significant effects (e.g., Firoozabadi, Uitdewilligen, \& Zijlstra, 2018, Hamesch, Cropley, \& Lang, 2014; Querstret \& Cropley 2012).

The present study aims to extend this prior research by considering two principles. First, where previous studies have focused on between-person effects, perseverative thinking may differ not only between but also within persons over time; individuals may experience different levels of affective rumination and problem-solving pondering across working days. According to Xanthopoulou, Bakker, and Ilies (2012), the study of within-person fluctuations is important because it provides insight into the dynamics of work and well-being and furthers understanding of employee well-being on a day-to-day basis. Given that previous research indicates that a significant amount of variance in core indicators of employee well-being may be attributed to within-person fluctuations (Xanthopoulou et al., 2012), a within-person design can explain additional variation on recovery and well-being by daily variations on these two different types of work-related perseverative thinking. Second, problem-solving pondering may not be beneficial for everyone as it is likely to depend on the extent to which employees experience progress in thinking (e.g., discovering a solution), whether they experience positive affect and prolonged cognitive processing is terminated. There may be crucial contingency factors that influence people's ability to generate solutions to work-related problems and thereby the effect of problemsolving pondering on recovery from work. One such factor is self-regulation, which refers to the set of cognitive and affective processes that enable individuals to guide their goal-directed activities over time and across changing circumstances (Karoly, 1993). This study thus investigates how the relationship between problem-solving pondering during the evening and the state of being recovered at bedtime is influenced by between-person differences in trait self-regulation.

Taken together, this study makes three contributions to the literature. First, by adopting a day-level approach, we examine the idea that being mentally engaged with work-related issues does not necessarily inhibit the state of being recovered during the evening as this depends on the type of work-related perseverative thinking. Second, our study contributes to the work-related rumination literature by investigating whether the extent to which individuals are able to regulate their cognitions and emotions acts as a moderator in the relationship between problem-solving pondering and the state of being recovered. Therefore, our findings may shed light on inconsistent previous findings concerning the relationship between problem-solving pondering and well-being (Bennett, Gabriel, Calderwood, Dahling, \& Trougakos, 2016; Syrek, Weigelt, 
Peifer, \& Antoni, 2017; Firoozabadi et al., 2018; Hamesch et al., 2014; Querstret \& Cropley, 2012). Third, we shed light on the mechanisms underlying these relationships by examining whether affective rumination and problem-solving pondering are related to well-being via inhibiting or facilitating the state of being recovered.

\section{Two types of perseverative thinking: Affective rumination and problem-solving pondering}

Perseverative thinking refers to a class of recurrent, pervasive, and prolonged thoughts representing work-related issues in the absence of immediate environmental demands. Scholars (e.g. Brosschot et al., 2005; Flaxman, Ménard, Bond, \& Kinman, 2012) conceptualized perseverative thinking as worry and rumination about stressors that cause impaired well-being. However, Cropley and Zijlstra (2011) distinguished between two fundamentally different types of workrelated perseverative thinking, namely affective rumination and problem-solving pondering. According to Cropley and Zijlstra (2011), compared to problemsolving pondering, affective rumination is more likely to cause prolonged psychophysiological activation and straining effects on the organism because it leads to prolonged exposure to dysfunctional emotions associated with work-related issues.

To explain the differential impact of affective rumination and problemsolving pondering on psycho-physiological activation, we draw on the Cognitive Activation Theory of Stress (CATS: Ursin \& Eriksen, 2004; Ursin \& Eriksen, 2010). According to CATS, the key feature in determining the degree to which psycho-physiological activation may be influenced by dealing with stressors is the type of associated response outcome expectancies. Response outcome expectancies refer to individuals' outlooks about the outcomes of their available responses. Response outcome expectancies are described as negative or positive if the produced response is expected to handle the problem with negative or positive results, respectively. Based on this theoretical framework, we argue that affective rumination leads to prolonged activation because it is more likely to be associated with negative outcome expectancies. This means that individuals expect that their available responses lead to negative results and they are not able to solve the problem and cope with the situation. On the contrary, problem-solving pondering can be conceptualized as a form of thinking about work-related issues that is more likely to be associated with positive outcome expectancies. Therefore, individuals may have a feeling of being able to control the situation by finding a solution to 
the problem. Finding a solution and feeling a sense of control are both known as adequate ways of reducing psycho-physiological activation (Ursin \& Eriksen, 2004).

\section{Effects of affective rumination and problem-solving pondering on recovery}

Recovery refers to the process during which individuals are no longer confronted with work-related stressors (Meijman \& Mulder, 1998) and their depleted resources are replenished (Hobfoll, 1989). Therefore, depending on the degree of unwinding from work demands and work stressors, and the amount of resources that are replenished, employees experience different levels of being recovered after non-work time. In this study, we focused on the subjective state of being recovered at bedtime as an indicator of the success of recovery during the evening after controlling for the state of being recovered immediately after work. The state of being recovered indicates the degree to which individuals feel recovered and physically and mentally refreshed (Sonnentag \& Kruel, 2006; Binnewies, Sonnentag, \& Mojza, 2009a).

Psychological detachment has been argued as an essential recovery experience that benefits well-being (Sonnentag \& Fritz, 2015; Wendsche \& Lohmann-Haislah, 2017). Several diary studies showed that experiencing psychological detachment during non-work time facilitates the recovery process (Sonnentag, Binnewies, \& Mojza, 2008; Binnewies, Sonnentag, \& Mojza, 2010; Sonnentag \& Bayer, 2005). Lack of detachment during the evening implies that individuals remain mentally engaged with work-related issues. Although, employees may experience lack of detachment in different ways, one such experience that seems to have a crucial effect on the recovery process is ruminative thinking. A few studies have investigated the effects of work-related rumination on the recovery process during non-work time. Rydstedt, Cropley, Devereux, and Michalianou (2009) showed that trait rumination is positively related to levels of evening cortisol and need for recovery. A study (Cropley, Rydstedt, Devereux, \& Middleton, 2015) with a sample of school teachers also found that compared with low ruminators, people scoring high on work-related rumination during a midweek evening showed higher levels of cortisol secretion at bedtime. However, neither of these studies explicitly distinguished between affective rumination and problem-solving pondering. 
Cropley and Zijlstra (2011) suggest that being mentally occupied with work-related thoughts is not necessarily an inhibiting factor of the recovery process, as it may depend on the type of work-related perseverative thinking whether it has a detrimental or beneficial effect. When experiencing affective rumination, individuals remain cognitively occupied with their work stressors in a way that is likely to impede recovery from work during the evening. Affective rumination is described as a way of thinking in which attention is drawn to feelings associated with negative aspects of work such as failure or negative events (Binnewies, Sonnentag, \& Mojza, 2009b). Therefore, it appears that affective rumination hinders the recovery process by causing prolonged activation (Brosschot, van Dijk, \& Thayer, 2002), and by continuously drawing on both cognitive and emotional resources (Hobfoll, 1989). In contrast, problem-solving pondering draws mainly on cognitive resources while individuals engage in cognitive processes aimed at discovering solutions for work-related problems or at finding ways to improve their work-related performance. Because the processing of dysfunctional emotions does not play a prominent role in problem-solving pondering, it is less likely (vs. affective rumination) to cause prolonged activation and subsequent straining effects on the organism (Cropley \& Zijlstra, 2011).

During non-work time, employees may engage in problem-solving pondering in order to manage their work-related problems and reduce their uncertainty about their work performance. According to Cropley and Zijlstra (2011), people may engage in problem-solving pondering because they enjoy dealing with work-related issues. During pondering, employees try to clarify problems, develop plans, generate solutions, or even picture a positive outlook about their job. These positive thinking processes are likely to promote positive affect because by engaging in them, people experience a sense of achievement, competence, and proficiency. Such brief experiences of positive emotions have been shown to have energizing effects and to counteract fatigue by replenishing depleted resources (Tice, Baumeister, Shmueli, \& Muraven, 2007; Ren, Hu, Zhang, \& Huang, 2010). They also counteract the straining effects of negative emotions by returning individuals to a neutral physiological state (Fredrickson \& Levenson, 1998; Fredrickson, Mancuso, Branigan, \& Tugade, 2000), increasing motivation related to cognitive performance (Erez \& Isen, 2002), and facilitating creative processes of thinking (Isen, Daubman, \& Nowicki, 1987). According to the self-regulation model of ruminative thought (Martin \& Tesser, 1996), finding solutions acts as a goal attainment mechanism that prevents ruminative thinking. When the work-related problem is solved, the individual may benefit from the rest 
of non-work time by engaging in other resource-providing experiences such as mastery and relaxation.

In the current study, using a within-person design, we investigate whether daily fluctuations in work-related affective rumination and problem-solving pondering are dynamically related to the daily recovery from work during the evening. We hypothesize that:

Hypothesis 1: Affective rumination during the evening is negatively related to the state of being recovered at bedtime.

Hypothesis 2: Problem-solving pondering during the evening is positively related to the state of being recovered at bedtime.

\section{The interaction effect of problem-solving pondering and self- regulation on recovery}

Unlike affective rumination, problem-solving pondering is conceptualized as a goal-directed cognitive process by which individuals aim to reduce a discrepancy between the current state and the desired state. Through problem-solving pondering, individuals reduce this discrepancy by discovering and generating solutions to work-related problems. To do so, individuals should successfully undertake the three steps of problem-solving process: assessing the problem, evaluating possible solutions to the problem, and eventually deciding about which solution to choose (Nolen-Hoeksema, 1996). Therefore in problem situations, individuals not only need to perform cognitive activities (e.g. activating existing knowledge or organizing new information), they need to set specific goals, plan and then monitor their performance during the process of problem-solving (Carver \& Scheier, 2011). Self-regulation is conceived as a cybernetic control process (Carver \& Scheier, 1998) that facilitates the process of problem-solving directed to reduce a discrepancy between the individual's current state and a desired state. Self-regulation refers to cognitive and affective processes enabling individuals to guide their goal-directed activities over time and across changing circumstances (Karoly, 1993). These mainly conscious processes (Posner \& Rothbart, 1998) aim to maintain goal-directed action by managing arousal (Blair \& Ursache, 2011), controlling the allocation of attention to goal-relevant and goal-irrelevant information (Papies \& Aarts, 2011; Kanfer \& Ackerman, 1989), and modifying the experience and expression of emotions (Thompson, 1994). 
Drawing on Kanfer and Ackerman's (1989) conceptualization, selfregulation influences the process of problem-solving in an adaptive way via three cognitive and affective mechanisms: self-monitoring, self-reactions, and selfevaluation. Self-monitoring refers to the allocation of attention toward specific aspects of the behavior (i.e., thinking about a work-related problem) and its consequences that have functional significance for goal attainment (i.e., discovering of a solution). Self-reactions involve self-satisfaction with performance and self-efficacy for goal attainment. Self-evaluation involves a comparison of the current state with a desired state, as well as checking the progression in reducing goal-performance discrepancy. Higher levels of selfmonitoring imply that people are capable to guide, evaluate and regulate their process of thinking and emotions to discover solutions to work-related problems. When people experience progress in their thinking process and discover solutions for their problems, they are likely to experience positive emotions related to their sense of achievement and self-efficacy for attaining work-related goals. Due to higher levels of efficacy and satisfaction with the self (i.e., self-reactions), people high in self-regulation are likely to benefit more from this experienced progress than people low in self-regulation. Moreover, higher capacities of self-evaluation serves as a protective mechanism, preventing employees from using excessive amounts of resources in circumstances where pondering is not beneficial for goal attainment or not likely to lead to a solution.

Therefore, in the current study, we investigate how individual differences in trait self-regulation influence the strength of the relationship between daily fluctuations of problem-solving pondering and recovery from work during the evening. We hypothesize that:

Hypothesis 3: Trait level self-regulation moderates the relationship between problem-solving pondering during the evening and the state of being recovered at bedtime. More specifically, the positive relationship between problem-solving pondering during the evening and the state of being recovered at bedtime is stronger for employees higher in self-regulation and weaker for employees low in self-regulation. 


\section{Affective rumination, problem-solving pondering, and well-being, the mediating role of recovery}

A number of cross- sectional and longitudinal studies have consistently shown that work-related affective rumination is negatively associated with well-being (Firoozabadi et al., 2018; Hamesch et al., 2014; Querstret \& Cropley, 2012; Donahue et al., 2012). However, the relationship between problem-solving pondering and well-being has not been consistently shown. In a cross-sectional study, Querstret and Cropley (2012) found a negative relationship between problem-solving pondering and both acute and chronic fatigue. However, they did not draw a definitive conclusion for these results due to the identified suppression effect (Pandey \& Elliott, 2010) of problem-solving pondering in their analysis. Moreover, comparing different profiles of recovery experiences, Bennett et al. (2016) concluded that lack of psychological detachment is less crucial for wellbeing specifically for employees who experience higher levels of problem-solving pondering. In contrast, two longitudinal studies found no significant effect of problem-solving pondering on well-being over time (Firoozabadi et al., 2018; Hamesch et al., 2014). Regarding the within-person research, Syrek et al. (2017) showed a positive relationship between affective rumination and sleep impairment and a marginally negative relationship between problem-solving pondering and sleep impairment during the weekend.

Given existing literature, there is a lack of knowledge on the withinperson relationships between the two types of work-related perseverative thinking and well-being. More specifically, there is a need to investigate the underlying dynamic processes by which these two experiences may have diverging effects on well-being in the short run. We propose the indirect effects of affective rumination and problem-solving pondering on well-being via the extent to which the two types of work-related perseverative thinking inhibit or facilitate the state of being recovered. In addition to the mediating role of recovery, taking into account the moderation effect of self-regulation on the relation between problem-solving pondering and recovery may explain the inconsistent previous findings concerning the relationship between problem-solving pondering and well-being.

According to a dynamic energetic approach of self-regulation (Baumeister, Muraven, \& Tice, 2000), individuals' capacity for emotion regulation depends on their momentary available energetic resources. Accordingly, the two different types of work-related perseverative thinking during non-work time are related to subsequent well-being by the extent to which they influence the process of restoring energetic resources (i.e., recovery). The more a 
person restores energetic resources during the evening, the more he or she will experience a state of being recovered at bedtime. Based on this approach, engaging in affective rumination during the evening is likely to inhibit the replenishment of depleted resources and even drain remaining resources because it leads to prolonged psycho-physiological activation. As a consequence of resource depletion (i.e., feeling fatigue), employees are less likely to regulate their dysfunctional feelings, which will lead to reduced well-being. In contrast, problemsolving pondering specifically for employees who are more likely to engage in constructive pondering (i.e., higher self-regulation) can facilitate the replenishment of depleted resources (i.e., feeling recovered) because it may lead to experienced progress in thinking and feelings of mastery. The restoration of energetic resources then promotes individuals' capacity to regulate emotions, which in turn increases well-being.

In the current study, we investigate the indirect link between daily variations in affective rumination and problem-solving pondering and well-being in the subsequent morning through the state of being recovered in the evening, while accounting for the moderating role of trait-self regulation on the ponderingrecovery relationship. Specifically, we examine a partial mediation model (vs. a full mediation model) because the state of being recovered may not be the only mechanism that links the two types of work-related perseverative thinking during the evening and the subsequent morning. For example, affective rumination may also be negatively related to well-being through its negative relationship with sleep quality (Syrek et al., 2017). In addition, our model predicts the subsequent morning well-being above and beyond the contribution of well-being measured immediately after work of the prior day. In line with prior diary studies of recovery (e. g., Sonnentag, Binnewies et al., 2008; Sonnentag, Mojza, Binnewies, \& Scholl, 2008), we use affective states as the state and short-term indicators of well-being. Research has shown that affective states play an important role in employees' organizational behavior (e. g., George \& Zhou, 2007; Ilies, Scott, \& Judge, 2006; Deluga \& Masson, 2000; Lyubomirsky, King, \& Diener, 2005). Affective states have been demonstrated to consist of two distinctive and independent dimensions, namely positive affect and negative affect (Watson, 1988; Watson, Clark, \& Tellegen, 1988). Positive affect refers to the state of high energy and full concentration. In contrast, negative affect is characterized by subjective distress and a variety of aversive mood states (Watson et al., 1988). Taking together, we hypothesize that:

Hypothesis 4: Affective rumination during the evening is indirectly related to impaired well-being ((a) lower positive affect and (b) higher negative 
affect) in the subsequent morning through its negative relationship with the state of being recovered at bedtime.

Hypothesis 5: The interaction between problem-solving pondering during the evening and trait self-regulation is indirectly related to improved wellbeing ((a) higher positive affect and (b) lower negative affect) in the subsequent morning via increase in the state of being recovered at bedtime. Namely, the positive relationship between problem-solving pondering and the state of being recovered is particularly strong for those higher (vs. lower) in trait self-regulation and consequently, relates to higher well-being.

Figure 3.1 shows our conceptual model.

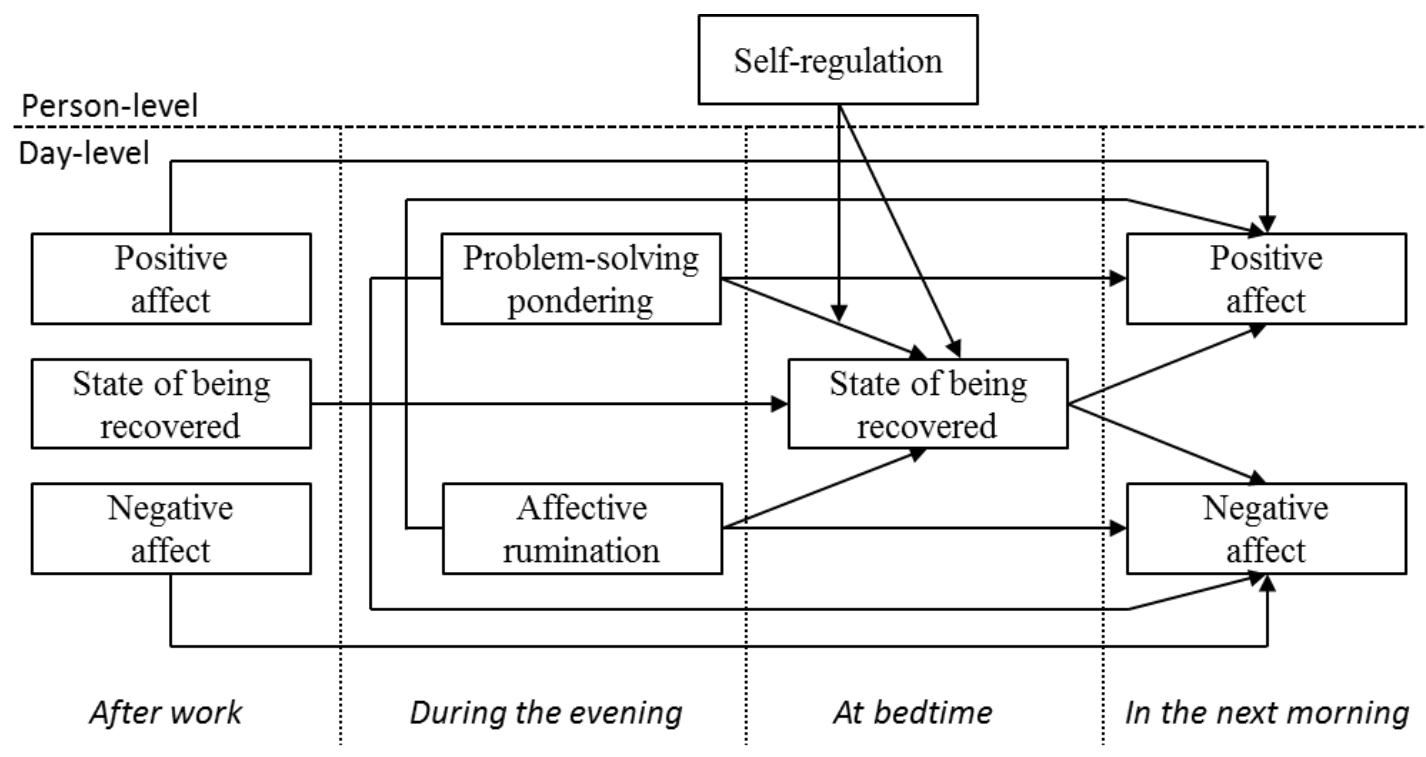

Figure 3.1. The study conceptual model 


\section{Method}

\section{Overview}

We collected data by conducting a general survey and daily surveys over five consecutive working days. The general survey assessed demographic information and trait self-regulation. Participants were asked once to complete the general survey before starting the daily diary surveys. Then over a period of five consecutive working days, participants responded to daily surveys at three measurement occasions per day. In the morning before going to work, we assessed momentary morning positive and negative affect as the indicators of morning well-being. After work before leaving work, we assessed momentary state of being recovered, positive affect, and negative affect as daily control variables for predicting the state of being recovered at bedtime, positive affect, and negative affect in the subsequent morning, respectively. In the evening before going to bed, participants were asked to report work-related affective rumination and problemsolving pondering that they experienced during the respective evening and momentary state of being recovered.

\section{Procedure and sample}

Our participants were recruited from a range of Iranian organizations. To recruit study participants, we contacted the managers of nine different organizations, including the educational office and a faculty of a university, two centers of health and social welfare services, a counseling center of a large university, two high schools, and a couple of local branches of a bank. After the managers agreed with participation of their organization, a total of 320 employees received information packages including an invitation form with a participation code, a description of the goal of project as a study on recovery during evenings, and a general description of the data collection procedure. With the invitation form we clarified the criteria that we only need those participants who have a full-time and primarily mentally demanding job (employees involved in teaching, planning, managing, administration, and research activities). They were informed about the anonymity and confidentiality of the data-collection and analysis process. Participants were offered to receive feedback about the related results after completion of the data collection as an incentive for participation. Participants were asked to email their willingness to participate in the study and provide an address where their survey packages could be delivered. In addition, each participant was asked to provide a 
cell phone number on a voluntary basis through which they received brief reminder messages for completing the diaries.

In total, 240 employees emailed their willingness to participate in the study. They received a paper-and-pencil general survey package (tagged with a participation code) by six assistants of the researchers who afterward collected the completed surveys. The paper-and-pencil daily survey packages were then delivered to 221 persons who completed the general surveys. To make sure that participants would not forget to complete the diaries at the designated times, brief reminder messages were sent on their cell phones. They were also asked to report the date and time of filling in the daily surveys. A total of 186 persons completed the daily surveys over five consecutive working days. We omitted the data from 15 participants due to missing data and failing to fill in the diaries at the scheduled times. Moreover, in line with our conceptual model predicting well-being in the morning from the daily variables of the prior day (Figure 3.1), the data collected in the morning of the first day and also after work and bedtime of the fifth day were not included in our analysis. Therefore, our final sample consisted of 171 participants (response rate: $71 \%$ ) with totally 677 day-level data points. Our participants provided on average 3.9 (range of 3 to 4 ) day-level data points.

Of the 171 participants included in analyses, 55 percent were female and 45 percent were male. The average age was 32.75 years $(S D=5.67)$, ranging from 21 to 54 years. The majority of the participants $(82.5 \%)$ were married; about 76.6 percent of the participants lived with their spouse; and 55 percent had children. The sample was fairly educated, ranging from Basic Diploma to $\mathrm{PhD}(7.6 \%$ basic diploma, 9.4\% associate, 54.4\% bachelor, $24.6 \%$ master, and $4 \% \mathrm{PhD}$ ). Participants' average tenure with their organizations was 7.54 years $(S D=6.63)$ ranging from 1 to 29 years. Participants held a variety of jobs $(30.4 \%$ in health services, $38 \%$ in educational services, and $31.6 \%$ in social services). All participants worked full-time with an average weekly working time of $39.07 \mathrm{~h}$.

\section{Measures}

Data were collected by conducting a general survey and five daily surveys. All items were in Persian. Items developed in English were translated into Persian by the first author and translated back to English by two interpreters. Translation/back-translation procedure was used to ensure that conceptual consistency remained unchanged during the translation process. 


\section{General survey data}

Self-regulation. We assessed trait self-regulation with a scale developed by Yeo and Frederiks (2011). The scale contains 8 items measuring affective and cognitive aspects of self-regulation each with four items. Example items for affective and cognitive regulation were respectively: "I maintain control over my emotions" and "I pay close attention to the kinds of difficulties or problems I am facing." Participants were asked to respond on an 11-point scale, ranked from 0 (not at all) to 10 (very much). We ran a set of confirmatory factor analyses to test whether the scale represents two distinct constructs. Compared to the one-factor model $\left(\chi^{2}(17)=51.884, p<0.001\right.$; comparative fit index [CFI] = .97; TuckerLewis index $[\mathrm{TLI}]=.95$; root-mean-square error of approximation [RMSEA] $=$ .11 ; standardized root-mean-square residual $[\mathrm{SRMR}]=.04)$, the two-factor model $\left(\chi^{2}(16)=49.874, p<0.001\right.$; CFI $=.97$; TLI $=.95 ;$ RMSEA $=.11$; SRMR $=$ $.04)$ was not found to fit the observed data significantly better $\left(\Delta \chi^{2}(1)=2.01, p=\right.$ $.15)$. Therefore, we used data based on one-factor model representing affective and cognitive aspects of self-regulation. Cronbach's alpha was .76.

\section{Daily survey data}

State of being recovered. We assessed the momentary state of being recovered in the after work and the bedtime surveys with four adapted items from the scale developed by Sonnentag and Kruel (2006): "I feel mentally recovered," "I feel physically recovered," "I feel well-rested," "I am full of new energy." On a 7point Likert scale from 1 (totally disagree) to 7 (totally agree), the scale measures the degree to which an individual feels recovered. Cronbach's alphas ranged from .84 to .87 over the after work measurements and from .85 to .88 over the bedtime measurements.

Affect. We measured positive and negative affect in the after work and the morning surveys with a shortened version of the positive and negative affect schedule (PANAS; Watson et al., 1988). We assessed positive affect with seven items ("active", "alert", "interested", "strong", "excited", "attentive", and "inspired"), and negative affect with six items ("irritable", "upset", "distressed", "nervous", "afraid", "jittery"). Participants responded to all affective states measures on a 5-point Likert scale from 0 (very slightly or not at all) to 4 (extremely). For positive affect, Cronbach's alphas ranged from .88 to .91 over the after work measurements and from .89 to .92 over the morning measurements. 
For negative affect, Cronbach's alphas ranged from .89 to .93 over the after work measurements and from .83 to .88 over the morning measurements.

Given the hierarchical structure associated with the analysis of multilevel data, we ran a set of multilevel confirmatory factor analyses (MCFAs) suggested by Muthén (1994) to confirm that whether the three study outcomes (i.e. the state of being recovered at bedtime, morning positive affect, and morning negative affect) represent distinct constructs. Compared to the one-factor model ( $\chi 2$ (204) $=1254.534, p<0.001 ; \mathrm{CFI}=.74 ; \mathrm{TLI}=.69 ; \mathrm{RMSEA}=.09 ;$ SRMR-within $=.15$, SRMR-between $=.46)$, the three-factor model $\left(\chi^{2}(198)=462.098, p<0.001\right.$; $\mathrm{CFI}=.93$; TLI $=.92 ; \mathrm{RMSEA}=.04 ;$ SRMR-within $=.04$, SRMR-between $=.08)$ resulted in a significantly better fit (Satorra-Bentler $\Delta \chi^{2}(6)=806.056, p<.001$ ). Moreover, the three-factor model showed a better model fit than the best fitting two-factor model (Satorra-Bentler $\Delta \chi 2(4)=178.319, p<.001)$.

Work-related perseverative thinking. We measured affective rumination and problem-solving pondering in the bedtime survey with items adapted from the work-related rumination questionnaire (WRRQ; Cropley, Michalianou, Pravettoni, \& Millward, 2012). The scale measured the two different types of work-related rumination: affective rumination and problem-solving pondering each by five adapted items. The items were adapted to the day level measuring affective rumination and problem-solving pondering experienced during the previous evening. Affective rumination and problem-solving pondering subscales included items such as, "During the evening, I was troubled by work-related issues" and "During the evening, I found solutions to my work-related problems", respectively. Items were responded by using a five-point Likert scale ranging from 1 (very seldom/never) to 5 (very often/always). Cronbach's alphas ranged from .90 to .91 for affective rumination and from .86 to .88 for problem-solving pondering over all daily measurements.

To examine whether the measure represents the two distinct constructs, we conducted MCFAs. Although the one-factor model did not appear well-fitting $\left(\chi^{2}(70)=688.983, p<0.001 ; \mathrm{CFI}=.72 ; \mathrm{TLI}=.64 ; \mathrm{RMSEA}=.11 ;\right.$ SRMR-within $=.19$, SRMR-between $=.64)$, the two-factor model $\left(\chi^{2}(68)=198.694, p<0.001\right.$; $\mathrm{CFI}=.94 ; \mathrm{TLI}=.92 ; \mathrm{RMSEA}=.05 ; \mathrm{SRMR}$-within $=.05$, SRMR-between $=.07$ ) fit the data significantly better (Satorra-Bentler $\Delta \chi^{2}(2)=102.285, p<.001$ ). 


\section{Data analysis}

There were two levels of data for each person: the person level (Level 2) and the day level (Level 1), with day-level data nested within persons. Given this hierarchical data structure, we examined the hypotheses with multilevel structural equation modeling (MSEM; Preacher, Zhang, \& Zyphur, 2011), using Mplus statistical software version 7 (Muthén \& Muthén, 2012). We simultaneously tested all hypotheses by conducting a moderated multilevel mediation model (see Figure 3.1) suggested by Bauer, Preacher, and Gil (2006). To do so, a 1-1-1 mediation model is tested using predictor, mediator, and outcome variables all assessed on the day level in which the strength of the indirect relationship between the day level variables depends on a person level variable. More specifically, our mediation analysis involved a cross-level moderation effect by examining a random intercept and slope model in which the relationship between day level variables (i.e., problem-solving pondering and the state of being recovered) was allowed to vary across persons (i.e., trait self-regulation). Accordingly, 95\% confidence intervals for the indirect paths are calculated based on the Monte Carlo method (Preacher \& Selig, 2012).

As Preacher, Zyphur, and Zhang (2010) discussed, estimating the mediation effect only in the within-person model results in a conflated estimation. This means that between-person relationships may be detected as within-person relationships if only the within-person model is estimated. Preacher et al., (2010) suggested the unconflated multilevel model (UMM) approach as the solution to this conflation by which the same mediation relationships on the within-person and between-person level are simultaneously estimated. Within the MSEM analysis, all observed variances of Level- 1 variables are implicitly divided into two latent parts; a within-person and a between-person component (Preacher et al., 2010). In the within-person part, between-person variation is removed by centering variables at the respective person mean (i.e., group mean centering) in such a way that coefficients indicate within-person relationships between variables at Level 1 . In the between-person part, variables are centered at the grand mean (i.e., grand mean centering), regardless of clustering and thereby coefficients indicate between-person relationships between variables at Level 2 .

Regarding the study hypotheses, we presented the results related to within-person paths (Table 3.2). However, the between-person results were additionally reported (see Footnote 1). 


\section{Results}

Means, standard deviation, and both person-level and day-level correlations are displayed in Table 3.1. In order to examine the variability of outcome variables we calculated the intraclass correlations (ICC; Hoffman, 2007) based on an unconditional random coefficient models. The results showed that for daily state of being recovered, morning positive affect, and morning negative affect, withinperson variation was $52 \%, 49 \%$, and $54 \%$, respectively. These results showed that a substantial portion of the variance in outcome variables was attributed to withinperson variation.

\section{Table 3.1}

Mean, standard deviation, and correlation between study variables

\begin{tabular}{|c|c|c|c|c|c|c|c|c|c|c|c|}
\hline & Variable & $\bar{M}$ & $S D$ & 1 & 2 & 3 & 4 & 5 & 6 & 7 & 8 \\
\hline 1 & Affective rumination & 1.98 & .83 & - & $.40^{* * *}$ & $-.17^{* * *}$ & $-.10^{*}$ & $.24^{* * *}$ & $-.30^{* * *}$ & $-.15^{*}$ & $.17^{* * *}$ \\
\hline 2 & $\begin{array}{l}\text { Problem-solving } \\
\text { pondering }\end{array}$ & 2.41 & .81 & $.43^{* * *}$ & - & $-.11^{*}$ & .007 & .04 & -.02 & .07 & -.09 \\
\hline 3 & $\begin{array}{l}\text { State of being } \\
\text { recovered after work }\end{array}$ & 4.17 & 1.50 & $-.46^{* * *}$ & -.04 & - & $.48^{* * *}$ & $-.34^{* * *}$ & $.25^{* * *}$ & -.02 & -.03 \\
\hline 4 & $\begin{array}{l}\text { Positive affect after } \\
\text { work }\end{array}$ & 2.04 & .67 & $-.41^{* * *}$ & -.02 & $.63^{* * *}$ & - & $-.30^{* * *}$ & $.15^{*}$ & -.06 & -.05 \\
\hline 5 & $\begin{array}{l}\text { Negative affect after } \\
\text { work }\end{array}$ & .48 & .66 & $.53^{* * *}$ & $.34^{* * *}$ & $-.29^{* *}$ & $-.20^{*}$ & - & $-.21^{* * *}$ & .002 & $.17^{*}$ \\
\hline 6 & $\begin{array}{l}\text { State of being } \\
\text { recovered at bedtime }\end{array}$ & 4.05 & 1.54 & $-.42^{* * *}$ & .05 & $.95^{* * *}$ & $.57^{* * *}$ & $-.22^{* *}$ & - & $.18^{*}$ & $-.21^{* * *}$ \\
\hline 7 & $\begin{array}{l}\text { Next morning } \\
\text { positive affect }\end{array}$ & 2.29 & .68 & $-.24^{*}$ & .16 & $.42^{* * *}$ & $.75^{* * *}$ & -.17 & $.37^{* * *}$ & - & $-.40^{* * *}$ \\
\hline 8 & $\begin{array}{l}\text { Next morning } \\
\text { negative affect }\end{array}$ & .37 & .53 & $.46^{* * *}$ & $.32^{* * *}$ & $-.21^{* *}$ & -.13 & $.94^{* * *}$ & -.11 & $-.22^{* *}$ & - \\
\hline 9 & Trait self-regulation & 7.30 & 1.72 & -.07 & .07 & $.20^{*}$ & $.35^{* * *}$ & $-.21^{* *}$ & .13 & $.25^{* *}$ & $-.16^{*}$ \\
\hline
\end{tabular}

${ }^{*}$ Note: Correlations below the diagonal are person-level correlations $(\mathrm{N}=171)$. Correlations above the diagonal are day-level correlations $(\mathrm{N}=676,683) .{ }^{*} p<.05$ (twotailed). ${ }^{* *} p<.01$ (two-tailed). ${ }^{* * *} p<.001$ (two-tailed). 


\section{Test of hypotheses}

Table 3.2 shows the results for the moderated multilevel mediation model examining all hypotheses. The results related to the state of being recovered showed a positive but non-significant relationship between the person-level of self-regulation and the state of being recovered at bedtime. Moreover, as a control variable, the state of being recovered after work was positively related to the state of being recovered at bedtime. Regarding the core predictors of interest (Hypotheses $1 \& 2$ ), the results showed that affective rumination and problemsolving pondering were negatively and positively related to the state of being recovered at bedtime, respectively. The correlation coefficients (see Table 3.1) showed no significant correlation between problem-solving pondering and the state of being recovered at bedtime. However, problem-solving pondering was strongly correlated with affective rumination, which in turn was significantly correlated with the outcome variable. This pattern of correlation suggested that problem-solving pondering might act as a suppressor variable. According to Pandey and Elliott (2010), a suppressor variable is a predictor that is uncorrelated or weakly correlated with the outcome variable but is strongly correlated with other predictors that are correlated with the outcome variable. Hence, further analysis was needed to reveal that whether problem-solving pondering meets the criteria of acting as a suppressor variable (Pandey \& Elliott, 2010; Cohen, Cohen, West, \& Aiken, 2003) in the model predicting the state of being recovered at bedtime.

We then tested for the suppressor effect by conducting additional analyses in which each variable of interest (i.e., affective rumination or problemsolving pondering) was separately included in the model. The results showed a significant relationship between affective rumination and the state of being recovered $(\beta=-.562, p<.001)$ whereas the relationship between problem-solving pondering and the state of being recovered was not found significant $(\beta=.043, p$ $=.68$ ). Moreover, by having both affective rumination and problem-solving pondering as the predictors of the state of being recovered (see Table 3.2) two changes occurred: (a) the predicting power of affective rumination improved, and (b) the effect of problem-solving pondering on the state of being recovered became significant. These results indicate that problem-solving pondering acted as a classic suppressor (Pandey \& Elliott, 2010; Cohen et al., 2003) in our Model. Therefore, Hypothesis 1 was supported. However, in contrast to the finding provided by the initial analysis (see Table 3.2), these additional analyses of the suppression effect did not provide support for Hypothesis 2. 
The model showed a significant cross-level interaction indicating that the trait level of self-regulation was positively related to the slopes of problem-solving pondering with the state of being recovered. To test the suppression effect of problem-solving pondering, affective rumination was removed from the model. The results showed that although problem-solving pondering was not significantly related to the state of being recovered $(\beta=.043, p=.68)$, the cross-level interaction of problem-solving pondering and self-regulation remained significant $(\beta=.157, p<.001)$. Furthermore, we examined the pattern of the interaction effect by conducting simple slope tests (Preacher, Curran, \& Bauer, 2006) at one standard deviation above and below the mean of trait self-regulation. The analyses revealed a significant and positive simple slope $(\beta=.323, p<.001)$ for employees high in trait self-regulation $(+1 S D)$ and a significant and negative simple slope $(\beta$ $=-.267, p<.001)$ for employees low in trait self-regulation $(-1 S D)$. These findings provided support for Hypothesis 3 indicating that the positive relation between problem-solving pondering and the state of being recovered was stronger for employees high in trait self-regulation. However, contrary to our expectation, the pattern of this interaction effect (illustrated in Figure 3.2) indicated that the relation between problem-solving pondering and the state of being recovered even became significantly negative for employees low in trait self-regulation. 


\section{Table 3.2}

Moderated multilevel mediation model predicting morning affect from affective rumination, problem-solving pondering experienced during the evening and state of being recovered at bedtime

\begin{tabular}{|c|c|c|c|c|c|c|c|c|c|}
\hline \multirow[t]{2}{*}{ Variable } & \multicolumn{3}{|c|}{ State of being recovered } & \multicolumn{3}{|c|}{ Positive affect } & \multicolumn{3}{|c|}{ Negative affect } \\
\hline & Estimate & $S E$ & $t$ & Estimate & $S E$ & $t$ & Estimate & $S E$ & $t$ \\
\hline Outcome after work (control) & .227 & .064 & $3.523^{* * *}$ & -.103 & .046 & $-2.220^{*}$ & .100 & .056 & 1.784 \\
\hline Affective rumination (AR) & -.635 & .112 & $-5.677^{* * *}$ & -.149 & .053 & $-2.814^{* *}$ & .112 & .038 & $2.922^{* *}$ \\
\hline Problem-solving pondering (PS) & .278 & .109 & $2.557^{*}$ & .116 & .052 & $2.212^{*}$ & -.103 & .041 & $-2.525^{*}$ \\
\hline General level of self-regulation (SR) & .043 & .048 & .896 & & & & & & \\
\hline Interaction effect: $P S \times S R$ & .112. & .042 & $2.692^{* *}$ & & & & & & \\
\hline State of being recovered (SBR) & & & & .057 & .021 & $2.726^{*}$ & -.044 & .016 & $-2.668^{* *}$ \\
\hline Indirect effect: $\mathrm{AR} \rightarrow \mathrm{SBR} \rightarrow$ morning & & & & -.036 & .016 & $-2.284^{*}$ & .028 & .013 & $2.223^{*}$ \\
\hline Indirect effect: $\mathrm{PS} \times \mathrm{SR} \rightarrow \mathrm{SBR} \rightarrow$ mor & affect & & & .006 & .003 & $2.076^{*}$ & -.005 & .002 & $-2.047^{*}$ \\
\hline Residual variance & .820 & .118 & $6.924^{* * *}$ & .197 & .031 & $6.456^{* *}$ & .097 & .018 & $5.530^{* * *}$ \\
\hline
\end{tabular}

${ }^{*}$ Note: All paths were simultaneously tested in one model. The results are related to within-person paths (Hypotheses $1,2, \& 4$ ) and a cross-level interaction (Hypothesis $3 \& 5)^{1}$. Outcomes after work were the state of being recovered after work to predict the state of being recovered at bedtime, positive affect after work to predict positive affect in the next morning, and negative affect after work to predict negative affect in the next .morning. ${ }^{*} \mathrm{p}<.05$ (two-tailed). ${ }^{* *} \mathrm{p}<.01$ (two-tailed). ${ }^{* * *} \mathrm{p}<.001$ (two-tailed).

${ }^{1}$ The results related to the between-person level of analysis provided support for Hypothesis $1(\beta=-.906, p<.001)$ indicating that employees who reported higher levels of affective rumination experienced lower levels of recovery at bedtime. The positive relationship between problem-solving pondering and recovery was not significant $(\beta=.174, p=.42)$. Therefore, Hypothesis 2 was not supported at the between-person level of analysis. Furthermore, the level in which employees experienced the state of being recovered at bedtime was positively associated with morning positive affect $(\beta=.125, p<.05)$. However, the relationship between the state of being recovered at bedtime and morning negative affect was not significant $(\beta=.034, p=.31)$. Finally, the results related to the between-person indirect relationships provided support only for Hypothesis $4 \mathrm{a}(\beta=-.114, p<.05)$ indicating that recovery mediated the relationship between affective rumination and morning positive affect. 


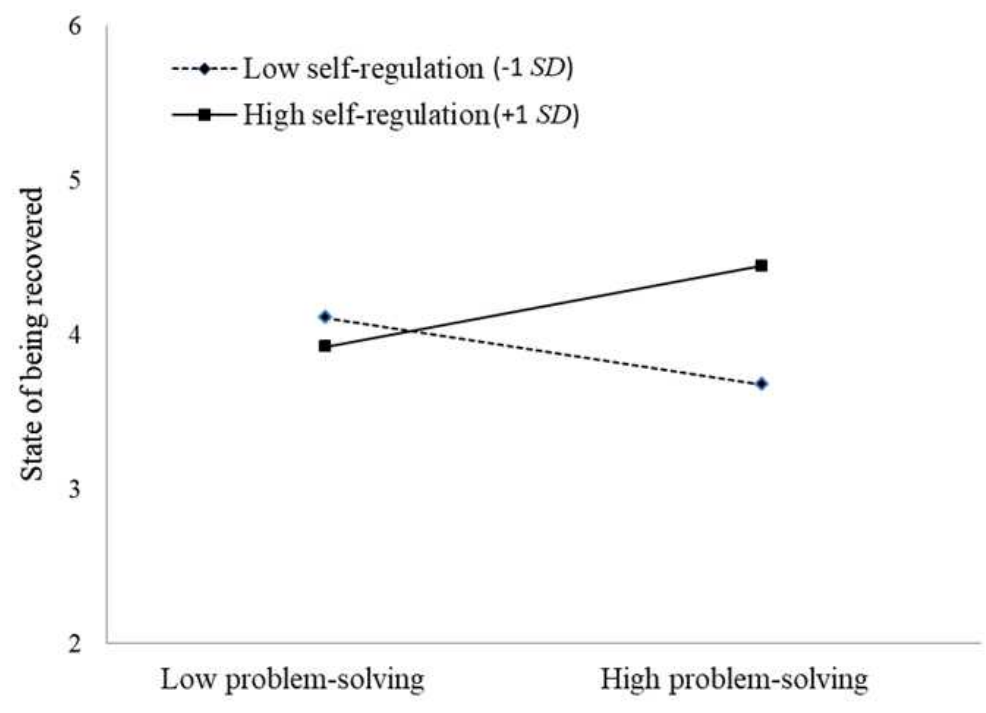

Figure 3.2. The interaction effect of problem-solving during the evening (PS) and self-regulation (SR) on the state of being recovered at bedtime

In order to conduct a more conservative test of Hypotheses 4 and 5, the model controlled the state of positive and negative affect after work for predicting positive and negative affect in the subsequent morning, respectively. Positive affect was negatively related to positive affect in the subsequent morning, whereas the relationship between negative affect after work and negative affect in the subsequent morning was not found significant. The model then provided evidence for the indirect relationships between affective rumination during the evening and the lower level of positive affect and the higher level of negative affect in the subsequent morning via its negative relationship with the state of being recovered at bedtime (Indirect effect $=-.036,95 \%$ confidence interval $[\mathrm{CI}]=-$ .068 to -.009 for positive affect; Indirect effect $=.028,95 \% \mathrm{CI}=.008$ to .052 for negative affect). Therefore, Hypothesis 4 was fully supported.

The results showed that the interaction between problem-solving pondering during the evening and trait self-regulation was significantly related to the two affect outcomes in the subsequent morning through the extent to which people feel recovered at bedtime (Indirect effect $=.006,95 \% \mathrm{CI}=.001$ to .014 for positive affect; Indirect effect $=-.005,95 \% \mathrm{CI}=-.011$ to -.001 for negative affect) . 
The data partly supported Hypothesis 5, since the relationship between problemsolving pondering and the state of being recovered was positive for employees high in trait self-regulation, but negative for employees low in trait self-regulation (see Figure 3.2). These findings show that problem-solving pondering during the evening was indirectly (through a higher level of the state of being recovered at bedtime) related to the higher level of well-being in the subsequent morning for employees high in trait self-regulation. In contrast, problem-solving pondering during the evening was indirectly (through a lower level of the state of being recovered at bedtime) related to the lower level of well-being in the subsequent morning for employees low in trait self-regulation.

Additionally, we compared the examined partial mediation model with the full mediation model in which the direct paths between the two variables of interest (i.e., affective rumination and problem-solving pondering) and the two affect outcomes in the subsequent morning were excluded. We conducted a model comparison test for nested models as suggested by Finch and Bolin (2017, p. 68). The results showed that the partial mediation model (log-likelihood $=$ 3283.874; Akaike information criterion $[\mathrm{AIC}]=6635.749$; Bayesian information criterion $[\mathrm{BIC}]=6789.350$; scaling correction factor $=1.418$; number of free parameters $=34)$ provides a significantly better fit to the data $\left(\Delta \chi^{2}(8)=64.901, p\right.$ $<.001)$ than the full mediation model (log-likelihood $=-3315.319 ;$ AIC $=$ 6682.638 ; $\mathrm{BIC}=6800.097$; scaling correction factor $=1.556$; number of free parameters $=26$ ).

These findings indicate a partial mediation effect of the state of being recovered at bedtime for Hypothesis 4 and $5 .{ }^{2}$

\footnotetext{
2 The suppressor effect examination showed that problem-solving pondering acts as a classic suppressor to predict the two morning affect outcomes. Unlike the results presented by Table 3.2, the suppression test showed no significant direct relationships between problem-solving pondering during the evening and positive affect $(\beta=.054, p=.28)$ and negative affect $(\beta=-.058, p=.11)$ in the subsequent morning. Nevertheless, given this suppression effect of problem-solving pondering, the comparison test for nested models showed that the partial mediation model fits the data better than the full mediation model $\left(\Delta \chi^{2}(4)=25.011, p<.001\right)$ for Hypothesis 5 .
} 


\section{Discussion}

The aim of this study was to examine how daily fluctuations in affective rumination and problem-solving pondering are related to evening recovery using a within-person design (Hypotheses $1 \& 2$ ). We also investigated whether the relationship between problem-solving pondering and evening recovery is more positive for employees high in trait self-regulation than for employees low in trait self-regulation (Hypotheses 3). Finally, we examined whether daily fluctuations in affective rumination and problem-solving pondering are related to well-being in the subsequent morning through the state of being recovered at bedtime, while the relationship between problem-solving pondering and evening recovery is moderated by trait self-regulation (Hypotheses $4 \& 5$ ). Results from a moderated multilevel mediation analysis provided support for Hypotheses 1, 3, 4, and 5 whereas Hypotheses 2 was not supported.

The results showed that the higher level of work-related affective rumination during the evening was negatively associated with the lower level of the state of being recovered at bedtime. This finding indicates that the experience of affective rumination during the evening inhibits the recovery process. This finding is in line with past research that reported work-related rumination to be related to higher levels of physiological arousal and need for recovery (Rydstedt et al., 2009; Cropley et al., 2015). The model then showed that affective rumination during the evening was indirectly related to well-being in the subsequent morning through the extent in which the individual feels recovered at bedtime. This finding contributes to findings of previous research using between-person designs (Firoozabadi et al., 2018; Hamesch et al., 2014; Querstret \& Cropley, 2012; Donahue et al., 2012) by showing the recovery process as a mechanism through which affective rumination is negatively related to psychological well-being.

Although the primary results showed that problem-solving pondering was positively related to the state of being recovered at bedtime, the additional analyses confirmed the classic suppression effect of problem-solving pondering in the models including affective rumination and problem-solving pondering both as the predictors of recovery. Given the results of the suppression test, the relationship between problem-solving pondering and evening recovery was not found significant when affective rumination was excluded from the model. This finding is in line with a previous cross-sectional study (Querstret \& Cropley, 2012) that showed that problem-solving pondering acts as a suppressor variable to negatively predict both acute and chronic fatigue. One explanation might be that 
apart from a positive effect of problem solving on recovery, it may also spill over into affective rumination which may negatively affect recovery. Only when this second effect is controlled for, we observe the positive effect of problem-solving pondering on recovery. Our findings shed light on the assumption provided by Nolen-Hoeksema (1996) indicating that although in both problem-solving and rumination, thoughts are directed to reduce goal discrepancies, they are differentiated from each other in terms of whether progression in the thoughts occurs over a reasonable period of time. According to Nolen-Hoeksema (1996), problem-solving is conceptualized as the process of thinking directed at resolving current or future problems by which some progression in the thoughts occurs over a reasonable period of time. If engaging repeatedly in problem-solving does not lead to any progression toward choice of a solution over a reasonable period of time, affective rumination may occur.

The results related to the cross-level interaction showed that problemsolving pondering was significantly related to the state of being recovered at bedtime by taking into account the moderating role of trait self-regulation. This result was in line with our expectation that problem-solving pondering is more likely to facilitate recovery from work during the evening for employees higher in trait self-regulation. According to Karoly (1993), individuals high in selfregulation are more capable to guide their goal-directed activities to reduce the discrepancy between the current state and a desired state. Therefore, they are more likely to experience problem-solving pondering as a process of thinking that probably often results in solutions to work-related problems. Drawing on the selfregulation model (Martin \& Tesser, 1996), finding a solution acts as a goal attainment mechanism by which the ruminative thinking will be stopped and the individual feels a sense of achievement. Additionally, the results of the simple slope tests showed that the relationship between problem-solving pondering and the state of being recovered was even negative for employees low in self-regulation (-1 SD). This finding also provides additional support for Nolen-Hoeksema's (1996) assumption indicating that individuals are more likely to switch to affective rumination when they do not experience a progressive and productive process of problem-solving over a limited time.

This study showed that problem-solving pondering during the evening was indirectly related to well-being in the subsequent morning via the state of being recovered at bedtime in such a way that this indirect effect was positive for employees high in trait self-regulation and conversely negative for employees low in trait self-regulation. However, for employees low in trait self-regulation (-1 SD), 
the interpretation of the indirect effect was different regarding their different pattern of relationship between problem-solving pondering and recovery. Therefore, specifically for employees low in trait self-regulation, one may conclude that problem-solving pondering during the evening was indirectly related to the lower level of well-being in the subsequent morning via its inhibiting effects on recovery from work. These findings can explain the inconsistent findings of previous research concerning the relationship between problemsolving pondering and well-being (Bennett et al., 2016; Firoozabadi et al., 2018; Syrek et al., 2017; Hamesch et al., 2014; Querstret \& Cropley, 2012).

Our study extended the recovery and occupational health literature by showing the day-level effects of the two different experiences of being mentally engaged with work-related issues on the recovery process and well-being. Moreover, it extended the literature of work-related perseverative thinking by addressing self-regulation as an individual factor that determines the facilitating or inhibiting role of problem-solving pondering on the recovery process. This suggests that problem-solving pondering is not a risk factor for insufficient recovery and impaired well-being if employees are high in trait self-regulation. On the contrary, problem-solving pondering is a risk factor for insufficient recovery and impaired well-being if employees are low in trait self-regulation. Drawing on CATS theory (Ursin \& Eriksen, 2004; Ursin \& Eriksen, 2010), perseverative thinking is less likely to cause prolonged activation if it is associated with positive outcome expectances in which the process of thinking is expected to handle the situation with positive results. In contrast, it leads to prolonged activation if it is associated with negative outcome expectancies in which the process of thinking is not expected to handle the situation. Our findings are also in line with studies that found recovery as a crucial mechanism by which job stressors translate into poor well-being (e.g., Syrek et al., 2017; Syrek \& Antony, 2014; Sonnentag, Binnewies, \& Mojza, 2010; Sonnentag, Kuttler, \& Fritz, 2010; Sonnentag \& Zijlstra, 2006).

Additionally, the comparison of findings between the two levels of analysis showed some differences. These different findings support the assumption of emergent processes in multilevel research (Bliese \& Jex, 2002) indicating that individual characteristics may differ in meaning and function differently across the within- and between-person levels of analysis. Therefore, researchers should draw conclusions by taking into consideration the level of results (i.e., within-person fluctuations or between-person differences). 


\section{Study limitations, directions for future research and practical implications}

This study has several limitations. First, we collected the data with self-report measures which may raise concerns about common method bias (Podsakoff, MacKenzie, Lee, \& Podsakoff, 2003). However, the longitudinal design, with measurement assessed at different time points reduces the effects of common method bias. Second, our path-modeling approach to examine the hypotheses did not allow us to draw causal conclusions. Therefore, we avoided the use of causal language. However, because of the diary nature of our study with multiple waves in which we controlled for the initial level of outcomes variables after work as well as testing for reverse causation, causal conclusions were more trustworthy to be drawn. Third, in accordance with our theoretical framework, we assessed the state of being recovered at the same time with work-related rumination as the reported experiences in the previous time-period. Therefore, we could not rule out the momentary influences of the state of being recovered on the ratings of the different types of work-related rumination. Fourth, the data were collected using paper-and-pencil and therefore we did not have an indication of the day and time that participants filled in the diaries. However, in order to ensure compliance with the measurement timing of the study design, participants received reminders on their cell phones and they were asked to report the date and time of filling the diary survey. Fifth, although the measures that we used to assess affective rumination and problem-solving pondering have been used in previous studies, they have not yet been conceptually validated. Future research is needed to improve and validate these measures.

We recommend future research to investigate the underling psychophysiological mechanisms of the two different types of work-related perseverative thinking using experimental designs and psycho-physiological measures. For instance, a study may investigate whether affective rumination and problemsolving pondering differently affect endocrinological and cardiovascular indicators of prolonged activation (Brosschot et al., 2005). In the current study selfregulation was found as a between-person variable that positively influences the effect of problem-solving pondering on recovery from work. Future research can investigate other between-person or even within-person factors that may play a determining role in the occurrence of a problem-solving pondering that facilitates the recovery process. In this paper, we discussed that problem-solving pondering may facilitate the recovery process by causing positive emotions that replenish depleted resources. However, this is still a speculative suggestion and future 
research examining this mediation role of positive emotions is required. Moreover, well-controlled intervention studies are needed in order to demonstrate the causality relationships between different types of work-related perseverative thinking, recovery, and well-being.

Based on the findings of the current study, organizations are recommended to improve their employees' ability to recover from work during non-work time. It seems important to improve the employees' knowledge of recovery especially regarding the different types of being mentally engaged with work-related issues during non-work time. Organizations are recommended to screen their high-ruminating employees who are more vulnerable to burnout (Firoozabadi, et al., 2018). These employees may then be treated with cognitive interventions such as cognitive behavior therapy and mindfulness-based techniques (Querstret, Cropley, \& Fife-Schaw, 2017; Querstret, Cropley, Kruger, \& Heron, 2016) that help them to disengage from affective rumination. Moreover, training problem-solving skills may help these employees to act as more successful problem solvers and shift them away from ruminative thinking (Watkins \& Baracaia, 2002) if they deal mentally with work-related problems during the time of recovery. However, further research is needed to adapt and investigate psychological intervention approaches on overcoming work-related rumination. 


\section{References}

Bauer, D. J., Preacher, K. J., \& Gil, K. M. (2006). Conceptualizing and testing random indirect effects and moderated mediation in multilevel models: New procedures and recommendations. Psychological Methods, 11, 142-163. http://doi.org/ 10.1037/1082-989X.11.2.142

Baumeister, R. F., Muraven, M., \& Tice, D. M. (2000). Ego depletion: A resource model of volition, self-regulation, and controlled processing. Social Cognition, 18, 130150. https://doi.org/10.1521/soco.2000.18.2.130

Bennett, A. A., Gabriel, A. S., Calderwood, C., Dahling, J. J., \& Trougakos, J. P. (2016). Better together? Examining profiles of employee recovery experiences. Journal of Applied Psychology, 101, 1635-1654.http://doi.org/10.1037/apl0000157

Binnewies, C., Sonnentag, S., \& Mojza, E. J. (2009a). Daily performance at work: Feeling recovered in the morning as a predictor of day-level job performance. Journal of Organizational Behavior, 30, 67-93. http//doi.org/10.1002/job.541

Binnewies, C., Sonnentag, S., \& Mojza, E. J. (2009b). Feeling recovered and thinking about the good sides of one's work. Journal of Occupational Health Psychology, 14, 243-256. http://doi.org/10.1037/a0014933

Binnewies, C., Sonnentag, S., \& Mojza, E. J. (2010). Recovery during the weekend and fluctuations in weekly job performance: A week-level study examining intraindividual relationships. Journal of Occupational and Organizational Psychology, 83, 419-441. http://doi.org/10.1348/096317909X418049

Blair, C., \& Ursache, A. (2011). A bidirectional model of executive functions and selfregulation. In K. D. Vohs \& R. F. Baumeister (Eds.), Handbook of selfregulation: Research, theory, and applications (pp. 300-320). New York, NY: Guilford Press.

Bliese, P. D., \& Jex, S. M. (2002). Incorporating a multilevel perspective into occupational stress research: Theoretical, methodological, and practical implications. Journal of Occupational Health Psychology, 7, 265-276. http://doi:10.1037/1076-8998.7.3.265

Brosschot, J. F., Pieper, S., \& Thayer, J. F. (2005). Expanding stress theory: Prolonged activation and perseverative cognition. Psychoneuroendocrinology, 30, 10431049. http://doi.org/10.1016/j.psyneuen.2005.04.008

Brosschot, J. F., van Dijk, E., \& Thayer, J. F. (2002). Prolonged autonomic activation, perseverative negative cognition, and daily stressors. International Congress Series, 1241, 329-336. http://doi.org/10.1016/S0531-5131(02)00615-5

Carver, C.S., \& Scheier, M.F. (1998). On the self-regulation of behavior. Cambridge: Cambridge University Press.

Carver, C.S., \& Scheier, M.F. (2011). Self-regulation of action and affect. In K. D. Vohs \& R. F. Baumeister (Eds.), Handbook of self-regulation: Research, theory, and applications (pp. 3-21). New York, NY: Guilford Press. 
Cohen, J., Cohen, P., West, S. G., \& Aiken, L. S. (2003). Applied multiple regression/correlation analysis for the behavioral sciences. Mahwah, NJ: Lawrence Erlbaum.

Cropley, M., Michalianou, G., Pravettoni, G., \& Millward, L. J. (2012). The relation of post-work ruminative thinking with eating behaviour. Stress and Health, 28, 2330. http://doi.org/10.1002/smi.1397

Cropley, M., Rydstedt, L. W., Devereux, J. J., \& Middleton, B. (2015). The relationship between work-related rumination and evening and morning salivary cortisol secretion. Stress and Health, 31, 150-157. http://doi.org/10.1002/smi.2538

Cropley, M., \& Zijlstra, F. R. H. (2011). Work and rumination. In J. Langan-Fox \& C. L. Cooper (Eds.), Handbook of stress in the occupations. Cheltenham: Edward Elgar.

Deluga, R. J., \& Masson, S. (2000). Relationship of resident assistant conscientiousness, extraversion, and positive affect with rated performance. Journal of Research in Personality, 34, 225-235. http://doi.org/10.1006/jrpe.1999.2272

Donahue, E. G., Forest, J., Vallerand, R. J., Lemyre, P. N., Crevier-Braud, L., \& Bergeron, É. (2012). Passion for work and emotional exhaustion: The mediating role of rumination and recovery. Applied Psychology: Health and Well-Being, 4, 341368. http://doi.org/10.1111/j.1758-0854.2012.01078.x

Erez, A., \& Isen, A. M. (2002). The influence of positive affect on the components of expectancy motivation. The Journal of Applied Psychology, 87, 1055-1067. http://doi.org/10.1037//0021-9010.87.6.1055

Etzion, D., Eden, D., \& Lapidot, Y. (1998). Relief from job stressors and burnout: Reserve service as a respite. The Journal of Applied Psychology, 83, 577-585. http://doi.org/10.1037/0021-9010.83.4.577

Finch, W. H., \& Bolin, J. E. (2017). Multilevel modeling using Mplus. Boca Raton: CRC Press.

Firoozabadi, A., Uitdewilligen, S., \& Zijlstra, F. R. H. (2018). Should you switch off or stay engaged? The consequences of thinking about work on the trajectory of psychological well-being over time. Journal of Occupational Health Psychology, 23, 278-288. http://dx.doi.org/10.1037/ocp0000068

Flaxman, P. E., Ménard, J., Bond, F. W., \& Kinman, G. (2012). Academics' experiences of a respite from work: Effects of self-critical perfectionism and perseverative cognition on postrespite well-being. Journal of Applied Psychology, 97, 854865. http://dx.doi.org/10.1037/a0028055

Fredrickson, B. L., \& Levenson, R. W. (1998). Positive emotions speed recovery from the cardiovascular sequelae of negative emotions. Cognition and Emotion, 12, 191220. http://dx.doi.org/10.1080/026999398379718

Fredrickson, B. L., Mancuso, R. A., Branigan, C., \& Tugade, M. M. (2000). The undoing effect of positive emotions. Motivation and Emotion, 24, 237-258. http://dx.doi.org/10.1023/A:1010796329158 
Fritz, C., \& Sonnentag, S. (2006). Recovery, well-being, and performance-related outcomes: The role of workload and vacation experiences. The Journal of Applied Psychology, 91, 936-945. http://doi.org/10.1037/0021-9010.91.4.936

George, J. M., \& Zhou, J. (2007). Dual tuning in a supportive context: Joint contributions of positive mood, negative mood, and supervisory behaviors to employee creativity. Academy of Management Journal, 50, 605-622. http://doi.org/ 10.5465/AMJ.2007.25525934

Hamesch, U., Cropley, M., \& Lang, J. (2014). Emotional versus cognitive rumination: Are they differentially affecting long-term psychological health? The impact of stressors and personality in dental students. Stress and Health, 30, 222-231. http://doi.org/10.1002/smi.2602

Hobfoll, S. E. (1989). Conservation of resources. A new attempt at conceptualizing stress. The American Psychologist, 44, 513-524. http://doi.org/10.1037/0003$\underline{066 X .44 .3 .513}$

Hoffman, L. (2007). Multilevel models for examining individual differences in withinperson variation and covariation over time. Multivariate Behavioral Research, 42, 609-629. http://doi.org/10.1080/00273170701710072

Ilies, R., Scott, B. A., \& Judge, T. A. (2006). The interactive effects of personal traits and experienced states on interindividual patterns of citizenship behavior. Academy of Management Journal, 49, 561-575. http://doi.org/10.5465/AMJ.2006.2 $\underline{1794672}$

Isen, A. M., Daubman, K. A., \& Nowicki, G. P. (1987). Positive affect facilitates creative problem solving. Journal of Personality and Social Psychology, 52, 1122-1131. http://dx.doi.org/10.1037/0022-3514.52.6.1122

Kanfer, R., \& Ackerman, P. L. (1989). Motivation and cognitive abilities: An integrative/aptitude-treatment interaction approach to skill acquisition. Journal of Applied Psychology, 74, 657-690. http://doi.org/10.1037/00219010. $\underline{74.4 .657}$

Karoly, P. (1993). Mechanisms of self-regulation: A systems view. Annual Review of Psychology, 44, 23-52. http://dx.doi.org/10.1146/annurev.ps.44.020193.000 $\underline{323}$

Lyubomirsky, S., King, L., \& Diener, E. (2005). The benefits of frequent positive affect: Does happiness lead to success? Psychological Bulletin, 131, 803-855. http://doi.org/10.1037/0033-2909.131.6.803

Martin, L. L., \& Tesser, A. (1996). Some ruminative thoughts. In R. S. Wyer, (Ed.), Advances in social cognition (Vol., IX, pp. 1-47). Hillsdale, NJ: Erlbaum.

Meijman, T. F., \& Mulder, G. (1998). Psychological aspects of workload. In P. J. D. Drenth \& H. Thierry (Eds.), Handbook of work and organizational psychology: Vol. 2. Work psychology (pp. 5-33). Hove, England: Psychology Press.

Muthén, B. O. (1994). Multilevel covariance structure analysis. Sociological Methods and Research, 22, 376-398. http://doi.org/10.1177/0049124194022003006

Muthén, L. K. \& Muthén, B. O. (2012). Mplus User’s Guide. Seventh Edition. Los Angeles, CA: Muthén \& Muthén. 
Nolen-Hoeksema, S. (1996). Chewing the cud and other ruminations. In R. S. Wyer, (Ed.), Advances in social cognition (Vol., IX, pp. 135-144). Hillsdale, NJ: Erlbaum.

Pandey, S., \& Elliott, W. (2010). Suppressor variables in social work research: Ways to identify in multiple regression models. Journal of the Society for Social Work and Research, 1, 28-40. http://doi.org/10.5243/jsswr.2010.2

Papies, E. K., Aarts, H. (2011). Nonconscious self-regulation, or the automatic pilot of human behavior. In K. D. Vohs \& R. F. Baumeister (Eds.), Handbook of selfregulation: Research, theory, and applications (pp. 125-142). New York, NY: Guilford Press.

Park, Y., Fritz, C., \& Jex, S. M. (2011). Relationships between work-home segmentation and psychological detachment from work: the role of communication technology use at home. Journal of Occupational Health Psychology, 16, 457467. http://doi.org/10.1037/a0023594

Perlow, L. A. (2012). Sleeping with your smartphone: How to break the 24/7 habit and change the way you work. Boston, MA: Harvard Business School Press.

Podsakoff, P. M., MacKenzie, S. B., Lee, J. Y., \& Podsakoff, N. P. (2003). Common method biases in behavioral research: A critical review of the literature and recommended remedies. The Journal of Applied Psychology, 88, 879-903. http://doi.org/10.1037/0021-9010.88.5.879

Posner, M. I., \& Rothbart, M. K. (1998). Attention, self-regulation and consciousness. Philos. Trans. R. Soc. Lond. B. Biol. Sci., 353, 1915-1927. http://dx.doi.org/ $10.1098 / \mathrm{rstb} .1998 .0344$

Preacher, K. J., Curran, P. J., \& Bauer, D. J. (2006). Computational tools for probing interactions in multiple linear regression, multilevel modeling, and latent curve analysis. Journal of Educational and Behavioral Statistics, 31, 437-448. http:// dx.doi.org/10.3102/10769986031004437

Preacher, K. J., \& Selig, J. P. (2012). Advantages of Monte Carlo confidence intervals for indirect effects. Communication Methods and Measures, 6, 77-98. http:// dx.doi.org/10.1080/19312458.2012.679848

Preacher, K. J., Zhang, Z.,\&Zyphur, M. J. (2011). Alternative methods for assessing mediation in multilevel data: The advantage of multilevel SEM. Structural Equation Modeling, 18, 161-182. https://doi.org/10.1080/10705511.2 $\underline{011.557329}$

Preacher, K. J., Zyphur, M. J., \& Zhang, Z. (2010). A general multilevel SEM framework for assessing multilevel mediation. Psychological Methods, 15, 209-233. http://doi.org/10.1037/a0020141

Querstret, D., \& Cropley, M. (2012). Exploring the relationship between work-related rumination, sleep quality, and work-related fatigue. Journal of Occupational Health Psychology, 17, 341-353. http://doi.org/10.1037/a0028552

Querstret, D., Cropley, M., \& Fife-Schaw, C. (2017). Internet-based instructor-led mindfulness for work-related rumination, fatigue, and sleep: Assessing facets of mindfulness as mechanisms of change. A randomized waitlist control trial. 
Journal of Occupational Health Psychology, 22, 153-169. http://doi.org/ $10.1037 /$ ocp0000028

Querstret, D., Cropley, M., Kruger, P., \& Heron, R. (2016). Assessing the effect of a Cognitive Behaviour Therapy (CBT)-based workshop on work-related rumination, fatigue, and sleep. European Journal of Work and Organizational Psychology, 25, 50-67.http://dx.doi.org/10.1080/1359432X.2015.1015516

Ren, J., Hu, L., Zhang, H., \& Huang, Z. (2010). Implicit positive emotion counteracts ego depletion. Social Behavior and Personality, 38, 919-928. http://doi.org/ $\underline{10.2224 / \mathrm{sbp} .2010 .38 .7 .919}$

Rydstedt, L. W., Cropley, M., Devereux, J. J., \& Michalianou, G. (2009). The effects of gender, long-term need for recovery and trait inhibition-rumination on morning and evening saliva cortisol secretion. Anxiety, Stress, and Coping, 22, 465-474. http://doi.org/10.1080/10615800802596378

Sonnentag, S., \& Bayer, U. V. (2005). Switching off mentally: Predictors and consequences of psychological detachment from work during off-job time. Journal of Occupational Health Psychology, 10, 393-414. http://doi.org/ $10.1037 / 1076-8998.10 .4 .393$

Sonnentag, S., Binnewies, C., \& Mojza, E. J. (2008). “Did you have a nice evening?” A day-level study on recovery experiences, sleep, and affect. Journal of Applied Psychology, 93, 674-684. http://doi.org/10.1037/0021-9010.93.3.674

Sonnentag, S., Binnewies, C., \& Mojza, E. J. (2010). Staying well and engaged when demands are high: The role of psychological detachment. Journal of Applied Psychology, 95, 965-976. http://doi.org/10.1037/a0020032

Sonnentag, S., \& Fritz, C. (2015). Recovery from job stress: The stressor-detachment model as an integrative framework. Journal of Organizational Behavior, 36, S72S103. http://dx.doi.org/10.1002/job.1924

Sonnentag, S., \& Kruel, U. (2006). Psychological detachment from work during off-job time: The role of job stressors, job involvement, and recovery-related selfefficacy. European Journal of Work and Organizational Psychology, 15, 197217. http://doi.org/10.1080/13594320500513939

Sonnentag, S., Kuttler, I., \& Fritz, C. (2010). Job stressors, emotional exhaustion, and need for recovery: A multi-source study on the benefits of psychological detachment. Journal of Vocational Behavior, 76, 355-365. http://doi.org/ $10.1016 / j$.jvb.2009.06.005

Sonnentag, S., Mojza, E. J., Binnewies, C., \& Scholl, A. (2008). Being engaged at work and detached at home: A week-level study on work engagement, psychological detachment, and affect. Work \& Stress, 22, 257-276. http://doi.org/10.1080 $\angle 02678370802379440$

Sonnentag, S., \& Zijlstra, F. R. H. (2006). Job characteristics and off-job activities as predictors of need for recovery, well-being, and fatigue. The Journal of Applied Psychology, 91, 330-50. http://doi.org/10.1037/0021-9010.91.2.330 
Syrek, C. J., \& Antoni, C. H. (2014). Unfinished tasks foster rumination and impair sleeping-Particularly if leaders have high performance expectations. Journal of Occupational Health Psychology, 19, 490-9. http://doi.org/10.1037/a0037127

Syrek, C. J., Weigelt, O., Peifer, C. \& Antoni, C. H. (2017). Zeigarnik's sleepless nights: How unfinished tasks at the end of the week impair employee sleep on the weekend through rumination. Journal of Occupational Health Psychology, 22, 225-238. http://dx.doi.org/10.1037/ocp0000031

Thompson, R. A. (1994). Emotion regulation: A theme in search of definition. Monographs of the Society for Research in Child Development, 59, 25-52. http://doi.org/10.1111/j.1540-5834.1994.tb01276.x

Tice, D. M., Baumeister, R. F., Shmueli, D., \& Muraven, M. (2007). Restoring the self: Positive affect helps improve self-regulation following ego depletion. Journal of Experimental Social Psychology, 43, 379-384. http://doi.org/10.1016 Lj.jesp.2006.05.007

Ursin H., \& Eriksen, H. R. (2004). The cognitive activation theory of stress. Psychoneuroendocrinology, 29, 567-592. http://doi.org/10.1016/S03064530 (03)00091-X

Ursin, H., \& Eriksen, H. R. (2010). Cognitive activation theory of stress (CATS). Neuroscience and Biobehavioral Reviews, 34, 877-881. http://doi.org/ 10.1016/j.neubiorev.2009.03.001

Watkins, E., \& Baracaia, S. (2002). Rumination and social problem-solving in depression. Behaviour Research and Therapy, 40, 1179-1189. http://doi.org/10.1016/ S0005-7967(01)00098-5

Watson, D. (1988). Intraindividual and interindividual analysis of positive and negative affect: Their relation to health complaints, perceived stress, and daily activities. Journal of Personality and Social Psychology, 54, 1020-1030. http://doi.org/ $\underline{10.1037 / 0022-3514.54 .6 .1020}$

Watson, D., Clark, L. a, \& Tellegen, A. (1988). Development and validation of brief measures of positive and negative affect: The PANAS scales. Journal of Personality and Social Psychology, 54, 1063-1070. http://doi.org/10.1037 L0022-3514.54.6.1063

Wendsche, J., \& Lohmann-Haislah, A. (2017). A meta-analysis on antecedents and outcomes of detachment from work. Frontiers in Psychology, 7, 1-24. http://doi.org/10.3389/fpsyg.2016.02072

Xanthopoulou, D., Bakker, A. B., \& Ilies, R. (2012). Everyday working life: Explaining within-person fluctuations in employee well-being. Human Relations, 65, 10511069. http://doi.org/10.1177/0018726712451283

Yeo, G. B., \& Frederiks, E. R. (2011). Cognitive and affective regulation: Scale validation and nomological network analysis. Applied Psychology, 60, 546-575. http://doi.org/10.1111/j.1464-0597.2011.00447.x 


\section{CHAPTER 4}

\section{Week-level dynamics and person-level differences of the relation between work-related perseverative thinking and job performance- related outcomes, the mediating role of emotion regulation capability}

This chapter is based on: Firoozabadi, A., Uitdewilligen, S., \& Zijlstra, F. R. H. (under review). Week-level dynamics and person-level differences of the relation between work-related perseverative thinking and job performance-related outcomes, the mediating role of emotion regulation capability. 


\section{CHAPTER 5}

General discussion 



\section{Introduction}

Employees' capability to recover from work during non-work time has been considered crucial for their well-being and job-related performance (Sonnentag \& Zijlstra, 2006). Due to advances in communication technologies and the mentally demanding nature of many contemporary jobs and, the boundary between work and non-work time has become blurred. Therefore, people are more likely to be constantly exposed to work-related issues during non-work time. This lack of detachment may inhibit the recovery process and thereby cause impaired wellbeing and job performance (Meijman \& Mulder, 1998).

People may experience incomplete unwinding from their work-related issues when they engage in perseverative thinking. Perseverative thinking is described as repeated, pervasive, and prolonged activation of being mentally occupied with their work-related issues (Brosschot, Gerin, \& Thayer, 2006; Brosschot, Pieper \& Thayer, 2005). Perseverative thinking has been conceptualized as a mechanism that inhibits the recovery process and causes impaired well-being. However, Cropley and Zijlstra (2011) argued that whether or not work-related perseverative thinking during non-work time causes impaired well-being depends on the type of perseverative thinking. They conceptualized two fundamentally different types of work-related perseverative thinking, which they labeled affective rumination and problem-solving pondering.

This dissertation aimed to investigate the consequences of the two types of work-related perseverative thinking on well-being and job performance. It contributed to this topic by answering three research questions: Research question 1: What are the consequences of work-related affective rumination and problem-solving pondering on well-being and job-performance? Research question 2: Through what underlying dynamic processes do work-related affective rumination and problem-solving pondering have differential consequences on well-being and job-performance? Research question 3: How is the consequence of work-related problem-solving pondering on recovery from work influenced by individual differences in trait self-regulation?

In this conclusion chapter, I will first provide an overview of the main findings of the three empirical studies presented in Chapters 2, 3, and 4. I will then illustrate theoretical and practical implications of these results. Finally, I will discuss the strengths and limitations of our empirical studies and provide suggestions for future research. 


\section{Main findings}

In order to answer the three research questions, I conducted three empirical studies presented in Chapter 2, 3, and 4.

Chapter 2 presented a longitudinal three-wave study that contributed to Research question 1 by investigating how the experience of affective rumination and problem-solving pondering during evenings predict changes in two long-term well-being outcomes (i.e. exhaustion and general mental health complaints) over one year period. Using latent growth curve modeling (LGM), the study showed that employees who experience high levels of work-related affective rumination during evenings showed higher rates of growth in exhaustion across a period of 12 months. However, the findings showed that affective rumination was not a significant predictor of change in general mental health complaints over time. In addition, our results did not show a significant relationship between problemsolving pondering during evenings and changes in either exhaustion or general mental health complaints across a period of one year.

These findings demonstrate that when looking at the long term effects, not all types of work related perseverative thinking are equally negative for wellbeing outcomes. Whereas affective rumination particularly leads to increases in exhaustion, problem solving pondering is not related with such negative long-term outcomes. Moreover, this study showed that work-related affective rumination is particularly related to increase in exhaustion as a work-specific outcome of mental health, while it is not related to increase in mental health complaints as a general and context-free outcome of well-being. According to Warr (1987), contextspecific mental health refers explicitly to job-related mental health such as exhaustion. In contrast, context-free mental health is a more global construct that is not tied to a specific context and reflects the general status of well-being.

Chapter 3 reports on a diary study over five consecutive working days that investigated Research question 1, 2, and 3 by examining how daily fluctuations in work-related affective rumination and problem-solving pondering are dynamically related to recovery and well-being. In this study, I tested, using a within-person design, a model in which the state of being recovered at bed time mediates the relationship between the two types of work-related perseverative thinking during the evening and the level of well-being in the subsequent morning, while accounting for the moderating role of trait-self regulation on the ponderingrecovery relationship. 
The results of a moderated multilevel mediation analysis showed that affective rumination during the evening was indirectly related to impaired wellbeing in the subsequent morning through its negative relationship with the state of being recovered at bedtime. The results related to the cross-level interaction showed that problem-solving pondering was significantly related to the state of being recovered at bedtime by taking into account the moderating role of trait self-regulation. The findings demonstrated that problem-solving was indirectly related to well-being in the subsequent morning through its relationship with the state of being recovered at bedtime. However, this indirect effect was moderated by trait self-regulation in such a way that problem-solving pondering was positively related to the state of being recovered and consequently to improved well-being for employees high in self-regulation, while it was negatively related to the state of being recovered and consequently to impaired well-being for those low in self-regulation.

Contributing to Research question 1 and 2, these findings provide evidence to support the theoretical assumption proposing that the two types of work-related perseverative thinking operate differently on the recovery process and thereby have different effects on employees' well-being. Moreover, contributing to Research question 3, problem-solving pondering is beneficial or unfavorable for recovery and well-being, depending on the individuals' capability to regulate their thoughts and emotions. While, problem-solving facilitates the recovery process for employees with high levels of cognitive and emotion regulation, it inhibits the recovery process for employees with low levels of cognitive and emotion regulation.

Chapter 4 investigated Research question 1 and 2 by examining how the two types of work-related perseverative thinking are related to two performancerelated outcomes namely effort expenditure and task performance. Based on a diary study conducted over six consecutive weeks, I examined the role of emotion regulation capability as a mediator of the effect of work-related affective rumination and problem-solving pondering during the weekend on the job performance-related outcomes during the subsequent working week. Using multilevel structural equation modeling, this study found different patterns of relationships between variables at two levels of analysis: the within-person level (i.e. week-level dynamics) and the between-person level (person-level differences).

This study revealed that emotion regulation capability mediates the relationships between affective rumination and the two performance-related 
outcomes (i.e. effort expenditure and task performance) only at the within-person level. This finding means that experiencing affective rumination during the weekend leads to higher compensatory effort and lower task performance in the subsequent working week through its negative influence on individuals' capability to regulate their emotions. Moreover, the results showed a significant mediating role of emotion regulation capability on the relationship between problem-solving pondering and perceived task performance only at the between-person level. This means that employees who in general experience high levels of problem-solving pondering during their weekends generally perceive high levels of task performance because they have high levels of emotion regulation capability. The findings shed lights on our findings presented in Chapter 2 and 3 and provide empirical evidence supporting the theoretical assumption indicating that affective rumination and problem-solving pondering have different influences on the organism due to their diverging pattern of drawing on emotion regulatory resources.

\section{Theoretical implications}

The findings of the current dissertation provide several theoretical implications for the recovery and occupational health literature.

Previous empirical research has shown that lack of detachment (i.e. switching off mentally) from work-related issues during non-work time impedes the recovery process and causes impaired well-being and unfavorable job performance (see Sonnentag \& Fritz, 2015, for a review). However, the findings of my three empirical studies reported on in this dissertation advance the knowledge on recovery by showing that lack of detachment is not necessarily a threatening factor for the recovery process (Chapter 2), well-being (Chapter $2 \& 3$ ), and jobperformance (Chapter 4) as this depends on the type of work-related perseverative thinking (i.e. affective rumination versus problem-solving pondering) and on trait self-regulation.

Considering the findings presented in Chapter 3 , one contribution to the literature lies in identifying recovery from work as a process through which affective rumination and problem-solving pondering have differential influences on well-being. This means that the extent to which the two types of perseverative thinking decrease or enhance psychological well-being depends on their inhibiting or facilitating effects on the recovery process during non-work time. Particularly in the long run, this may explain how engaging in affective rumination causes emotional exhaustion (see Chapter 2) through cumulative effects of insufficient 
recovery. By engaging in affective rumination about work, job stressors remain mentally present which causes prolonged activation (Brosschot et al., 2005; Ursin \& Eriksen, 2004; Meurs \& Perrewe, 2011). As a result, prolonged activation causes impaired well-being as it chronically draws on the individuals' resources over time (Brosschot, van Dijk, \& Thayer, 2002; Sluiter, Frings-Dresen, van der Beek, \& Meijman, 2001). Therefore, the findings presented in Chapter 2 and 3 provide empirical evidence to support the theoretical assumption of the effortrecovery model (Meijman \& Mulder, 1998) proposing the detrimental cumulative effect of insufficient recovery on well-being in the long run. Research (e.g. Fleuren, van Amelsvoort, Zijlstra, de Grip, \& Kant, 2018) has documented insufficient recovery as a characteristic that negatively affects individuals' ability to effectively function in current and future work throughout their working life (i.e. sustainable employability).

In addition, it is concluded that the extent to which problem-solving pondering contributes to the recovery process should be taken into account for considering the effect of problem-solving on well-being. Accordingly, the study presented in Chapter 3 extends the knowledge on work-related perseverative thinking by showing that problem-solving pondering might be beneficial or unfavorable for recovery depending on individuals' trait level of self-regulation. This means that problem-solving pondering is not beneficial to everyone, but it is even detrimental for some people. Engaging in problem solving contributes to the recovery process and thereby is considered beneficial only for employees who possess the ability to effectively regulate their thoughts and feelings. In contrast, it causes insufficient recovery and thereby is considered detrimental for employees who possess less capability to regulate their thoughts and feelings. These findings suggest a more fine-grained conceptualization of problem-solving, where not the act of thinking about work by itself determines the effects on well-being, but this effect instead is driven by people's ability to effectively regulate this process and achieve progress in their thinking. In particular the importance of goal-directed progress in thinking has been neglected in research on perseverative cognition. Problem-solving pondering is conceptualized as a goal-directed cognitive process by which individuals aim to reduce a cognitive discrepancy between the current state and the desired state (e.g. caused by dealing with a work-related problem) by discovering and generating solutions. However, in order to have a more comprehensive conceptualization, researchers should take into account the degree to which individuals experience progress in their thinking about work. This is in line with the assumption of Nolen-Hoeksema (1996) that problem-solving and rumination are different from each other in terms of whether progression in the thoughts occurs over a reasonable period of time. Accordingly, progress occurs 
through completing three steps of the problem-solving process: assessing the problem, evaluating possible solutions to the problem, and eventually deciding about the most efficient solution.

Given Kanfer and Ackerman's (1989) conceptualization of selfregulation, for problem solving to be effective, people should be sufficiently capable to guide, evaluate, and regulate their process of thinking as well as the emotions elicited during this process. More specifically, they should manage and control the allocation of energetic resources and mental effort (Zijlstra, 1993, 1996) toward specific aspects of a problem and goal-relevant information (i.e. selfmonitoring). They are then less likely to be distracted and engaged with goalirrelevant information (e.g. dysfunctional emotions). Moreover, people should be sufficiently capable to compare the current state with a desired state (i.e. selfevaluation) in order to evaluate progression in reducing goal-performance discrepancies. If they notice progression in problem-solving process, they are likely to experience positive emotions related to their sense of achievement and self-efficacy for attaining work-related goals (i.e. self-reactions) (Amabile \& Kramer, 2011). This may broaden the individuals' prospect to solve the problem (Frederickson \& Joiner, 2002; Frederickson, 2001). However, in the case of notifying unfavorable progression, people should be capable to prevent excessive exertion of energetic resources for pondering that is not beneficial for goal attainment or not likely to solve the problem.

Our empirical study in Chapter 4 examined a model considering emotion regulation capability as a mechanism and dynamic through which affective rumination and problem-solving pondering are differentially related to performance-related outcomes. Given the conservation of resources theory (Hobfoll, 1989), the extent to which individuals can regulate their emotions in an optimal way depends on their momentary levels of emotion regulatory resources. The findings at the within-person level provide important theoretical contributions to the literature by indicating that affective rumination and problem-solving pondering have differential impacts on the organism due to their diverging pattern of drawing on emotion regulatory resources. It is thus concluded that affective rumination as a process that involves dysfunctional emotional processes drains emotion regulatory resources. In contrast, problem-solving pondering is considered as a cognitive activation process that is less likely to draw on emotion regulatory resources that are crucial for optimal emotion-regulation processes. Considering positive affect as an indicator of emotional resources, results presented in Chapter 3 also contribute to this conclusion. As presented earlier, this empirical research showed that the experience of affective rumination 
during the evening is related to lower levels of positive affect in the subsequent morning; whereas, the experience of problem-solving is related to higher levels of positive affect in the subsequent morning for employees who effectively regulate their dysfunctional feelings.

The results presented in Chapter 4 contribute to the recovery and occupational health research by demonstrating the importance of employing wellbeing-related outcomes that are conceptually related to the underlying processes of different recovery experiences. For example the findings regarding affective rumination at the within-person level may explain the results presented in Chapter 2 demonstrating that affective rumination causes increase in emotional exhaustion in the long run, while it does not cause change in general mental health. Compared to general mental health, emotional exhaustion is more likely to be caused by work-related affective rumination probably because this type of perseverative thinking drains considerably emotion regulatory resources. This finding is in line with the conceptualization that Quinn, Spreitzer, and Lam (2012) provided for emotional exhaustion. They conceptualized emotional exhaustion as a sense of incapability to achieve high levels of energetic activation (i.e. resources) to perform work domain activities. However, compared to emotional exhaustion, impaired general mental and physical health is a broader health outcome that is not directly influenced by the depletion of emotion regulatory resources that people require specifically to perform their work-related task.

Additionally, the findings presented in Chapter 4 provide important insights for the dynamic energetical-control approach of job performance (Hockey, 1997; Zijlstra 1993; Kahneman 1973; Hockey \& Earle, 2006; Beal, Weiss, Barros, \& MacDermid, 2005) by demonstrating the important role of emotion regulation capability on individuals' effort expenditure and task performance. More specifically, given the findings at the within-person level, this means that the active and dynamic management of emotion-regulatory resources affects job performance through the goal-directed mobilization of these resources to environmental demands. This motivational control of performance contributes to job performance not only by energizing individuals to adequately meet their work-related demands but also by causing initiation, maintenance, and regulation of their adaptive and goal-directed activities across work demanding conditions.

Methodologically, the findings presented in Chapter 3 and 4 contribute to the recovery research by showing that the patterns of relationships between variables might be different at different levels of analysis (i.e. within-person 
dynamics versus person-level differences). Therefore, research should take into account that results should cautiously be interpreted and compared with findings of previous research depending on the level of analysis.

\section{Practical implications}

Based on the findings reported in this dissertation, in order to enhance recovery from work and prevent the negative consequences of thinking about work on health and job-performance, a number of recommendations can be made for governments and legislative assemblies of labor laws, organizations (more specifically Human Resource (HR) managers), and employees.

Governments and legislative assemblies of labor laws should critically evaluate their current labor laws and assess whether these sufficiently protect employees from work-related factors that inhibit the recovery process during nonwork time. Current labor laws have often been developed in an era before developments, such as the intense use of communication technology and mentally demanding complex jobs became standard in our societies. As a result, most rules mainly cover issues related to basic working conditions such as salary rate, working environment, weekly working hours, daily working time, and holidays (see Arbeidswet 2000 BES of the Netherlands and the Labor Law of the Islamic Republic of Iran, 1990 as two examples). Yet, the findings of this dissertation suggest that also the way employees spend their time outside of work times, influences their well-being in the short and in the long run. Therefore, it would be advisable to revise these laws in such a way that they also protect employees' rights to not engage in work-related activities outside of their official working times that trigger work-related rumination. For instance, they may oblige organizations to limit the pressure they explicitly or implicitly put on their employees during nonwork time to engage in work-related cognitive processing (e.g. by limiting workrelated e-mail and smart-phone use or by planning assignments in such a way that they can be fully completed during work time). For example, these laws can protect employees' rights to refuse to respond to emails received from their managers during the evening or the weekend.

HR managers may provide recovery guidelines that help their employees to improve the balance between professional and personal life. More specifically for employees with mentally demanding jobs, they might develop guidelines that enable employees to overcome obstacles to unwind from work-related issues during the time of recovery from work. For example, the use of communication technology (e.g. email or phone) has been known as one of the main factors that 
blurs the work-home boundary and inhibits the recovery process by causing workrelated thoughts (Park, Fritz, \& Jex, 2011; Boswell \& Olson-Buchanan, 2007; Chesley, 2005; Valcour \& Hunter, 2005). Therefore, in order to prevent workrelated rumination, a guideline might be developed to protect employees to not be interrupted by work-related emails or phone calls after leaving work places. This strategy contradicts the Bring Your Own Device (BYOD) policy (Madkour, 2008) by which employees are financially and technically supported to buy and use their own devices (e.g. laptop, tablet, or smart phones) for work purposes.

HR managers can also provide facilities that encourage and enable employees to regularly engage in individual or group recreational activities during evenings of the working week or at weekends. These strategies not only directly facilitates the recovery process by improving a sense of detachment and positive affect but also implicitly improves employees' attitudes towards the importance of recovery after working time. For example, organizations may provide facilities to support employees for engaging in leisure activities in evenings or weekends. Studies showed that engaging in physical activities such as sports (e.g. Rook \& Zijlstra, 2006; Sonnentag \& Zijlstra, 2006) and mastery experiences (e.g. Fritz, Sonnentag, Spector, \& McInroe, 2010; Sonnentag \& Fritz, 2007) during nonwork time facilitates the recovery process.

This research demonstrated that high-ruminating employees are highly vulnerable for burnout over time due to the detrimental effects of affective rumination on the recovery process. Therefore HR managers may suggest psychological interventions to these employees, such as cognitive behavior therapy (Querstret, Cropley, Kruger, \& Heron, 2016) and mindfulness-based techniques (Querstret, Cropley, \& Fife-Schaw, 2017; Hülsheger, Feinholdt, \& Nübold, 2015; Hülsheger, Alberts, Feinholdt, \& Lang, 2013). These interventions help employees to disengage from affective rumination and improve the possibility to prevent impaired health and job-performance that affective rumination causes in the short and long run. Moreover, providing training courses aimed at promoting problem-solving skills such as internet-based RuminationFocused Cognitive Behavioral Therapy (RFCBT; Watkins, 2008) may help employees to act as more successful problem solvers. This intervention aimed at reducing dysfunctional thinking (i.e. abstract and evaluative thinking focused on negative outcomes and difficulties causing negative affect) by shifting individuals towards a functional thinking (concrete and action-oriented thinking involving cognitive strategies, such as anticipating coping, planning, rehearsal, and problem solving) if they deal mentally with work-related problems during the time of recovery. However, further research is needed to adapt and investigate 
psychological intervention approaches on overcoming work-related affective rumination and enhancing problem-solving skills.

Not only HR managers but also employees themselves could undertake actions to manage their recovery from work and prevent work-related rumination. As a first important step, employees should obtain knowledge on how the process of recovery works. In particular, it is relevant that they develop awareness about how different recovery experiences and more specifically different types of being mentally engaged with work-related issues during non-work time influence their recovery from work and consequently their well-being. Research has shown that health-related knowledge is an important factor for preventing impaired wellbeing (e.g. Chin et al., 2011; Parker \& Gazmararian, 2003). Employees are recommended to schedule and manage their non-work time in a way that the possibility of being caught up in thinking about work-related issues during nonwork time is reduced to a minimum level. For example, they may impose some restrictions on using technology after regular working hours (Kreiner, Hollensbe, \& Sheep, 2009). To do so, they may use separate communication devices, email accounts, or phone lines for work and personal activities. They may also deactivate the notifications of their mail and message inboxes on their mobile devices. For the case of necessity and when working is strictly required, they may determine a limited time span during which they are available to reply important emails or make phone calls.

As a finding of this dissertation, depending on the employees' capability to regulate cognitions and emotions, problem-solving pondering may have a positive or negative impact on recovery from work during non-work time. Given this finding, if employees find themselves engaged in thinking about work-related problems, they are recommended to become conscious of the nature and process of their thinking. They then should decide to continue their thinking only if their thoughts are directed at discovering solutions to a specific work-related problem over a reasonable time. They should ensure that they are completely in charge of finding a solution for that specific problem and have control over this experience. If they do not experience a progressive and productive thinking process (i.e. problem-solving), they should stop thinking about the issue. Although this sounds, like a simple decision rule, it may be much more difficult to apply in practice. Therefore, employees should receive specifically designed training to develop this meta-awareness and enhance their problem-solving skills. 


\section{Strengths and limitations}

The studies presented in this dissertation have several strengths. First, compared to the majority of studies that used samples of employees from western developed countries, using a sample of Iranian employees (in Chapter 2 and 3) allowed us to extend the recovery and occupational health literature particularly on people from a developing country. According to Schaufeli, Leiter, and Maslach (2009), people in developing countries are more likely to become exhausted because of rapid changes in modern working life and experiencing higher levels of work-related stressors. Second, using diary designs and multilevel analyses provided the possibility to examine the relationships of interest at within- and between-person levels of analysis. This provided the possibility to distinguish between withinperson dynamics versus person-level differences.

As with any study, these studies also have several limitations. First, I conducted our studies using a path-modeling correlational approach. Therefore, the patterns of relationships between study variables should not be interpreted in a causal way. Future research with experimental designs might extend the related knowledge by investigating causalities. Second, all data were gathered by selfreport measures. Using the self-report measures increase concerns about common method bias (Podsakoff, MacKenzie, Lee, \& Podsakoff, 2003). However, the within-person and longitudinal design of research with measurement assessed at different time points reduced the effects of common method bias.

\section{Future research}

One important issue that surfaced from this research that should still be addressed in the future, is a test of the causality of the relationships between the two types of perseverative thinking and outcomes variables (e.g. recovery). This is important because the current state of the literature does not fully rule out reversed causality nor that the effects may have been driven by an unmeasured variable. Therefore, I recommend scholars to design well-controlled experimental studies in order to demonstrate the causality relationships between different types of work-related perseverative thinking, recovery, well-being, and job performance. Experimental studies shed also light on the physiological and cognitive underling mechanisms by which affective rumination and problem-solving pondering lead to different levels of psycho-physiological arousal. For instance, an experimental study may investigate whether affective rumination and problem-solving pondering differently affect endocrinological and cardiovascular indicators of prolonged 
activation (Brosschot et al., 2005). Moreover, from the cognitive point of view discussed by the cognitive activation theory of stress (CATS: Ursin \& Eriksen, 2004; Ursin \& Eriksen, 2010), being mentally engaged with job stressors causes prolonged activation only when individuals experience negative outcome expectancies. Therefore, a study may investigate the different response outcome expectancies that people experience in affective rumination compared to problemsolving pondering.

Research is needed to further clarify the physiological or psychological characteristics of affective rumination and problem-solving pondering. In Chapter 3 , I found self-regulation as a between-person variable that positively influences the effect of problem-solving pondering on recovery from work. As a theoretical contribution, I concluded that the degree to which individuals experience progress in goal-directed thinking process should be taken into account to provide a more comprehensive conceptualization of problem-solving pondering. Future research can investigate other between-person or even within-person factors that may play a determining role in productive problem-solving pondering. This will lead to a more comprehensive conceptualization of work-related problem-solving pondering that may help researchers to develop problem-solving trainings. For example, regarding the findings presented in Chapter 3, research may focus on developing training that help employees to regulate the thinking process, recognize unproductive thinking, prevent affective rumination, and implement effective problem solving strategies.

According to our findings that showed that affective rumination leads to impaired well-being, one may be interested in developing and testing interventions to help employees who ruminate affectively about work-related issues. Moreover, research is called to develop trainings and interventions aimed at promoting problem-solving skills in a way that does not inhibit the recovery process.

\section{Conclusion}

The findings of this dissertation provided empirical evidence showing that the experience of perseverative thinking about work-related issues during non-work time is not always detrimental for well-being and job performance as it depends on the type of perseverative thinking (i.e. affective rumination versus problemsolving pondering). Compared to problem-solving pondering, affective rumination is more likely to draw on emotion-regulatory resources and thereby impede the recovery process during non-work time. Through prolonged 
activation and cumulative drawing on resources, affective rumination leads to impaired well-being in the long run. However, problem-solving pondering may be beneficial or unfavorable for recovery depending on the degree to which employees can regulate their cognitions and feelings. 


\section{References}

Amabile, T. M., \& Kramer, S. J. (2011). The power of small wins. Harvard Business Review, 89, 7080.

Arbeidswet 2000 BES. (2013). Arbeidswet 2000 BES. Retrieved from https://wetten.overheid.nl

Beal, D. J., Weiss, H. M., Barros, E., \& MacDermid, S. M. (2005). An episodic process model of affective influences on performance. Journal of Applied Psychology, 90, 1054-1068. http://doi.org/10.1037/0021-9010.90.6.1054

Boswell, W. R., \& Olson-Buchanan, J. B. (2007). The use of communication technologies after hours: The role of work attitudes and work-life conflict. Journal of Management, 33, 592610. https://doi.org/10.1177/0149206307302552

Brosschot, J. F., Gerin, W., \& Thayer, J. F. (2006). The perseverative cognition hypothesis: A review of worry, prolonged stress-related physiological activation, and health. Journal of Psychosomatic Research, 60, 113-124. http://doi.org/10.1016/j.jpsychores.2005.06.074

Brosschot, J. F., Pieper, S., \& Thayer, J. F. (2005). Expanding stress theory: Prolonged activation and perseverative cognition. Psychoneuroendocrinology, 30, 1043-1049. http://doi.org/10. 1016/j.psyneuen.2005.04.008

Brosschot, J. F., van Dijk, E., \& Thayer, J. F. (2002). Prolonged autonomic activation, perseverative negative cognition, and daily stressors. International Congress Series, 1241, 329-336. http://doi.org/10.1016/S0531-5131(02)00615-5

Chesley, N. (2005). Blurring boundaries? Linking technology use, spillover, individual distress, and family satisfaction. Journal of Marriage and Family, 67, 1237-1248. https://doi.org/ 10.1111/j.1741-3737.2005.00213.x

Chin, J., Morrow, D. G., Stine-Morrow, E. A., Conner-Garcia, T., Graumlich, J. F., \& Murray, M. D. (2011). Journal of Health Communication, 16, 222-241. https://doi:10.1080/10810 730.2011 .604702

Cropley, M., \& Zijlstra, F. R. H. (2011). Work and rumination. In J. Langan-Fox \& C. L. Cooper (Eds.), Handbook of stress in the occupations (pp. 487-503). Cheltenham, PA: Edward Elgar Publishing Ltd.

Donahue, E. G., Forest, J., Vallerand, R. J., Lemyre, P. N., Crevier-Braud, L., \& Bergeron, É. (2012). Passion for work and emotional exhaustion: The mediating role of rumination and recovery. Applied Psychology: Health and Well-Being, 4, 341-368. http://doi.org/10.1111/j.17580854.2012.01078.x

Fleuren, B. P. I., van Amelsvoort, L. G. P. M., Zijlstra, F. R. H., de Grip, A., \& Kant, I. J. (2018). Handling the reflective-formative measurement conundrum: a practical illustration based on sustainable employability. Journal of Clinical Epidemiology 103, 71-81. https://doi.org/ 10.1016/j.jclinepi.2018.07.007

Fredrickson, B. L. (2001). The role of positive emotions in positive psychology: The broaden-andbuild theory of positive emotions. American psychologist, 56, 218-226. http://dx.doi.org/ 10.1037/0003-066X.56.3.218

Fredrickson, B. L., \& Joiner, T. (2002). Positive emotions trigger upward spirals toward emotional well-being. Psychological Science, 13, 172-175. http://dx.doi.org/10.1111/14679280 .00431

Fritz, C., Sonnentag, S., Spector, P., \& McInroe, J. (2010). The weekend matters: Relationships between stress recovery and affective experiences. Journal of Organizational Behavior, 31, 1137-1162. https://doi.org/10.1002/job.672

Hamesch, U., Cropley, M., \& Lang, J. (2014). Emotional versus cognitive rumination: Are they differentially affecting long-term psychological health? The impact of stressors and personality in dental students. Stress and Health, 30, 222-231. http://doi.org/10.1002 
$\angle$ smi.2602

Hobfoll, S. E. (1989). Conservation of resources. A new attempt at conceptualizing stress. The American Psychologist, 44, 513-524. http://doi.org/10.1037/0003-066X.44.3.513

Hockey, G. R. J. (1997). Compensatory control in the regulation of human performance under stress and high workload: A cognitive-energetical framework. Biological Psychology, 45, 7393.http://doi.org/10.1016/S0301-0511(96)05223-4

Hockey, G. R. J., \& Earle, F. (1997). Control over the scheduling of simulated office work reduces the impact of workload on mental fatigue and task performance. Journal of Experimental Psychology: Applied, 12, 50-65. http://dx.doi.org/10.1037/1076-898X.12.1.50

Hülsheger, U. R., Alberts, H. J. E. M., Feinholdt, A., \& Lang, J. V. B. (2013). Benefits of mindfulness at work: The role of mindfulness in emotion regulation, emotional exhaustion, and job satisfaction. Journal of Applied Psychology, 98, 310-325. http://doi.org/10.1037/a0031313

Hülsheger, U. R., Feinholdt, A., \& Nübold, A. (2015). A low-dose mindfulness intervention and recovery from work: Effects on psychological detachment, sleep quality, and sleep duration. Journal of Occupational and Organizational Psychology, 88, 464-489. http://doi.wiley.com $\angle 10.1111 /$ joop. 12115

Kahneman, D. E. (1973). Attention and effort. Englewood Cliffs, NJ: Prentice Hall.

Kanfer, R., \& Ackerman, P. L. (1989). Motivation and cognitive abilities: An integrative/aptitudetreatment interaction approach to skill acquisition. Journal of Applied Psychology, 74, 657690. http://doi.org/10.1037/0021-9010.74.4.657

Kreiner, G., Hollensbe, E., \& Sheep, M. L. (2009). Balancing borders and bridges: Negotiating workhome interface via boundary work tactics. Academy of Management Journal, 52, 704-730. http://dx.doi.org/10.5465/AMJ.2009.43669916

Madkour, R. (2008, September 25). BYOC: Bring your own computer to work. Associated Press. Retrieved from http://www.msnbc.msn.com/id/26889537/

Meijman, T. F., \& Mulder, G. (1998). Psychological aspects of workload. In P. J. D. Drenth \& H. Thierry (Eds.), Handbook of work and organizational psychology: Vol. 2. Work psychology (pp. 5-33). Hove, England: Psychology Press.

Meurs, J. A., \& Perrewe, P. L. (2011). Cognitive activation theory of stress: An integrative theoretical approach to work stress. Journal of Management, 37, 1043-1068. http://doi.org/10.1177/ $\underline{0149206310387303}$

Nolen-Hoeksema, S. (1996). Chewing the cud and other ruminations. In R. S. Wyer, (Ed.), Advances in social cognition (Vol., IX, pp. 135-144). Hillsdale, NJ: Erlbaum.

Park, Y., Fritz, C., \& Jex, S. M. (2011). Relationships between work-home segmentation and psychological detachment from work: the role of communication technology use at home. Journal of occupational health psychology, 16, 457-467. http://doi.org/10.1037/a0023594

Parker, R. M., \& Gazmararian, J. A. (2003). Health literacy: essential for health communication. Journal of Health Communication, 8, 116-118. https://doi.org/10.1080/713851963

Podsakoff, P. M., Mac Kenzie, S. B., Lee, J. Y., \& Podsakoff, N. P. (2003). Common method biases in behavioral research: A critical review of the literature and recommended remedies. The Journal of Applied Psychology, 88, 879-903. http://doi.org/10.1037/0021-9010.88.5.879

Querstret, D., \& Cropley, M. (2012). Exploring the relationship between work-related rumination, sleep quality, and work-related fatigue. Journal of Occupational Health Psychology, 17, 341353. http://doi.org/10.1037/a0028552

Querstret, D., Cropley, M., \& Fife-Schaw, C. (2017). Internet-based instructor-led mindfulness for work-related rumination, fatigue, and sleep: Assessing facets of mindfulness as mechanisms of change. A randomized waitlist control trial. Journal of Occupational Health Psychology, 22, 153-169. http://doi.org/10.1037/ocp0000028 
Querstret, D., Cropley, M., Kruger, P., \& Heron, R. (2016). Assessing the effect of a cognitive behaviour therapy (CBT)-based workshop on work-related rumination, fatigue, and sleep. European Journal of Work and Organizational Psychology, 25, 50-67. http://dx.doi.org/ $\underline{10.1080 / 1359432 X .2015 .1015516}$

Quinn, R. W., Spreitzer, G. M., \& Lam, C. F. (2012). Building a sustainable model of human energy in organizations: Exploring the critical role of resources. The Academy of Management Annals, 6, 337-396. http://dx.doi.org/10.1080/19416520.2012.676762

Rook, J. W., \& Zijlstra, F. R. H. (2006). The contribution of various types of activities to recovery. European Journal of Work and Organizational Psychology, 15, 218-240. http://dx.doi.org/ $\underline{10.1080 / 13594320500513962}$

Schaufeli, W. B., Leiter, M. P., Maslach, C. (2009). Burnout: 35 years of research and practice. Career Development International, 14, 204-220. http://dx.doi.org/10.1108/1362043091 $\underline{0966406}$

Sluiter, J. K., Frings-Dresen, M. H. W., van der Beek, A. J., \& Meijman, T. F. (2001). The relation between work-induced neuroendocrine reactivity and recovery, subjective need for recovery, and health status. Journal of Psychosomatic Research, 50, 29-37. http://doi.org/10.1016 $\angle$ S0022-3999(00)00213-0

Sonnentag, S., \& Fritz, C. (2007). The recovery experience questionnaire: Development and validation of a measure for assessing recuperation and unwinding from work. Journal of Occupational Health Psychology, 12, 204-221. http://doi.org/10.1037/1076-8998.12.3.204

Sonnentag, S., \& Fritz, C. (2015). Recovery from job stress: The stressor-detachment model as an integrative framework. Journal of Organizational Behavior, 36, S72-S103. $\underline{\text { ttp://dx.doi.org/ }}$ 10.1002/job.1924

Sonnentag, S., \& Zijlstra, F. R. H. (2006). Job characteristics and off-job activities as predictors of need for recovery, well-being, and fatigue. Journal of Applied Psychology, 91, 330-50. http:// doi.org/10.1037/0021-9010.91.2.330

Syrek, C. J., Weigelt, O., Peifer, C. \& Antoni, C. H. (2017). Zeigarnik's sleepless nights: How unfinished tasks at the end of the week impair employee sleep on the weekend through rumination. Journal of Occupational Health Psychology, 22, 225-238. http://dx.doi.org/ $10.1037 /$ ocp0000031

The Labor Law of the Islamic Republic of Iran (1990, November 20). https://www.mcls.gov.ir

Ursin H., \& Eriksen, H. R. (2004). The cognitive activation theory of stress. Psychoneuroendocrinology, 29, 567-592.http://doi.org/10.1016/S0306-4530(03)00091-X

Ursin, H., \& Eriksen, H. R. (2010). Cognitive activation theory of stress (CATS). Neuroscience and Biobehavioral Reviews, 34, 877-881. http://doi.org/10.1016/j.neubiorev.2009.03.001

Valcour, P. M., \& Hunter, L. W. (2005). Technology, or- ganizations, and work-life integration. In E. E. Kossek \& S. J. Lambert (Eds.), Work and life integration: Organizational, cultural and individual perspectives (pp. 61-84). Mahwah, N. J.: Erlbaum Press.

Warr, P. (1987). Work, unemployment and mental health. New York, NY: Oxford University Press.

Watkins, E. R. (2008). Rumination-focused cognitive-behavioral therapy for depression. New York: Gildford Press.

Zijlstra, F. R. H. (1996). Effort as energy regulation. In W. Battmann, \& S. Dutke (Eds.), Processes of the molar regulation of behavior (pp. 219-235). Berlin, Germany: Pabst Science Publishers.

Zijlstra, F. R. H. (1993). Efficiency in work behaviour: A design approach for modern tools. Delft: Delft University Press. 


\section{Summary}



Recovery from work in the evening or the weekend is considered to be crucial for employees' well-being and job performance. Recovery refers to the process during which employees are no longer confronted with work-related demands and their depleted energetic resources are replenished. They then feel energized and again capable to take the subsequent course of working. The extent to which employees can switch off mentally from work-related issues (i.e. psychological detachment) during off-work time has been recognized as an essential recovery experience. Unwinding from work-related stressors prevents additional expenditure of remaining energetic resources and thereby prevents impaired well-being over time.

For many contemporary jobs, work nowadays is mentally demanding. Therefore, employees are more likely to be constantly confronted with workrelated issues during their off-work time, particularly due to recent advances in communication technologies. This has led to a more blurred and diffuse boundary between work and off-work domains which is considered as a high risk factor for insufficient recovery and thereby impaired well-being and inadequate job performance.

Employees may experience lack of psychological detachment during their off-work time because they engage in perseverative thinking about work-related issues. Perseverative thinking concerns the experience of repeated, pervasive, and prolonged activation of mental occupation with work-related issues. Although perseverative thinking has been conceptualized as a mechanism by which workrelated stressors are translated into impaired well-being, this might not always be true as it depends on the type of perseverative thinking (i.e. affective rumination and problem-solving pondering). Affective rumination is defined as perseverative cognitive processes in which thoughts are mainly directed to dysfunctional emotions associated with work-related issues. Problem-solving pondering refers to perseverative cognitive processes in which thoughts are directed to possible solutions to work-related problems in order to progress toward choice of a solution or reevaluate work-related performance in order to consider how it can be improved.

This dissertation contributes to three central research questions concerning the effects of the two types of work-related perseverative thinking on recovery, well-being, and job performance. The central questions of this dissertation are: 1) What are the consequences of work-related affective rumination and problem-solving pondering on well-being and job performance? 
2) Through what mechanisms do work-related affective rumination and problemsolving pondering have differential consequences on well-being and job performance? 3) How is the consequence of work-related problem-solving pondering on recovery from work influenced by between-person differences in trait self-regulation?

Chapter 2 presents the findings of a longitudinal three-wave study with a time lag of six months between each wave. This study investigated how the experience of affective rumination and problem-solving pondering during evenings predict changes in two long-term well-being outcomes (i.e. exhaustion and general mental health complaints) over a one year period. The three waves of data obtained from a total of 123 participants were analyzed using latent growth curve modeling. The results showed that employees who experience high levels of work-related affective rumination during evenings showed higher rates of growth in exhaustion across a period of 12 months. However, the findings showed that affective rumination was not a significant predictor of change in general mental health complaints over time. In addition, our results did not show a significant relationship between problem-solving pondering during evenings and changes in either exhaustion or general mental health complaints across a period of one year. Contributing to Research question 1, these findings demonstrate that when looking at the long term effects, not all types of work related perseverative thinking are equally negative for well-being outcomes. Whereas affective rumination particularly leads to increases in exhaustion, problem solving pondering is not related with such negative long-term outcomes.

Chapter 3 presents the findings of a diary study over five consecutive working days. This study examined, using a within-person design, how fluctuations in work-related affective rumination and problem-solving pondering during the evening are related to recovery and well-being, while accounting for the moderating role of trait-self regulation on the pondering-recovery relationship. Analyzing data obtained from 177 participants over 677 days revealed that affective rumination during the evening was indirectly related to impaired wellbeing in the subsequent morning through its negative relationship with the state of being recovered at bedtime. Problem-solving pondering was indirectly related to well-being in the subsequent morning through its relationship with the state of being recovered at bedtime. However, this indirect effect was moderated by trait self-regulation in a way that problem-solving pondering was positively related to the state of being recovered and consequently to improved well-being for employees higher in self-regulation, while it was negatively related to the state of being recovered and consequently to impaired well-being for those lower in self- 
regulation. These findings suggest that problem-solving pondering may be beneficial or unfavorable for recovery and well-being depending on the degree to which employees can regulate their cognitions and feelings. This chapter provides empirical evidence for Research question 1, 2, and 3.

Chapter 4 presents the findings of a diary study conducted over six consecutive weeks $(\mathrm{N}=107$; 490-568 week-level data points $)$ investigating whether the two types of work-related perseverative thinking have different consequences on two job performance-related outcomes (i.e. effort expenditure and task performance) via their differential draining effects on individuals' emotion regulatory resources. Using a multilevel approach, this study found different patterns of relationships between variables at two levels of analysis: the within-person level (i.e. week-level dynamics) and the between-person level (person-level differences). The results revealed that affective rumination negatively related to emotion-regulation capability only at the within-person level, whereas problem-solving pondering positively related to emotion regulation capability only at the between-person level. Emotion regulation capability mediated the relationships between affective rumination and the two performance-related outcomes only at the within-person level. However, the mediating role of emotion regulation capability was significant on the relationship between problem-solving pondering and task performance only at the betweenperson level. These findings provide empirical evidence to support the core assumption indicating that affective rumination is more likely to draw on emotion regulatory resources and thus to have straining effects on the organism than problem-solving pondering. This chapter provides empirical findings examining Research questions 1 and 2 .

Together the studies reported in this dissertation provided empirical evidence showing that the experience of perseverative thinking about work-related issues during off-work time is not always detrimental for well-being and job performance as it depends on the type of perseverative thinking (i.e. affective rumination versus problem-solving pondering). Compared to problem-solving pondering, affective rumination is more likely to draw on emotion-regulatory resources and thereby impede the recovery process during off-work time. Through prolonged activation and cumulative drawing on resources, affective rumination leads to impaired occupational health in the long run. However, problem-solving pondering may be beneficial or unfavorable for recovery depending on the degree to which employees can regulate their cognitions and feelings. 
Samenvatting 

Voor het welzijn en de productiviteit van werknemers is het cruciaal om in de avonduren of het weekend te herstellen van het werk ( of: bij te komen van het werk). Met dit herstel (of: Hiermee) wordt het proces bedoeld waarbij werknemers niet langer geconfronteerd worden met werk gerelateerde eisen of taken en ze zich opnieuw kunnen opladen. Hierdoor voelen zij zich weer energiek en in staat om hernieuwd aan de slag te gaan (of: aan een nieuwe werkdag te beginnen). De mate waarin werknemers in hun vrije tijd mentaal kunnen afschakelen van werk gerelateerde zaken (de zg. psychologische onthechting) wordt gezien als een essentiële herstel ervaring. Het afschakelen van werkgerelateerde stressoren voorkomt een extra aanslag op de overgebleven energiebronnen en voorkomt daarmee dat met de tijd het welzijn nadelig beïnloed wordt.

Voor veel banen is werk tegenwoordig mentaal veeleisend. Daarom hebben werknemers meer kans om ook buiten hun werktijd met werkgerelateerde problemen te worden geconfronteerd, met name door recente ontwikkelingen in communicatietechnologieën. Dit heeft geleid tot een onduidelijkere grens tussen het werk- enhet niet-werkdomein. Deze onduidelijke grens wordt beschouwd als een belangrijke risicofactor voor onvoldoende herstel en kan het welzijn en de prestaties op het werk aantasten.

Werknemers kunnen tijdens hun vrije tijd een gebrek aan psychologische onthechting ervaren omdat ze perseveratief denken aan werkgerelateerde kwesties. Het perseveratief denken aan werk betreft de ervaring van het herhaaldelijk, pervasief en langdurig mentaal bezig zijn met werkgerelateerde kwesties. Hoewel perseveratief denken is geconceptualiseerd als een mechanisme waarmee werkgerelateerde stressoren worden omgezet naar verminderd welzijn, is dit niet noodzakelijk terecht omdat er verschillende soorten perseveratief denken onderscheiden kunnen worden ( $\mathrm{nl}$. affectieve ruminatie en probleemoplossende overpeinzing). Affectieve ruminatie wordt gedefinieerd als perseveratieve cognitieve processen waarin gedachten zich voornamelijk richten op disfunctionele emoties die verband houden met werkgerelateerde problemen. Probleemoplossende overpeinzing omvat perseveratieve cognitieve processen waarin gedachten zich richten op mogelijke oplossingen voor werkgerelateerde problemen om tot oplossingen te komen of werkprestaties te heroverwegen om verbetermogelijkheden te genereren. 
Dit proefschrift draagt bij aan drie centrale onderzoeksvragen die de effecten van de twee soorten werkgerelateerd perseveratief denken op herstel, welzijn en werkprestaties beschouwen. De centrale vragen van dit proefschrift zijn: 1) Wat zijn de gevolgen van werkgerelateerd affectieve ruminatie en probleemoplossend overpeinzen voor het welzijn en de werkprestatie? 2) Via welke mechanismen hebben werkgerelateerd affectieve ruminatie en probleemoplossend overpeinzen verschillende gevolgen voor het welzijn en de werkprestatie? 3) Hoe worden de gevolgen van werkgerelateerd probleemoplossend overpeinzen op het herstel na werk beïnvloed door interindividuele verschillen in de trek zelfregulatie?

Hoofdstuk 2 presenteert de bevindingen van een longitudinaal onderzoek met drie meetmomenten die telkens zes maanden uit elkaar lagen. Deze studie onderzocht hoe de ervaringen van affectieve ruminatie en probleemoplossend overpeinzen gedurende de avonden veranderingen voorspellen in twee welzijnsmaten (nl. oververmoeidheid en algemene psychische gezondheidsklachten) over een periode van één jaar. De drie meetmomenten omvatten gegevens van in totaal 123 deelnemers, welke vervolgens zijn geanalyseerd middels latente groeicurve-modellen. De resultaten laten zien dat werknemers die 's avonds veel werkgerelateerde affectieve ruminatie ervaren ook een sterkere groei in oververmoeidheid laten zien over een periode van 12 maanden. De bevindingen laten echter ook zien dat affectieve ruminatie geen significante voorspeller is van veranderingen in algemene psychische gezondheidsklachten over de tijd. Bovendien laten de resultaten geen significant verband zien tussen probleemoplossend overpeinzen tijdens avonden en veranderingen in oververmoeidheid of algemene psychische gezondheidsklachten gedurende een periode van één jaar. Bijdragend aan Onderzoeksvraag 1 tonen deze bevindingen aan dat over de lange termijn niet alle soorten werkgerelateerd perseveratief denken dezelfde negatieve effecten op welzijn hebben. Waar affectieve ruminatie vooral relateert aan oververmoeidheid, houdt het probleemoplossend overpeinzen over de lange termijn geen verband met de welzijnsmaten.

Hoofdstuk 3 presenteert de bevindingen van een dagboekstudie over vijf opeenvolgende werkdagen. Deze studie onderzocht, door middel van een binnenpersoon onderzoeksopzet, hoe fluctuaties in werkgerelateerde affectieve ruminatie en probleemoplossend overpeinzen tijdens de avond gerelateerd zijn aan herstel en welzijn, terwijl rekening wordt gehouden met de modererende rol van zelfregulatie in de relatie tussen probleemoplossend overpeinzen en herstel. 
Gegevens van 177 deelnemers werden verzameld gedurende 677 dagen, en uit analyse van deze data bleek dat affectieve ruminatie tijdens de avond indirect verband hield met een verminderd welzijn in de volgende ochtend, via de staat van herstel van werk vóór het slapengaan. Probleemoplossend overpeinzen was indirect gerelateerd aan welzijn in de daaropvolgende ochtend door de relatie met de toestand van hersteld voor het slapengaan. Dit indirecte effect werd echter gemodereerd door de mate waarin men zelfregulerend vermogen bezit, op de manier dat probleemoplossend overpeinzen positief gerelateerd was aan de staat van herstel en bijgevolg aan een verbeterd welzijn voor werknemers met een hogere zelfregulatie, terwijl het negatief gerelateerd was aan de staat van herstel en bijgevolg tot een verminderd welzijn voor degenen die minder zelfregulerend vermogen bezitten. Deze bevindingen suggereren dat nadenken over het oplossen van problemen gunstig of ongunstig kan zijn voor herstel en welzijn, afhankelijk van de mate waarin werknemers hun cognities en gevoelens kunnen reguleren. Dit hoofdstuk biedt empirisch bewijs voor Onderzoeksvraag 1, 2 en 3.

Hoofdstuk 4 presenteert de bevindingen van een dagboekonderzoek dat gedurende zes opeenvolgende weken is uitgevoerd $(\mathrm{N}=107 ; 490-568$ weekniveau datapunten). In deze studie onderzocht ik of de twee soorten werkgerelateerde denkprocessen (affectieve ruminatie en Probleemoplossend overpeinzen) verschillende gevolgen hebben voor twee werkgerelateerde resultaten (d.w.z. inspanningen en taakuitvoering) doordat ze een verschillend effect hebben op het vermogen voor het reguleren van emoties van individuen. Gebruikmakend van een multilevel-aanpak, vond ik in deze studie verschillende patronen van relaties tussen deze variabelen op twee analyseniveaus: het binnenpersoonsniveau (d.w.z. dynamiek op weekniveau binnen een individu) en het tussen-persoonsniveau (verschillen tussen personen). De resultaten toonden aan dat affectieve ruminatie alleen negatief gerelateerd was aan emotie-regulerend vermogen op het binnen-persoonsniveau, terwijl probleemoplossend overpeinzen alleen positief gerelateerd was aan emotie-regulerend vermogen op het tussenpersoonsniveau Emotieregulatie vermogen was een alleen op het binnenpersoonsniveau een mediërende variabele in de relaties tussen affectieve ruminatie en de twee prestatiegerelateerde resultaten. De mediërende rol van emotieregulerend vermogen had echter alleen een significante invloed op de relatie tussen probleemoplossend overpeinzen en taakuitvoering op het tussenpersoonsniveau. Deze bevindingen bieden empirisch bewijs ter ondersteuning van de kernaanname die aangeeft dat affectieve ruminatie meer gebruik maakt van emotieregulerende middelen en dus belastende effecten op het organisme heeft 
dan probleemoplossend overpeinzen. Dit hoofdstuk biedt empirische bevindingen waarin Onderzoeksvragen 1 en 2 worden onderzocht.

Tezamen leveren de in dit proefschrift gerapporteerde studies empirisch bewijs dat aantoont dat de ervaring van perseveratief denken over werkgerelateerde problemen tijdens werktijd niet altijd nadelig is voor het welzijn en de prestaties op het werk, omdat het afhangt van het type perseveratief denken (d.w.z. affectieve ruminatie versus probleemoplossend overpeinzen). In vergelijking met probleemoplossend overpeinzen, heeft affectieve ruminatie een groter effect op het emotie-regulerende vermogen en heeft daardoor een belemmerende werking op het herstelproces buiten werktijd. Door langdurige activering en cumulatief gebruik van het emotie-regulerend vermogen leidt affectieve ruminatie op de lange termijn tot een verslechterde gezondheid op het werk. Probleemoplossend overpeinzen kan echter gunstig of ongunstig zijn voor herstel, afhankelijk van de mate waarin werknemers hun cognities en gevoelens kunnen reguleren. 


\section{Valorization}



In this valorization chapter I will expand on the social value of the findings presented in this dissertation. Therefore, I will first identify the target group of the research and groups that could potentially benefit from the findings. I then provide an overview of the practical insights that the findings presented in this dissertation provide for employers and employees. I will propose a number of products and innovations that could be based upon the findings of this research. Finally, I will consider the insights that the findings provide for society more generally including potential implications for labor legislation.

\section{Target group}

The target population of this dissertation are employees, and more particularly employees with mentally demanding jobs. The findings presented in this dissertation are therefore foremost useful for these employees. Our results shed light on how different types of being mentally engaged with work-related issues during off-work time influences their recovery from work and consequently their well-being and job performance. Employees can use this information to schedule and manage their off-work time in such a way that the possibility of being caught up in thinking about work-related issues during off-work time is minimized. Given the findings related to problem-solving pondering, employees need to know the condition under which experiencing problem-solving pondering during off-work time may facilitate their recovery process.

There are two additional groups that can potentially benefit from the findings of this research including HR managers in organizations and legislative assemblies of labor laws. The findings can help HR managers to design and implement not only strategies that minimize mental engagement with workrelated issues during off-work but also strategies that prevent the detrimental effect of thinking about work on the recovery process. The findings also provide insights for legislative assemblies of labor laws where the current labor laws can be evaluated to protect employees from work-related factors that have detrimental effects on the recovery process.

\section{Products, innovation, and implementation}

There are a number of products that could be developed based on the findings of this dissertation, including recovery guidelines, trainings, and well-being apps. The results presented in this dissertation demonstrated that employees with 
mentally demanding jobs are highly vulnerable for exhaustion over time if they engage in affective rumination during their off-work time. The results may encourage HR managers in organizations to design recovery guidelines that enable employees to overcome obstacles to unwind from work-related issues during off-work time. For example, a guideline might be developed to protect employees to not be interrupted by work-related emails or phone calls after leaving their work places.

Regarding the importance of employees' subjective experiences during off-work time on their well-being and productivity, HR managers may provide facilities that encourage and enable employees to regularly engage in individual or group recreational activities during the evening or the weekend. Moreover, HR managers may suggest psychological interventions such as cognitive behavior therapy and mindfulness-based techniques for their high-ruminating employees. These interventions can help employees to disengage from affective rumination and improve the possibility to prevent impaired health and job-performance that affective rumination causes in the short and long run. Employees themselves can also undertake actions to manage their recovery from work and prevent workrelated rumination. For example, they can impose restrictions on using technology (e.g. email, phone) during the evening or the weekend as a factor that may triggers affective rumination (Kreiner, Hollensbe, \& Sheep, 2009).

This research is innovating as it showed that the experience of workrelated problem-solving pondering has positive effects on the recovery process and well-being only if people can properly regulate their cognitions and emotions. This finding then suggests training courses aimed at promoting problem-solving skills as a strategy that HR managers can take to prevent burnout in their employees. These skills can help employees to act as more successful problem solvers when they are mentally engaging in work-related problems during the time of recovery. However, further research is needed to adapt and implement psychological intervention approaches on enhancing problem-solving skills. Given the findings related to problem-solving pondering, employees are recommended to become conscious of the nature and process of their thinking. They should then develop the ability to stop thinking about work-related issues if they do not experience a progressive and productive thinking that results in finding a solution for a specific problem. To enhance this capability, psychological self-awareness and problem-solving trainings can be useful. 


\section{Insights for society and implications for labor legislation}

The sixth European Working Conditions Survey (EWCS; 2016) showed that, on average, $10 \%$ of the EU workforce (ranging from $4.5 \%$ in Finland to $20.5 \%$ in France) feels severely "burned-out" against $17 \%$ of the non-EU countries (ranging from 13\% in Albania to 25\% in Turkey). The burnout prevalence is even worse in developing countries. For example a review study by Rezaei, Matin, Hajizadeh, Soroush, and Nouri (2018) showed that on average 36\% of Iranian nurses experience high levels of burnout. Research also showed that burnout is not only negatively related to work-related well-being (e.g. work engagement and job satisfaction), but it is also negatively related to context-free well-being (e.g. happiness). Occupational health at the country level can be considered as a factor determining productivity and economic performance. In countries where employees highly value not only work but also their leisure, the prevalence of burnout can be less and employees can be more productive. This means that in countries where employees work harder and longer, economic performance is not necessarily higher if employees are not productive due to their insufficient recovery during off-work time.

The findings of this dissertation demonstrated that the way employees spend their time outside of work time (i.e. during the evening or the weekend) influences their well-being and job performance. More specifically, the results showed that the ruminative form of thinking about work during off-work time has a negative influence on well-being and job performance. Given these results, governments and legislative assemblies of labor laws should critically evaluate their current labor laws and assess whether the current laws sufficiently protect employees from work-related factors that inhibit the recovery process. More specifically, these laws might be revised in such a way that they protect employees' rights to not engage in work-related activities outside of their official working time that trigger work-related rumination. For instance, they may oblige organizations to limit the pressure they explicitly or implicitly put on their employees during offwork time to engage in work-related cognitive processing (e.g. by limiting workrelated e-mail use or by planning assignments in such a way that they can be fully completed during work time). As an example, these laws can protect employees' right to refuse to respond to emails received from their managers during the evening or the weekend. 


\section{References}

Kreiner, G., Hollensbe, E., \& Sheep, M. L. (2009). Balancing borders and bridges: Negotiating workhome interface via boundary work tactics. Academy of Management Journal, 52, 704-730. http://dx.doi.org/10.5465/AMJ.2009.43669916

Rezaei, S., Karami Matin, B., Hajizadeh, M., Soroush, A. \& Nouri, B. (2018). Prevalence of burnout among nurses in Iran: a systematic review and meta-analysis. International Nursing Review, 65, 361-369. https://doi.org/10.1111/inr.12426

Schaufeli, W.B. (2018). Burnout in Europe: Relations with national economy, governance, and culture. Research Unit Occupational \& Organizational Psychology and Professional Learning (internal report). KU Leuven, Belgium 
Acknowledgements 

First of all, I am very grateful to the God for all the countless blessings and strength which provided me the capability to complete and finish my $\mathrm{PhD}$. Now, I am in the final destination of my PhD journey and I would like to thank all the amazing people who have directly and indirectly supported me during this journey. I am glad that, at least, this section of my dissertation provides the opportunity to name some of those amazing people who made the journey possible, memorable and enjoyable and I would like to express my heartfelt gratitude towards them.

This $\mathrm{PhD}$ would not have been possible without my two supervisors Fred and Sjir. Honestly, I do not know how to thank you and it is difficult to find proper words to express my gratitude to you. Thank you for investing your time and effort in supervising me during my $\mathrm{PhD}$. The $\mathrm{PhD}$ is just part of the experience that I have had with you over all of the past years. You have been the creators of all the moments that have brought me confidence and happiness and those that have taught me new lessons for my life.

Dear Fred, I still remember your quick and positive reaction to my first email which eventually gave me the chance to start my $\mathrm{PhD}$. You have always asked about my and my family's situation before any question about the $\mathrm{PhD}$ project. I really appreciate it. I will never forget your support when I shared my problems with you and you always did your best to support me (so no prolonged affective rumination after leaving your office). When I came to your office you were always welcoming, even if you had a lot of printed papers - waiting for your pen and paper comments - on your desk. Contrary to what I expected from the Dutch culture, I have never heard during these years (even once) that you would ask me to visit you for a better and later time. I think (or at least hope) that this did not lead to any exhaustion in you as it might be experienced as a positive deep acting experience (you are always the boss, so no pressure for any surface acting). I also appreciate the learning opportunities you provided me with regarding teaching (e.g. supervising several master theses together).

Dear Sjir, regarding all experiences we have had together in the past years, I do not know what I should call you; my supervisor, my teacher, my colleague, or my best friend. Of course I keep all in my mind and prefer to call you as my best Dutch friend who supported me a lot during my $\mathrm{PhD}$. When I had no clue how to proceed or where I simply got stuck, you excellently guided me by leaving your office, sitting in the kitchen, and accompanying me for a constructive problem 
solving pondering. If it did not work or it needed more time, you suggested a nature walk around the University which always worked! Thank you for your excellent guidance, support and consideration.

I would like to thank Prof. dr. B. A. Ghanbari Hashemabadi, my former teacher and supervisor in Iran, who has kindly supported me during my $\mathrm{PhD}$ over all the past years. Thanks also to Prof. dr. M.R. Sadeghi, my former teacher in master education in Iran, who encouraged me to pursue my education.

My officemates, Alicia, Philippe, and Alicia (Sui); thank you for all memorable moments we have had together in the office as the $\mathrm{PhD}$ candidates. Alicia, you were my first officemate in WSP. You provided me very useful information about the Dutch culture. Thanks for all the discussions we had about our cultures and thank you for being my Paranymph. Philippe, sharing the office with you was really awesome. When I had a question, usually about shopping, you could easily search it on Google (of course in Dutch) and always showed me the best one. Throwing your stress ball in the pot was a good coping, and we still have to wait for the football match between Iran (the Cheetahs of Persia) and Belgium (the Red Devils). I wish in 2022. Alicia (Sui), you were my last officemate in WSP. Working as a teacher did not allow me to spend much time in our office. However, it was always nice to have you as a quiet officemate who understood and allowed me to keep concentration on my thesis. I would also like to thank Bram, a gentleman who accepted to be my Paranymph. You were always very welcoming for any question and help. As you already thanked me in your great book, I would like to thank you in return for all theoretical discussions. Of course, you will be welcome for visiting Iran in the future.

I would like to thank all my colleagues in WSP and some of them in particular. Mariëlla and Trudy, thanks for all the kind support with administrative issues. You always did your best and cared about me and my family. Gerjo and Rob, two great professors in WSP, thank you for all the support you provided me during my PhD. Thank you also for the scientific support that you provided for Iranian researchers and students. Ute, thank you for your support of using Mplus and Multilevel analysis. I also appreciate your effort as the chair of the assessment committee. Gemma, thanks for your positive attitude. Talking with you was always full of empathy and consideration. Margje, I would like to appreciate all the support that you provided me regarding the BKO-program. You were always available for my questions and encouraged me for attending the teaching workshops. Gerda, thanks for suggesting me as the trainer of the Psychiatric 
anamnesis course. This practical course provided the opportunity for me to retrieve and update my clinical skills. Fleurie, I appreciate all the support that you provided me to act as the supervisor of the academic writing skills course. You were always welcoming for any question. Robert, thank you for all the information you gave me to supervise bachelor and master theses. I really admire your sense of humor. Merve, it was really nice to have a colleague from our neighbor, Turkey. We always had many things to talk about our cultures. Marie, thanks for all the friendly moments. Astin, thanks for all the positive cultural discussions. Phil, as office neighbors, we had much fun and very good discussions. It was always nice and fun to meet you around the printer zone. Annika, I really appreciate your support during tutoring the Personality course. Sylvia, I did not see you often, but it was always nice to see you somewhere. Mart, thanks for sharing your experiences in the Research practical course. It was always nice to know more and more about your $\mathrm{PhD}$ project. Rosine, working with you to supervise two groups of master students was a great experience for me. Thank you also for helping me to prepare the Dutch summary. Tobias, I know that people thank you for your role in social events. However, I was not a lot in the events. Thank you for your cooperation in supervising some master thesis. Irma, thanks for all the support and information about mentoring students. Herco, we had good discussions together. Thank you. Karlijn, thank you for the good advice you provided for parenting. Thanks for replacing me for tutoring the Motivation and Emotion course. Untung, it was really nice to meet you in your office and talked about your lovely children. Thank you Fraukje, for your positive attitude and all the fun conversation we had about the Netherlands weather. Philippe (Verduyn), it was always nice to hear a different Dutch accent when you were speaking in the kitchen. Finally, thank you Kai, Darta, Joedith, Nathalie, and Gill for contributing to the pleasant working climate at WSP.

I would like to appreciate and thank my Iranian former colleagues and all friends who helped me to collect data in Iran; Mahin Hashemi, Parvaneh Nikkhah, Ali Sadr (also for importing data into the Excel), Hamid Daroudi, Maliheh \& Mitra Naroui, Abolfazl Daroudi, Homam Moayedfar, Mehdi Rahmani, Morteza Nouri, Danial and my family members Mojtaba (for printing the booklets and designing the cover), Mahmoud and Mehdi (for all the support), Nematollah, Neda (also for importing data into the Excel), Batool, Fatemeh, Zeynab, and Zahra. Without your help, it would not be possible to prepare the booklets, to distribute and collect them, and to import data into the software. Living thousands kilometers far from your homeland is not easy, even though people of the host country are so friendly to you. My dear friends; Iman, Morteza 
Karami, Mohammad, Naser, Naghi, Javad Salehi and Zohreh Sepehri, , Morteza Keyvanloo, Majid, Reza, Ali Mashhadi and Leon, thank you for all the support.

I would like to thank my parents Ali and Nesa. I love you a lot and appreciate your effort and love in raising me and bringing me up to be a better individual. I am much lucky to have you both as my parents and thank God for giving me you. I would also like to appreciate my wife's parents for their kindness and patience during all the past years.

My dearest Mahboubeh, it is really difficult to find proper words to thank you for all your efforts, attention, and love which have supported me to pursue my education from the beginning to the end of this journey. Thank you for making all the relaxing and amazing moments at our home after each working day. This all helped me to have a sufficient level of recovery. My lovely Elsa, you have been my lovely companion on this journey. Thank you for all beautiful colors you poured on our life which made it incomparably delightful. 



\section{Curriculum vitae}

Abbas Firoozabadi was born on 11 March 1983 in Sirjan, Iran. He grew up in this city and completed high school there. In 2001, he started his Bachelor of Clinical Psychology at Ferdowsi University of Mashhad. He continued studying at Ferdowsi University by pursuing a Master in Clinical Psychology by which he obtained the knowledge of mental health, psychopathology, psychiatric diagnosis, and psychotherapy. Having obtained his master in 2008, Abbas worked as a lecturer in BSc program at Bojnord University. At the same time he worked as a psychotherapist at a mental health clinic for almost four years. Since June 2012, he has been working as a $\mathrm{PhD}$ candidate at the department of Work and Social Psychology at Maastricht University. His research was about the consequences of thinking about work during off-work time for employees' recovery, occupational health, well-being, and job performance. Since 2017, Abbas has also worked as a teacher at Maastricht University's Faculty of Psychology and Neuroscience. 


\section{Publications}

Firoozabadi, A., Uitdewilligen, S., \& Zijlstra, F. R. H. (2018). Should you switch off or stay engaged? The consequences of thinking about work on the trajectory of psychological well-being over time. Journal of Occupational Health Psychology, 23, 278-288. http://dx.doi.org/10.1037/ocp0000068

Firoozabadi, A., Uitdewilligen, S., \& Zijlstra, F. R. H. (2018). Solving problems or seeing troubles? A day-level study on the consequences of thinking about work on recovery and wellbeing, and the moderating role of self-regulation. European Journal of Work and Organizational Psychology, 27, 629-641. DOI: 10.1080/1359432X.2018.1505720

Firoozabadi, A., Uitdewilligen, S., \& Zijlstra, F. R. H. (under review). Week-level dynamics and person-level differences of the relation between work-related perseverative thinking and job performance-related outcomes, the mediating role of emotion regulation capability.

Firoozabadi, A., Asgharnejad Farid, A. A., Mirzaei, J., \& Shareh, H. (2010). Normalization of Clinician Administered PTSD Scale-version 1 (CAPS-1) for psychological effects due to war. Iranian Journal of Psychiatry and Clinical Psychology, 15 (4), 334 -342.

Firoozabadi, A., Ghanbari Hashemabadi, B. A., \& Tabatabaei, S. M. (2010). The efficacy of detached mindfulness and distraction techniques in craving and relapse rates in opiate dependent male subjects. Iranian Journal Fundamentals of Mental Health, 11 (4), 292301.

Firoozabadi, A., \& Shareh, H. (2009). Effectiveness of detached mindfulness techniques in treating a case of obsessive compulsive disorder. Iranian Journal of Advances in Cognitive Science,11(2), 1-7.

Soliemanian, A. A., \& Firoozabadi, A. (2012). The relationship between motivational structure, mental health and attitude to opiate substances in students. Iranian Journal of Research on Addiction, 20(5), 25-40.

Soliemanian, A. A., \& Firoozabadi, A. (2011). The effect of Elaboration of Positive Perspectives Intervention (EPOS) based on goal conflict reduction on life satisfaction. Iranian Journal of Advances in psychological research, 22, 57-70. 